3. 3 (2)

s.5

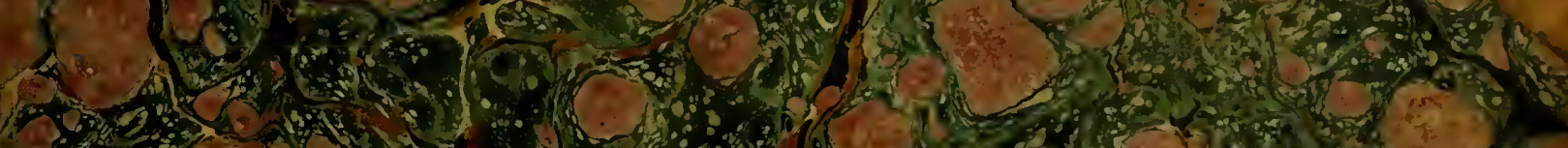

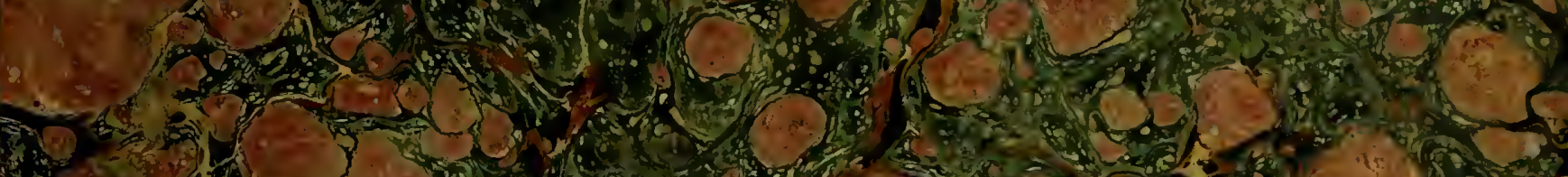

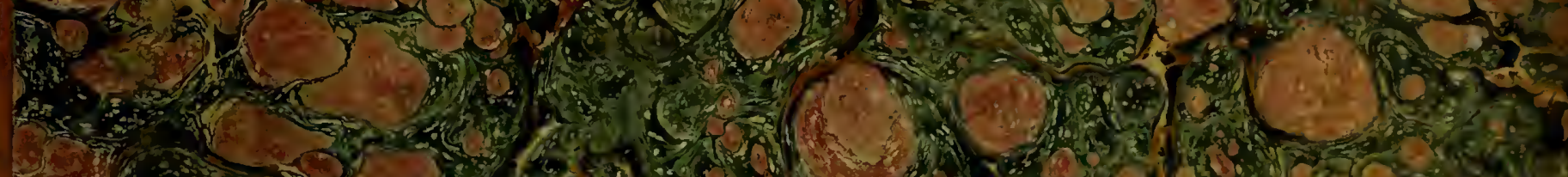

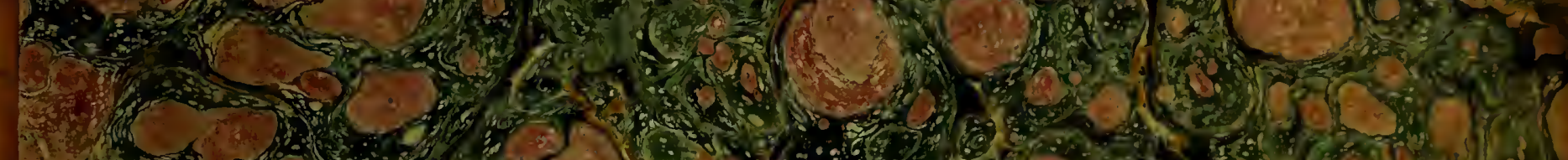

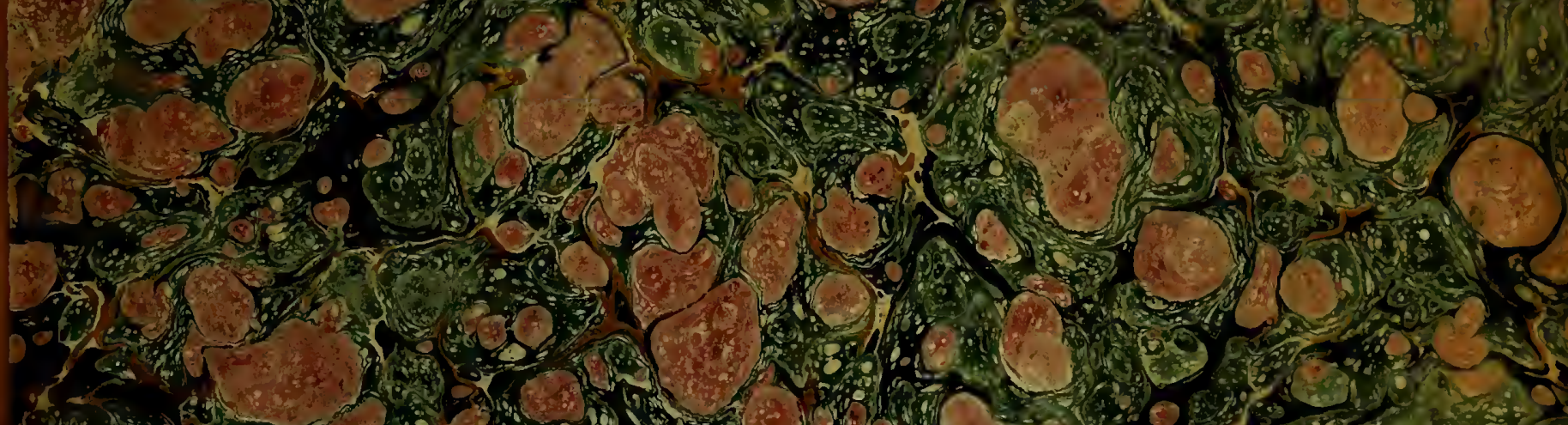
2.5.

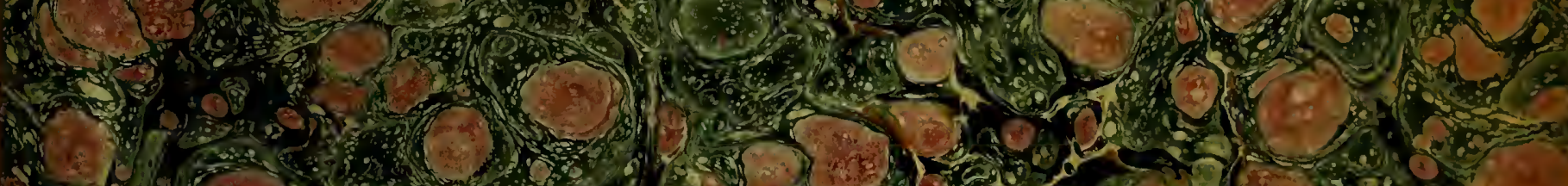

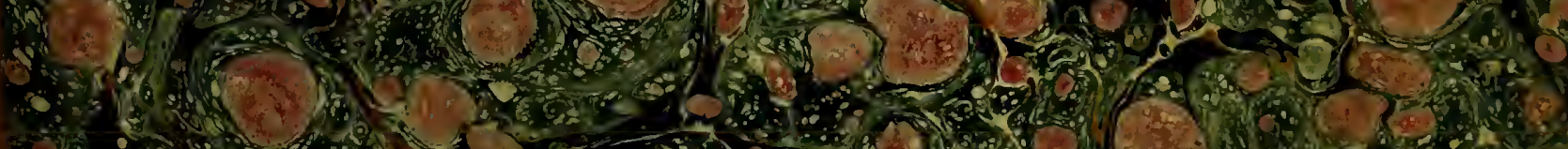

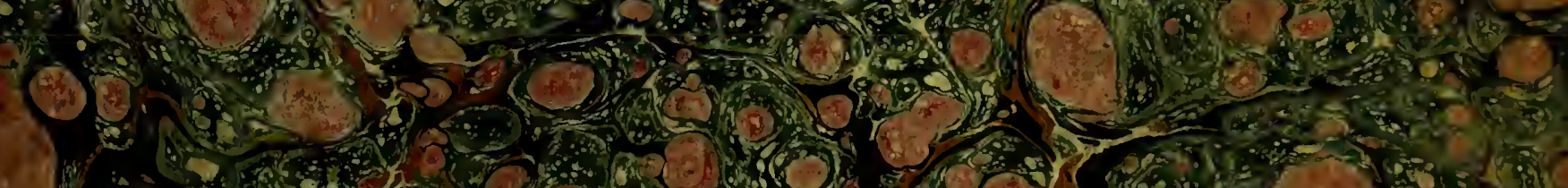
4.5. 1.9. (c) be (

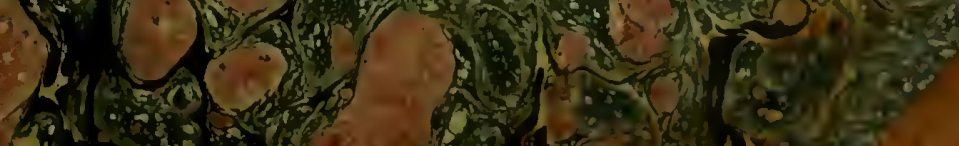


Glay. bollige aiby.

$$
63.35
$$

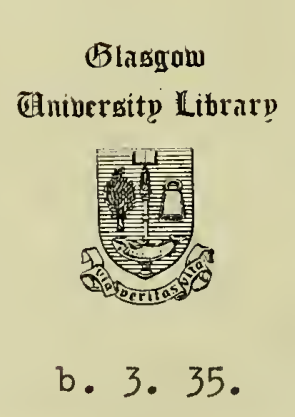


SL

Engte

subes.

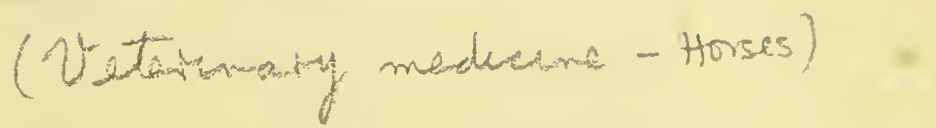

Pa. 


GLASGOW
VNINERSTY
LBRARY: 


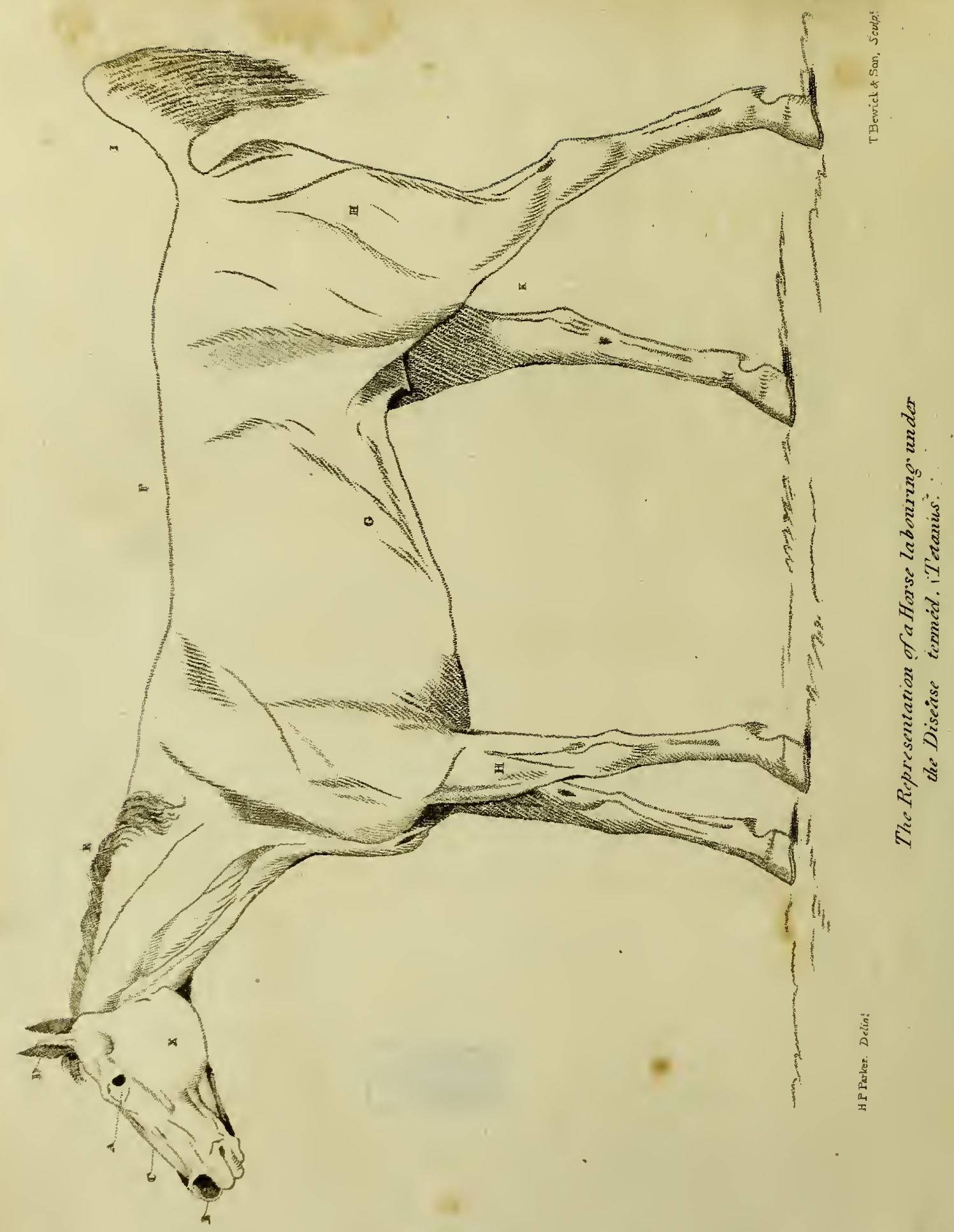


A

\title{
TREATISE
}

ON TWO OF THE MOST

\section{IMPORTANT DISEASES}

WHICH ATTACK

\section{THE HOR SE.}

\author{
IN TWO PARTS.
}

PART I.

CONTAINING AN ACCURATE aCcount of THE CAUSE, PROGRESS, AND TERMINATION TOGETHER WITH THE MODE OF 7 REATMENT FOUND MOST SUCCESSFUL FOR THE CURE OF THAT DIEADFUL DISEASE

TERMED

\section{正ocked Jatw and Zetanus,}

ILLUSTRATED

WITH SEVERAL CASES SUCCESSFULLY TREATED; BEING THE RESULT OF MANY YEARS EXPERIENCE.

$$
\text { PART II. }
$$

\section{A TRB}

$$
\text { ON THE }
$$

\section{Epioemical distase, or eatarrbal Zffection,}

WHICH SOMETIMES PREVAILS AMONG HORSES;

WHEREXN ARE DESCRIBED,

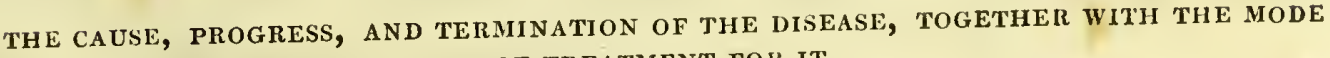
OF TREATMENT FOR IT, Jllugttateo with $\mathbb{C a g e s ~ g u c c e g g f u l l y ~ t r e a t e d . ~}$

BY WILLIAM WILKINSON, VETERINARY SURGEON, NEWCASTLE UPON TYNH.

NEWCASTIL:

PKINTED BY EDWAKD WALKER.

SOLD IN LONDON, BY LONGMAN AND CO. PATERNOSTER ROW; BY CONSTABLE AND CO. IN EDINBURGII;

AND ALL BOOKSELLERS. 


\section{4arthatu?}

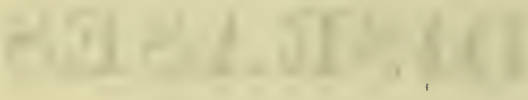

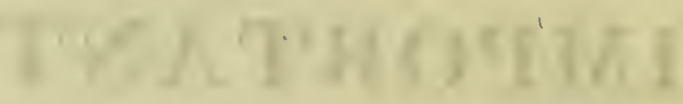

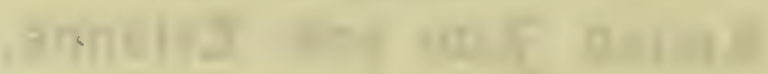

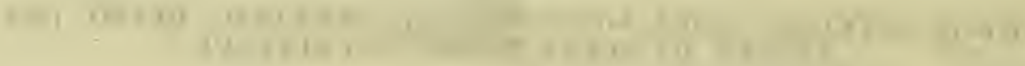

1) nir

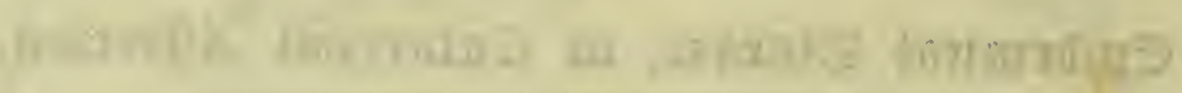

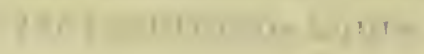

GLAS GOW

VNIVERSTY

LIBRARY: 


\section{DEDICATION.}

TO

\section{EDWARD COLEMAN, Esquire,}

Professor of the Veterinary College, Principal Veterinary Surgeon to the British Cavalry, and to His Majesty's most Honourable Board of Ordnance, and Honorary Member of the Board of Agriculture.

Sir,

THE eminent Situation you have so honourably filled for upwards of Twenty-five Years, and the Ardour with which you have pursued the Science you profess, and have taught with so much Satisfaction to your Pupils, and Benefit to your Country, justly entitle you to no small Share of the public Patronage.

Having imbibed the Principles of the Veterinary Art when a resident Pupil under you, I should think myself ungrateful not to acknowledge the same, when an Opportunity is offered me, by the Presentation of the following Pages to your Notice. 
Yeur ready Condescension in permitting me to dedicate the following Sheets to you, gives me great Pleasure; and should the Work meet with your Approbation and l'atronage, as the first Fruits of my Labours to render myself useful in my Profession, I shall think them an ample Reward for my Exertions.

I remain,

Dear Sir,

With an ardent Wish for your Prosperity and Happiness,

Your much obliged and most obedient humble Servant,

\section{WILLIAM WILKINSON, \\ Veterinary Surgeon.}

Newcastle upon Tyne, 1818. 


\section{P R E F A C E.}

$P_{\text {Revious to the establishment of the Veterinary College, the veterinary }}$ art, in a general way, was practised at random, without being governed by any scientific principles, although we are certainly much indebted to Gibson, Bracken, Bartlet,; Osmer, Clark, and a few more respectable Authors, for many judicious observations which they have advanced in their works.

But the combined effect of all their exertions for the improvement of the veterinary art would have availed little, if it had not been for the establishment of the Veterinary Institution. And since its establishment, it is generally allowed, and with propriety may be said, that the art has been greatly improved; and the seat of many diseases ascertained, and remedies found out, which before were totally unknown; and many remedies that were formerly cherished and much used, are totally rejected, they being found to be attended with pernicious consequences. Others, again, that were held in great repute, have, upon a fair trial, been found to be quite inert, and have no effect whatever.

Such important improvements must be attributed principally to the art being studied on scientific principles, well conducted; this being the only means to come at perfection.

Great benefit has likewise been derived from dissections, in investigating the nature and seat of diseases. 
But there are some diseases not generally understood, and much less successfully treated.

That dreadful disorder in horses termed Tetanus, being very little understood, has induced me to attempt to investigate the nature, seat, and cause of it; and at the same time to attempt a mode of treatment for its cure.

It is the success I have met with in the treatment of Tetanus, that induces me to publish the result of many years experience; and particularly, as this complaint has been considered by many to be incurable.

In the course of my practice, which has been upwards of twenty years, I have attended about sixty cases of Tetanus in the horse; and I have frequently found, that if the disease be taken before the jaws get quite locked, so as a medicine may be administered as a drench with a small horn, or given in small pieces as a ball on the end of a cane or a piece of whalebone, a cure may be performed.

The dissections I have made in those cases that were unsuccessfully treated, I think have afforded considerable light on the nature and seat of this complaint.

Tetanus being a disease not so generally known as many of the complaints which are incident to the horse, I have thought it necessary to give an Engraving of the Animal as a Frontispiece, exhibiting the disease at an advanced stage; at the same time to annex an Explanation of the most striking symptoms indicating the disorder.

We sometimes find an epidemical disease attacks horses, and rages with great violence. The success I have met with in the treatment of such complaints, also induces me to publish the result of my practice, which I hope will be found, upon an attentive perusal, to be in some measure useful.

I must not forget thus publicly to acknowledge the obligation I am under to the following gentlemen, whose talents no one can dispute, viz. :-Dr Baillie, Dr George Fordyce, Mr John Hunter, Mr Cruikshanks, and $\mathrm{Mr}$ Home; they having generously granted to the pupils 
of the College the liberty of gratuitous attendance at several courses of their Lectures, for which I shall always be proud to acknowledge myself much indebted, and shall ever hold it in grateful remembrance.

Mr Cline, Mr Astley Cooper, and Mr Abernethy, all equally eminent in their profession, have each taken an active part for the welfare of the Institution.

\section{EXPLANATION}

OF THE

\section{F R O N T I S P I E C E,}

(Which exhibits a Horse in an advanced Stage of Tetanus.)

A-The Membrana Nictitans, commonly called the Haw, covering a great part of the Ball of the Eye, when the Head is elevated.

B-The Nostrils greatly expanded.

C-The Nose thrown out from the Chest.

D-The Ears erect, or pricked up, and immoveable.

E E F G H H-The Muscles of the Jaws, Head, Neck, Back, Abdomen and Extremities, spasmodically afficcted and rigidly contracted.

I-The Tail greatly elevated.

K-The hinder Extremities much asunder. 


\section{I $\mathrm{N} D \mathrm{E} X$}

\section{TO THE \\ WORK ON TETANUS.}

Blaine Mr Delabere, his treatment for tetanus in horses, with remarks on the same

PAGE.

Blanchard Mr V. S., account of a case of tetanus successfully treated in the horse, by

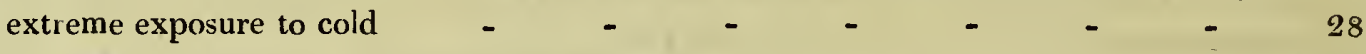

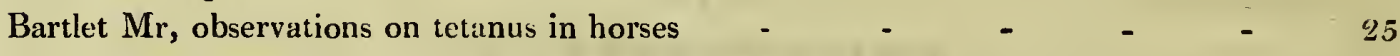

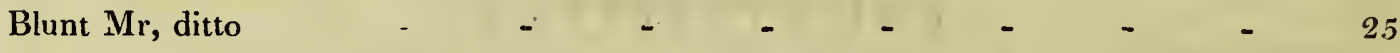

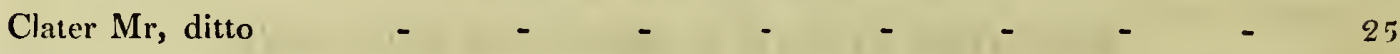

Cold, the inefficacy of exposure to, in a case of tetanus in the horse $\quad$ - $\quad 28$

Cooper Mr Samuel, observations on various authors who have written on the treatment of the wounded part in symptomatic tetanus in the human subject $\quad-\quad$ - $\quad 49$

Ferron Mr John, V. S., observations on the good effect of the warm bath on tetanus in

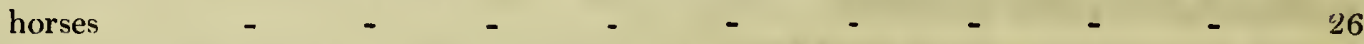

Gibson Mr, observations on his mode of treatment for tetanus in horses - $\quad 20$

Larry Monsieur, account of a case of symptomatic tetanus in the human subject,

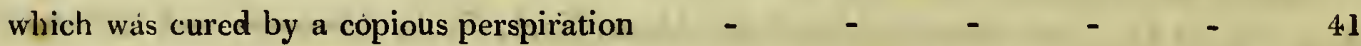

Moorcoft Mr, V. S. is said to have successfully treated a case of tetanus in the horse,

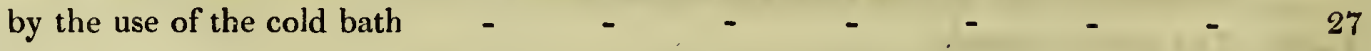

Parry Dr, observations on the failure of the cold bath in tetanus in lambs $\quad-\quad 28$

Parry Dr, observations on the sympathy that existed between the injured part in the fingers, and the muscles of the back, in symptomatic tetanus of a boy - - 32

Rush Dr, observations on a case of tetanus in the human subject, which was cured by a miliary eruption on the skin

Rush Dr, treatment of the wounded part in symptomatic tetanus in the human subject

Rush Dr, account of two cases of tetanus in the horse, which he saw successfully

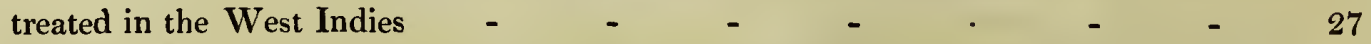

Thomas Dr, treatment of the wounded part, in symptomatic tetanus in the human subject 


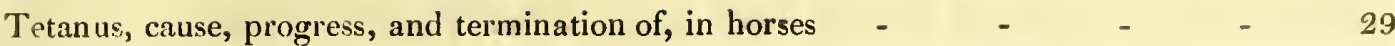

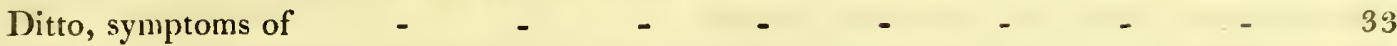

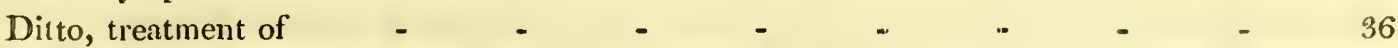

Ditto symptomatic, treatment of to the wounded part, found most successful in horses $\quad 53$

Ditto symptomatic, case 1st, successfully treated, which originated from a nail being driven into the sensible part of the foot in shoeing _ _ _ _ _ _ 56

Ditto symptoniatic, case 2nd, successfully treated, which originated from the amputa-

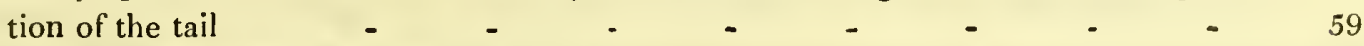

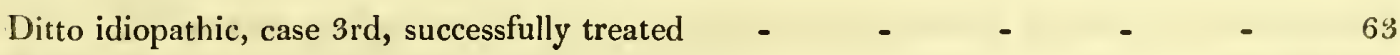

Ditto symptomatic, case 4 th, successfully treated, which originated from an injury in

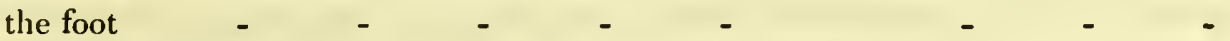

Ditto symptomatic, case 5 th, successfully treated, which originated from the amputation of the tail

Ditto symptomatic, case 6 th, successfully treated, which originated from the amputation of the tail

Ditto symptomatic, case 7 th, successfully treated, which originated from the ainputation of the tail

Ditto, case 8th, successfully treated, which originated from exposure to cold

Ditto symptomatic, case 9 th, successfully treated, which originated from the amputation of the tail

Ditto symptomatic, case 10th, successfully treated, which originated from an injury of the hinder extremity

Ditto idiopathic, case 11 th, successfully treated - _ _ _ _ _

Ditto symptomatic, case 12 th, successfully treated, which originated from a puncture of the extensor tendon of the foot

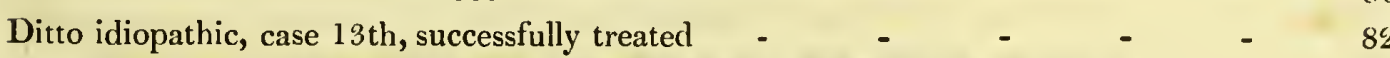

Ditto symptomatic, case 14th, successfully treated, which originated from the amputation of the tail

Ditto symptomatic, case 15 th, successfully treated, which originated from a nail being

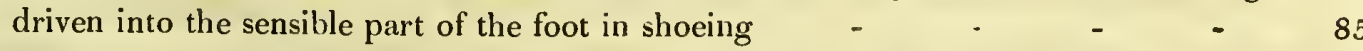

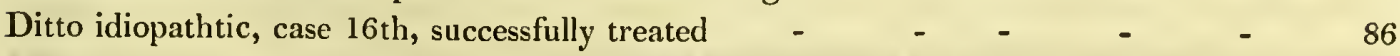

Ditto symptomatic, case 17 th, successfully treated, which originated from the amputatation of the tail

Ditto symptomatic, case 18th, successfully treated, which originated from the amputation of the tail

Ditto, case 19th, successfully treated, which commenced on the recovery from an inflammation of the lungs

Ditto symptomatic, case 20 th, successfully treated, which originated fiom the amputation of the tail 
Tetanus, case 21st, successfully treated, which originated from exposure to cold - $\quad 94$

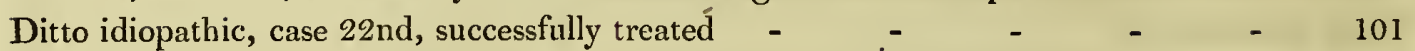

Ditto symptomatic, case $23 \mathrm{rd}$, successfully treated, which originated from the amputa-

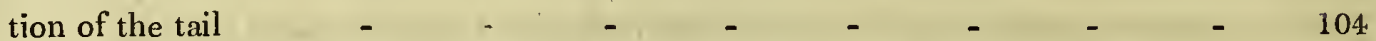

Ditto symptomatic, case 24th, successfully treated, which originated from castration 106

Ditto idiopathic, case 1st, unsuccessfully treated, with the morbid appearances on dissection

Ditto idiopathic, case 2nd, unsuccessfully treated, with the morbid appearances on dissection

Ditto symptomatic, case $3 \mathrm{rd}$, unsuccessfully treated, with the morbid appearances on dissection - $\quad-\quad \begin{array}{llllllllll} & - & - & - & - & - & - & - & -\end{array}$

Ditto symptomatic, case 4 th, unsuccessfully treated, with the morbid appearances on

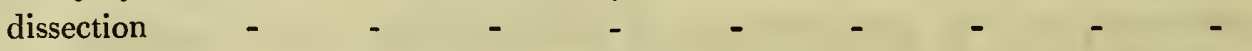

White Mr J., V. S., account of a case of trismus or locked jaw in the horse, which he

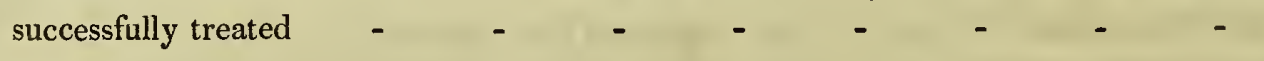
successfully treated

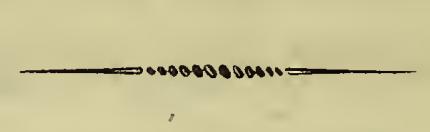

\section{N D E X}

TO THE

\section{WORK ON THE EPIDEMICAL DISEASE.}

Blood, the appearance of the, in inflammatory cases
the appearance of the, in cases of debility
the appearance of the, in the diseased state of the body, a good criterion with respect to the treatment

Blood-letting, practised by many Farriers, with the erroneous idea of drawing grease 


\section{$\mathrm{xi}$}

PAGE.

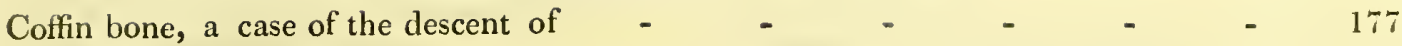

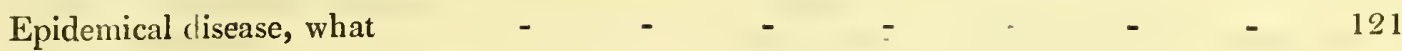

what seems to have been the cause of, in horses in the year $1798 \quad 141$

what part of the body was mostly the seat of the complaint in the

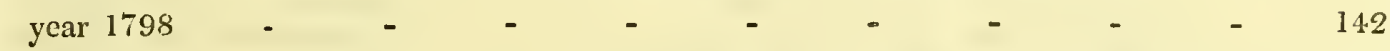

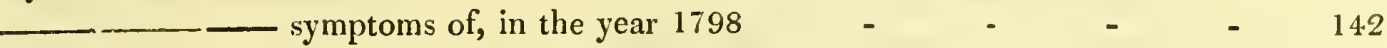

- what seemed to be conducive to its production in the year $1815 \quad 142$

year 1815

what part of the body was mostly the seat of the disease in the

symptoms of, in the year $1815 \quad-\quad-\quad-\quad-\quad$ - 143

affects various parts of the body, therefore it is thought right to

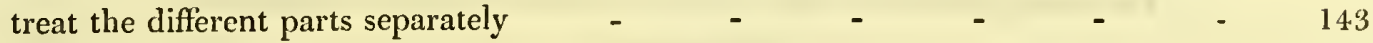

eyes affection of, with the mode of treament $\quad$ - $\quad$ - 163

head affection of, with the mode of treatment $\quad-\quad$ - 162

intestines, affection of the mucus membrane, with the mode of

treatment

lungs, the bronchia, affection of the muscus membrane of, with the

mode of treatment

lungs, the bronchia, affection of the mucus membrane of, with an

affection of the mucus membrane of the throat, and the mode of treatment

156

throat, affection of the mucus membrane, with the mode of treat-

ment

case 1st, which occurred in the year 1798

case 2 nd, which occurred in the year 1798

case $3 \mathrm{rd}$, which occurred in the year 1798

case 1st, which occurred in the year 1815

case 2nd, which occurred in the year 1815

case 31 d, which occurred in the year 1815

case 4 th, which occurred in the year 1815

160

151

144

200

202

203

205

206

208

Introduction, wherein is stated Messrs Gibson's, Osmer's, and White's treatment for

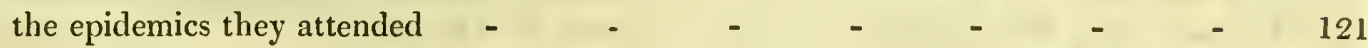

Observations on Messrs Gibson's, Osmer's, and White's treatment of the epidemics they attended 


\section{A LIST}

of

\section{S U B S C R I B E R S.}

The names marked thus * have had Horses cured of Tetanus, by the Author,

Askew Adam, Esq. Redheugh Allgood R. L. Esq. Nunwick

Anderson $\mathrm{Mr}$ Wm, Kenton

Anderson Mr John*

Abbs R. B. Esq. surgeon

Archbold Mr James

Atkinson Ralph, Esq.

Adamson Mr, Durham

Anderson $\mathrm{Mr}$ Francis, Bent House, near South Shields*

Arkless $\mathrm{Mr}$

Atkinson $\mathrm{Mr}$

Brandling C. J. Esq. Gosforth House

Brandling the Rev. Ralph, Shotton

Brandling R. W. Esq.

Brandling John, Esq.

Barrendale Mr

Bowlby Mr, South Shields

Bigge C. Wm, Esq. Linden

Bigge T. H. Esq. Little Benton

Blakiston $\mathrm{Mr}$

Bearcroft Mr John

Bell Matthew, Esq. Woolsington

Bell Henry, Esq. Newbigin

Butson Mr P., Lambton

Blair Mr Thomas, Abbey Mill

Bullock T. Esq. Spittle Hill

Burdon Sir 'Thomas, Kuight*

Browı Dixon, Esq. Long Benton*

Blackett Christopher, Esq. Wylam

Bacon J. W. Esq. Styford

Burras John, Esq. Kibblesworth

Barras George, Esq. Horton
Bragg H. Esq.

Beckwith Wm, Esq. Herrington

Brown Mr Wm

Coulson Lieut.-Colonel, Blenkinsopp Castle

Clark J. G. Esq. Fenham Hall

Currey Mr Thomas, sen. Jarrow

Currey Mr Thomas, jun. Westoe

Clark Wm, Esq. Benton House

Clayton Henry, Esq.

Clayton Wm, Esq.

Clapham Anthony, Esq. Benwell Grove

Coleman Mr

Carr Mr John

Carr John, Esq. Dunston

Cuthbertson Mr Thomas, Chester-le-Street

Crawhall Mr George, near Alston

Croser Joseph, Esq.

Cooper Mr, surgeon

Cookson John, Esq. Pelaw

Cookson Thomas, Esq.

Cramlington Henry, Esq.

Cruddace Thomas, Esq. Lumley Thicks

Cutter Mr George**

Dunn George, Esq.

Dunn Matthew, Esq. Stella Hall

Davison Mr, Crawcrook*

Dufour Mr Joseph, Whitfield

Errol the Right Hon. the Earl of

Ellison Cuthbert, Esq. M P. Hebburn Hall

Ellison Nathaniel, Esq.

Easton Mr Thomas

Fenwick George, Esq. Pallion

Fenwick Thomas, Esq. 
Fenwick Addison, Esq. Sunderland Fairs Mr Christopher, Gateshead Fell* Fife William, Esq. surgeon

Frost $\mathrm{Mr}$ George

Forster George, Esq.

Forster Mr Robert

Foggett Mr J. B. Doncaster

Falconer Mr, Whickham

Forsyth $\mathrm{Mr}$

Fawcitt Lieutenant

Foster Mr John

Grey Ralph William, Esq. Backworth

Goldburn Mr, North Shields

Gilhespy Mr, Higham Dykes*

Gibson Mr Taylor

Gallon Mr, Weetslet*

Gibson Mr George

Grace Mr John, Gosforth

Gilhespy Mr J., Cowgate

Glenton Frederick, M. D.

Hodgson John, Esq. Elswick

Haggerston Thomas, Esq. Ellingham

Hetherington Edward, Esq.*

Hollier Mr, Coventry

Harrison $\mathrm{Mr}$

Hodgson George, Esq.

Hill Captain

Hunter Matthew, Esq. Byker Hill

Harrison Mr, Longacre

Hutchinson Mr, Monkwearmouth

Hustler Wm, Esq. Sunderland

Hedley Robert, Esq. Long Benton

Hodson the Rev. S., Bywell

Hudsoll Mr John

Hawks John, Esq.

Hall Mr Francis, near North Shields

Ingham William, Esq. surgeon

Ilderton Sanderson, Esq. Ilclerton

Jobling Wm, Esq. Newton Hall

Johnson Francis, Esq. Woodliorn

Jobling $\mathrm{Mr}$

Jackson $\mathrm{Mr}$

Jowsey $\mathrm{Mr}$ Thomas, Sunderland

Kyle Mr, Ponteland*

Liddell Sir T. H. Bart. Ravensworth Castle

Liddell H. T. Esq. Ravcnsworth Castle

Loraine Sir Charles, Bart. Kirkharle

Lawson Wm, Esq. Longhurst

Lawson M. De C. Esq. Cramlington

Lilleyman Mr Joln, near Doncaster, 2 copies

Lidclell Mr Cutlibert
Lisle Mr Joseph

Lowman $\mathrm{Mr}$

Leighton $\mathrm{Mr}$ Thomas, surgeon

Monck Sir C. L. M. Bart. M. P. Belsay Castle

Maxwell Sir Wm, Bart.

Maxwell Mr Thomas, Blyth

Major Edward, Esq. Monkton *

Morgan E. Esq. Tynemouth

Maling Captain, R. N., Scotch House

Milner Charles, Esq. Lambton

Martindale John, Esq.

Marley $\mathrm{Mr}$

Mitchell $\mathrm{Mr}$

Martin $\mathrm{Mr}$

Maude Jacob, Esq.

Marshall Mr, Nottingham, 2 copies

Northumberland His Grace the Duke of, 6 copies

Nesham J. D. Esq. Houghton-le-Spring

Naters Nicholas, Esq. Sandyford

Nicholson $\mathrm{Mr}$

Ord Wm, Esq. M. P., Whitfield

Oliver $\mathrm{Mr}$

Prosser the Rev. Dr, Archdeacon of Durham

Price the Rev. Dr, Durham

Pearson Robert, Esq.

Pattison $\mathrm{Mr}$

Parker S. W. Esq.

Potts $\mathrm{Mr}$.

Peters Wm, Esq.

Parker Mr H. P.

Queensberry the Most Noble the Marquis of

Ridley Sir M. W. Bart. M. P. Blagdon*

Ridley the Rev. Richard*

Ramsay Colonel, Woolwich

Robson Thomas, Esc. Farwdon

Reed Colonel, Chipchase Castle

Robinson Mr, Bedlington

Robson Mr John, Felling

Ramsay James, M. D.

Reay Mr, Walker

Robson $\mathrm{Mr}$ Wm, Heddon West Bunlis

Ridley $\mathrm{Mr}$ John, Heaton

Riddell R. Esq. Cheeseburn Grange

Robson Mr, Swalwell

Reay Mr

Robson Mr George, Sunniside

Ruddock Jolın, Esq. Hexham

Robson Mr, Chester-le-Street

Strathmore the Right Hon. the Earl of

Storey Robert, Esq. Arcot 
Smith N. T., M. D.

Smith Wm, Esq. St Lawrence

Smart Mr, Harton

Smith Wm, Esq. Sunderland

Skipsey Mr George

Storey $\mathrm{Mr} \mathrm{Wm}$, Arcot

Swan Mr, North Shields*

Swan Mr, Walker

Sample Mr, Hexham

Surtees Anthony, Esq. Hamsterley Hall

Shepherd Mr J.

Shaw Robert, Esq. Usworth

Stoker Mr

Trotter Thomas, M. D.

Taylor R R. Esq.

Tinniswood $\mathrm{Mr}$, near Carlisle

Turner Mr Charles**

Turner Mr D. Blagdon xiv

Taylor Mr Cook, York

Thompson Mrs

Turnbull Mr

Thompson Mr, Byker Bar

Urwin Mr, Byker Bar

Usher Mr, Usworth

Walker John, Esq. Wallsend

Wilkinson Mr George, Sunderland, surgeon

Wolf Mr, Chester-le-Street, surgeon

Wright Thomas, Esq. Whitley Park

Wilkinson Mr, Bishopwearmouth

Wright Mr Richard *

Weight Mr John

Wailes Mr Anthony, Bearle

Ward Mr, North Shields

Wilson $\mathrm{Mr}$

Wheldon Mr George

Weale Mr Edward, York 
PRACTICAL TREATISE

ON

\section{TETANUS AND LOCKED JAW}

IN HORSES. 


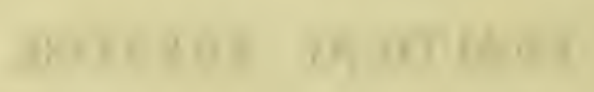

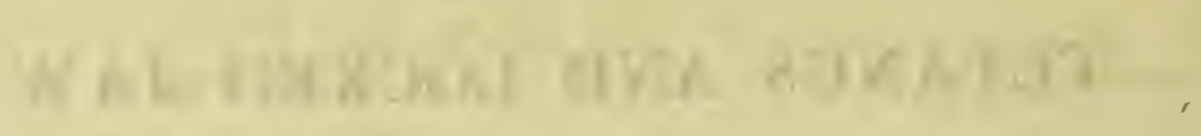
Examati $\mathrm{kI}$ 


\section{INTRODUCTION.}

'THE ancient writers on the Veterinary Art seem to have had very little knowledge of the dreadful disease called Tetanus; and it may be said, from the time of Markham until the time of Gibson, little has been written concerning the nature of the complaint, or attempted towards adopting any rational mode of treatment for its cure.

Therefore, as an introductory matter to this work, I shall mention the opinions of the few authors who have taken notice of this Disease in the Horse, and shall afterwards state my own opinion concerning the cause, progress, termination, and treatment of it.

Mr Gibson, in his Treatise on the Diseases of Horses, 1st vol. 2nd edition, page 278, being the first who gives a detailed account of this disease, I shall mention what he observes, in his own words.

Every one, says he, must needs be sensible that violent and excessive pain in any part of the body will excite convulsions, but especially when the pain is in those parts where the nerves abound most, - as the stomach, the guts, the midriff, and tendinous parts of the limbs; therefore, we find horses often convulsed in the gripes and strangury, when the nervous parts of the guts and bladder are affected with violent pain and inflammation. Sometimes horses become convulsed with wounds in the feet, when the tendons in those parts are pricked and bruised, or in any other part where the tendons are wounded; but especially punctured wounds in the joints, with forks or with sharp splinters, cause very great anguish and excessive pain, 
and sometimes with a disposition to gangrene and mortification, which often excites convulsions. These things are plain and visible, and it is no less plain that inward imposthumations, especially in the stomach, lungs, and midriff, will produce convulsions that are most dangerous, and often prove deadly; and further, we may often observe horses have convulsive disorders from plenitude and fulness of blood, which, however, is sometimes easily removed, as also those that proceed from a plenitude of the stomach, or when the guts are crammed with dung and aliment, especially when the dung, by long continuance, is grown hard and dry: all these things will occasion convulsive disorders, with the staggers. But I shall now proceed to treat of those things more particularly.

CONVULSIONS FROM THE STOMACH, AND OTHER PRINCIPAL BOWELS.

Of this kind is that deplorable distemper so well known, but little understood, which locks up the Jaws of a Horse so close, that it is almost impossible to force them open by any means whatsoever, either to receive food or physic.

Solleysell calls this malady the Stag's Evil, or Palsy in the Jaws, though in most of its symptoms it is directly contrary to palsy. With our English Farriers it goes under the general name of convulsions; and indeed it soon turns to an universal cramp or convulsion that seizes all the muscles of the body of a horse. But the true nature and cause of this extraordinary convulsion seem not as yet to have been rightly understood, either by our own countrymen or the writers of foreign nations. It almost always seizes suddenly, and without any previous symptoms, such as the want of appetite, and the other signs of sickness : for I have often known horses clear their racks in the night, and in the morning drink their water, and eat their allowance of corn as usual, and in less than half an hour have had their mouths close shut up, and their whole bodies convulsed. 
As soon as a horse is seized in this manner, his head is raised, with his nose towards his rack, his ears pricked up, and his tail cocked, looking with an eagerness as an hungry horse when hay is put down to him, or like a high spirited horse when he is put upon his mettle, insomuch that those who are strangers to such things, when they see a horse stand in this manner, will scarce believe any thing of consequence ails him, and I have seen such persons greatly surprised when they have been told of the danger; but they are soon convinced when they see other symptoms come on apace, that his neck grows stiff, cramped, and almost immoveable; and if a horse in this condition lives a few days, several knots and ganglions will rise on the tendinous parts thereof, and all the muscles, both before and behind, will be so much pulled and cramped, and so stretched, that he looks as if he was nailed to the pavement, with his legs stiff, wide, and straddling; his skin is drawn so tight on all parts of his body, that it is almost impossible to move it, and if trial be made to make him walk, he is ready to fall at every step, unless he be carefully supported; his eyes are so fixed with the inaction of the muscles, as gives him a deadness in his looks. He snorts and sneezes often, pants continually with shortness of breath; and this symptom increases continually till he drops down dead, which generally happens in a few days, unless some very sudden and effectual turn can be given to the distemper.

These are the usual signs of that fatal distemper, which here in England, passes more particularly under the name of convulsions; and though it differs in many respects from an epilepsy, both as to its symptoms and cause, yet it is the most universal in its effects of all other convulsive disorders.

Young horses, from four to six years old, are the most subject to it, and the large coach breed, and all kinds of draught horses, more than saddle horses. The most usual cause of this universal cramp or convulsion is from bots in the stomach, which being bred 
there from the eggs, generally come to their maturity in the months of April, May, or June : this being the season wherein this distemper chiefly prevails among young horses. And when it happens at any other time of the year, or to horses above six years old, that have been in business, it is then for the most part owing to other causes,as imposthumations or ulcers in the midriff, or some other of the principal viscera, which I have seen; but these instances are not so frequent as those from vermin in the stomach, and even the latter are not so frequent some seasons as others, which I have also observed, and therefore they may probably be owing to unwholesome food, wherein the eggs of those animals have been deposited, but chiefly to high foul feeding, for this sort of convulsion is most usual among those horses that have been kept up and pampered for sale, with little or no exercise, which disposes their blood to putrefaction whenever they come to be heated in their work.

I shall not here take up the reader's time with the different opinions and conjectures of physicians, concerning the conveyance of the eggs of insects into the stomach, or into the streight gut, where they are most usually found; but it is certain the stomach, as well as the streight gut, becomes a proper nidus to bring them to life. They appear to be no other than large maggots, with sharp prickly feet on both sides of their bellies. Those in the streight gut are commonly of a yellowish colour, and are no ways dangerous; but in the stomach they are generally of a larger size, and more inclined to orange, but without any other specific difference.

The eggs from whence these bots are produced are dispersed in clusters all round the lower orifice of the stomach, where it is thickest, and where probably the muscular action is most languid, that being as it were constantly distended by the weight of the aliment.

They are laid under the inner coat or thin membrane of the stomach, which covers them all over, as the eggs of those vermin that blight the trees in the spring are covered over with a fine filamentous 
membrane, and as these destroy the young tender leaf, and curl it up into folds, so those, when they come to form and life, they burst through the inner coat of the stomach, with their breech and tail straight outwards, and their trunks fixed so into the muscular or fleshy coat, that it sometimes requires a good pull to disengage them. From the blood of this muscular coat they draw their nourishment, which they suck like so many leeches, every one ulcerating and pursing up the part where it fixes, like a honey comb. I have seen in the same stomach, part of the eggs covered over with the inner membrane, and those of various sizes, some no larger than a millet seed, others about the size of peas, and some larger, stretching out the inner coat and just bursting through it; others in full life, and in thick clusters, sucking blood from the muscular coat. By this gradation the symptoms suddenly increase, and often make such quick havock in the stomach as renders the distemper incurable. From all which we may infer, that perhaps the muscles of the stomach are not endowed with so great a force as Bellini and many other modern physicians, have imagined, but that something else may be required in digestion, besides the bare muscular action. But be that as it will, we may easily account for the convulsive symptoms that attend this malady, and their universality, froin the distribution of the nerves over the coats of the stomach, which appear to be more numerous there than in any other of the viscera, and have their derivations by communicating branches, both from the head and from the spines of the back and loins; and this is the reason of what we see from daily experience, that whatever offends the stomach in any degree, always affects the head and other parts of the body. But these things do not often cause dangerous convulsions in those creatures that have a capacity to vomit. But when ulcers are thus engendered in the stomach of a horse, that has not this capacity, and all the powers and faculties thereof thereby destroyed, the case must be then very desperate, and the whole body, and all its parts, must of consequence be convulsed. 
The like symptoms are also in some measure produced from ulcerations in the diaphragm or midriff, by the vast distribution of twigs of nerves all over the tendinous parts thereof, having their derivations and communications in the same manner with those of the stomach. Besides, the midriff being placed near the centre of the whole body, and its muscular action being in concert with the muscles of the breast, shoulders, lower belly, and loins, it is no wonder if imposthumations there, or in any other part near it, should also bring on universal convulsions.

But it is of use in the cure of these maladies, to distinguish between an universal convulsion that takes its rise from vermin in the stomach; and when it proceeds from a distemperature of the midriff, or any of the principal viscera, which will also teach us how to make a right prognostic in these and all such extraordinary cases.

When the distemper arises, from bots in the stomach, it seizes suddenly, and without any previous notice; the convulsions in this case often seize a horse at once, and the horse appears with all the symptoms above described; and when his mouth is shut so close, as even sometimes, at the first on-set of the distemper, so as it cannot by any means be opened, the case is then exceedingly dangerous, and the cure almost impracticable. But when the mouth is so far free from the convulsions, that a medicine may be administered, though it be with some difficulty, and that he can make a shift to lick up a little bran, and swallow a little white water or gruel, there may be some hopes of recovery, especially if the neck is not excessively stiff and cramped, which is always a bad sign.

But if a horse is able to turn his head pretty freely, and can move his eyes backwards and forwards, or side ways, these may be reckoned promising signs, and the horse in such circumstances may be cured with proper care and right applications.

But when this sort of universal cramp or convulsion proceeds from a distemperature of the midriff, or any other of the principal viscera, 
there are always some previous symptoms that go before, by which it may be distinguished from the convulsions that proceed from bots or vermin. When this is the case, a horse first of all falls off his stomach, grows gradually weak, feeble, and dis-spirited in his work, and turns short breathed with the least exercise. These are the signs which I have observed to go before this distemper, though they are also common in many other inward disorders, and are generally owing to some mismanagement : as the working of holses beyond their strength, especially when they are growing old; by working on a starving low diet; and from want of gradual cooling, and not allowing proper intervals of rest, and such like neglects.

And though the distemper advances more slowly in this case, than in the other that proceeds from vermin, yet it is no less dangerous, because the true cause is seldom known till it be too late to provide a remedy. Whereas a horse that turns convulsed by vermin in his stomach, has a better chance, not only because it generally happens to young horses that have been neither broke by age nor labour; nor do we suppose any previous indisposition in the blood more than what is usual to young horses, from foul feeding, and want of sufficient exercise.

In order to the cure, it will be necessary to observe carefully these distinctions : and if a young horse that has been but lately in the dealer's hands, happens to be seized suddenly, and if this falls out in the spring and beginning of the summer, without any previous symptoms or foretokens of sickness, we may reasonably conclude the distemper to be owing to bots in the stomach, and to no other cause : in which case no time is to be lost; but before his mouth is quite shut up, the following ball may be given :-

\author{
$\xi \frac{2}{2}$ Mercurius Dulcis \\ $\zeta \frac{1}{2}$ Diapente \\ Conserve of Roses sufficient to make it into a ball.
}


I have seen very extraordinary effects from this and the other preparations of mercury in such cases. When this ball has been administered, make the following infusion :-

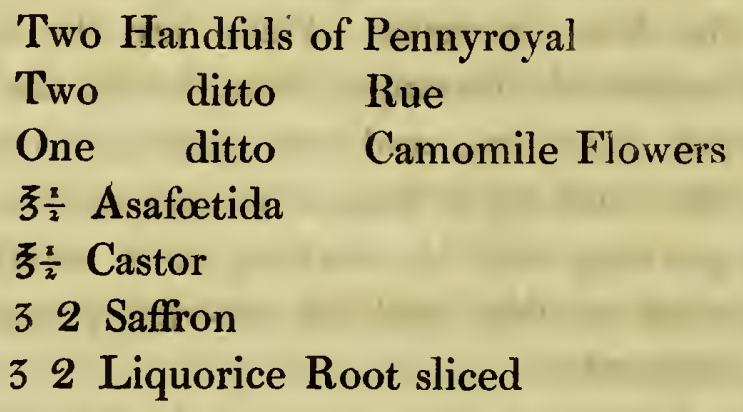

Let these be infused in four quarts of boiling water, and when the infusion has stood till almost cold, give three or four hornfuls, and repeat the dose three or four times a day, letting the ingredients continue always in infusion, and the castor and asafotida tied in a rag, which may be squeezed into the drench horn: for, though we suppose the convulsions in this case to be only from the ulceration in the stomach, yet the same method ought to be followed as if they proceeded immediately from the head, and origins of the nerves, both with respect to internals and externals, and therefore I would recommend the following, which I have always found to be of great use in all cramps and convulsive contractions of the muscles :-

\section{₹ 4 Nerve Ointment \\ 36 Marsh Mallows \\ 32 Mustard Seed ground \\ $\zeta 2$ Flanders Oil of Bays \\ 32 Oil of Amber}

With a sufficient quantity of Spirits of Wine to make it into a liniment. 
This must be rubbed into the cheeks, temples, the neck, shoulders, spines of the back and loins, and wherever there is the greatest stiffness. Mustard seed alone, fresh ground, worked well into the affected parts, with camphorated spirits, may be also used successfully to horses of small value for outward application; and internally, the following cheap drink, which may be given two or three hornfuls once in four hours :-

$\begin{array}{ll}\text { One Handful of } & \text { Tobacco } \\ \text { One ditto } & \text { Rue } \\ \text { One ditto } & \text { Pennyroyal } \\ \overline{3} 1 \text { Asafoetida } & \end{array}$

Boil them in a quart of forge water, and let the decoction stand constantly on the ingredients.

But sometimes horses' mouths are locked up so close in this distemper, that scarce any thing can be administered that way; and if this symptom is not speedily removed, the case soon proves deadly. I have had many convulsed horses under my care, some of which have died, others have perfectly recovered; though whenever horses are seized in this manner, the practitioners in farriery generally give them up for dead; and their method is to try if they can get any thing down, and when they find that impracticable, they administer glysters, and fill them full of rowels and other issues, though by reason of the contraction and closeness of the skin, scarce any of them come to a kindly digestion. I shall, therefore, relate some few instances of cures that were made by my direction, which, if rightly understood, may be of use to those who practise farriery, and will shew how much apparatus is necessary in removing this desperate distemper, which cannot possibly be effected without some expence and very great labour:-

About twelve years ago, a young troop horse was seized with this sort of convulsion, but not so severely as in some other cases that will be related. It began with the staggers, and sudden fits of starting, 
which made him rear up, and often get his fore feet into the manger. His sudden fits made me apprehend his distemper to proceed from vermin in the stomach, which is a constant symptom in all the convulsions that proceed from this cause; but as his mouth was not so constantly and closely shut as in many the like cases where $I$ have been concerned, we could, therefore, at times, make a shift to convey some medicines into him; and though he could not at first eat his common food, yet he could, by allowing him time, sip a pretty good quantity of water gruel, which sustained him till the medicines took effect. $\mathrm{He}$ was cured with mercurials, and the other things above directed, and afterwards by the help of mild aloetic purges.

Much about the same time, a young drum horse was also seized within a few days after he came out of the dealer's hands. He was so far relieved in a fortnight's time, that he could make a shift to eat some scalded bran, with a small quantity of hay, though very leisurely, which was given in handfuls, and frequently by the hand day and night to keep his jaws moving. Two men were also employed continually to rub his head, neck, and cheeks, and wherever else the stiffness appeared most, and these were relieved by others : for a horse in this condition never lies down till the convulsions of the muscles are in a great measure removed, and therefore, if the rubbing had been omitted, it would have been difficult to save him; and I have always observed, if a convulsed horse stands two hours without rubbing, the stiffness and insensibility increases, and certainly for want of this management many horses have been lost, that otherwise might have been saved. An ounce of asafoetida was also tied in a strong coarse linen rag, and put between his grinders to champ on.

This was rolled in the cloth, and tied at both ends with two pieces of pack-thread, which were fastened to his collar, and one side was always untied when any thing was to be given him, either of food or physic. This horse recovered perfectly in about two months time, and has been since abroad in Germany and the Netherlands, where he has 


\section{1}

undergone a great deal of fatigue, and returned home with the troop in perfect health.

I could add several instances of this kind, which for brevity sake I am obliged to pass over, and therefore shall only take notice of one more, which; for its singularity, deserves very well to be regarded, and that was a case of a young horse in the other troop of grenadiers. He had been but a few days taken into the troop, when he was all of a sudden seized with this kind of convulsion, which was first discorered as he was leading out to water, at the afternoon's watering time. I happened then to be present, and perceived him come reeling along, with his nose turned out, his eyes fixed and immoreable, with all the other signs that usually attend this fatal distemper, and when he came to the trough he could not reach the water, because of the cramp and stiffness of the neck; and when it was held to him in a pail, could not drink, though he shewed an eagerness for it, his mouth being shut up so close that it was scarce possible to put a knife between his teeth. This was sudden, as all these maladies generally are, for he had eaten his common allowance just before he was seized, except a small matter of hay, which he had partly pulled out of the rack into the manger.

We found it impracticable to administer any kind of medicine, till by rubbing his cheeks, jaws, and temples, and his whole neck, for a considerable time, we made a shift, with great difficulty, to thrust down part of a calomel ball on the end of a small stick, and then to pour into his nostrils a very small portion of a strong cephalic drink, thinking by that means to convey the ball downwards into his stomach, which however had but little effect any further than this, that he had not such sudden fits and agitations, as I have seen in others in like circumstances, but continued more quiet; neither did his fever increase, as usually happens when the distemper is gaining ground; but all this while his mouth continued so much shut, that he could neither eat nor drink for three weeks, only by continually rubbing his jaws and neck, he would sometimes make a shift to suck about a handful of scalded bran, or 
sometimes a little oatmeal moistened with warm water, but in so small a quantity, that it is possible he might have starved, if other methods had not been taken to keep him alive.

1 have often observed, that the forcing the jaws open by violent means, puts a horse into such agonies, that it rather increases than abates the symptoms, and therefore I contrived to give him both his food and physic by the fundament, through a pipe fourteen inches long, by which he seemed to receive great benefit, for we could perceive the symptoms daily abate, his flanks grew more quiet, he stood more still and free from sudden fits and startings, all which symptoms are usual in the continuance and increase of this distemper. The glysters were contrived in the following manner:-
One Handful Pennyroyal
One ditto Rue
One ditto Camomile Flowers
Half ditto Savin
Half ditto Box
$\zeta 1$ Garlic
$3 \frac{5}{2}$ Castor
$\zeta \frac{x}{2}$ Asafoetida

In making this glyster, the herbs are to be boiled first, in two quarts of water, in a covered vessel, the space of ten minutes, with the castor and asafoetida cut in small pieces, and tied in a rag, not only to save the castor from waste, but that it may be squeezed into several glysters ; then the garlic to be added, and continued close covered over the fire the space of ten minutes longer; after this the liquor to be poured off into a pan, or any convenient vessel; then add linseed oil or treacle, of eagch four ounces, and last of all, half an ounce of unrectified oil of amber. The treacle and the oils are to be mixed with the decoction when it is put into the bag. 
This glyster was repeated once a day for a fortnight; and by way of diet, was given every day, three or four quarts of milk, boiled with oatmeal and water, a bag, with a long pipe, being left in the stable for that purpose. He retained every thing that was administered that way, which he generally sucked up of himself without force. This, perhaps, was, in some measure, owing to the nature of this universal convulsion, which causes such irregular motions in the midriff and muscles of respiration, as in some measure inverts the natural motion of the guts; and for the same reason, horses in this condition seldom dung, but stale often, and when they dung, it drops from them in a manner insensibly, and often no more than one or two balls at a time; and therefore, as this horse could receive little or no sustenance by the mouth, I was determined to make trial how far he might receive nourishment by way of injection backwards; whether a thin diluted food thrown into the streight gut, and from thence over into the small guts by the help of a long pipe, might not find a passage into the blood vessels through the lacteals, especially there being experiments of this kind made on the human body, both in administering food and physic, particularly in giving the bark by way of glyster in agues and intermitting fevers, which has been found successful where the stomach was not able to bear its austerity. It was upon this footing, that I treated him in the manner I have described, which, I imagined, was not altogether without its effect, for he scarce eat in three weeks, what was sufficient to sustain him one day, so that it was impossible for him to have lived had he not been supported by what was thrown into his bowels; and though by this means he lost his flesh very sensibly, yet he still retained a good deal of vigour and vivacity. He had two men constantly to look after him, and those relieved by others, who had orders to rub his whole body often, which greatly helped to relax his skin, and remove the crampiness of his muscles, and though he had not for the first fortnight recovered the use of his jaws, yet we observed him daily to move with less stiffness, and often to lick in his manger, as if he craved after food. He also breathed with 
less difficulty, and had several other good signs. This encouraged me to try another experiment with opium, from the known quality of that drug in relaxing the animal fibres, which I therefore thought might be of service to remove the contractions of the muscles about his mouth and jaws, which all this while continued in some measure obstinate, and without some powerful relief, might prove fatal, even though the original cause was in a great measure taken away. Therefore, I caused half an ounce of crude opium to be dissolved in one of his glysters, which was followed with these circumstances : that the horse soon lay down, he began to point his ears backwards and forwards, and could move his neck pretty freely, and his mouth was so far at liberty, that he took his drinks with little or no difficulty, and could eat hay and bran sufficient to sustain him: he likewise moved his whole body so readily, that we could walk him an hour every day. And that I might follow up what I imagined had been successfully begun by the opiate glyster, I ordered him, some days after, an ounce of the common Mathew's pill, which contains about two drachms of opium, and the same quantity of asafoetida, made into a ball, which was given at his mouth, and washed down with a hornful of gruel, which was done with great ease, his mouth being grown pretty pliable. This ball being once more repeated, he recovered daily. Being continued for some time in the use of the drinks, which were now administered only twice a week, with good rubbing; and as soon as he began to recover his flesh, he was gently purged. By this method he was perfectly cured without any other ill effect than a blemish on one eye, caused by the violence and strong contraction of the muscles during the convulsions, which indeed were as bad as any I ever saw, even where they proved the most fatal.

Thus I judged it might be proper to relate the history of this cure in its whole process, including all the principal circumstances thereof, wherein it may be observed, that I have scarcely in any respect followed the common method of repeated bleedings, purging glysters, and rowels, all of which might be proper, if the convulsions proceeded 


\section{5}

either originally from the head, or from a viscid sizy blood, or from wounds or contusions, \&c.

But as I have discovered this kind of convulsion or universal cramp in young horses, usually to take its rise from the causes above assigned, to wit,-from vermin in their stomachs, I have therefore in such cases bled but seldom. I made use of no purging glysters, because the irritation made in the bowels, and a discharge from thence, can be of little or no use, but hurtful where a powerful revulsion is not absolutely necessary, especially where a horse cannot feed; and as for rowels, I have seen the farriers put a rowel on each side of the neck, one in the belly, one in the forehead, and one in each thigh; but the ill success they meet with, has made them not so fond of that kind of practice of late, as formerly, for the skin is drawn so tight in all parts, that the rowels seldom come to a kindly digestion, but are apt to mortify, and thereby increase the horse's misery, and therefore I have seldom ordered rowelling in this disease but under the jaws or in the breast, there being no room for rowels any where else.

What effect opiates may have in destroying vermin, I shall not offer positively to determine: whether by rarifying the blood to a great degree, and consequently augmenting its motion, or by any other quality they cause these eggs to come loose from their adhesion, as we see tobacco water destroy the eggs of vermin on the leaves of plants. In these things we have no way to come at any certainty without experiments; though it is likely, by its relaxing quality, it may be useful in such an universal cramp, especially when the management of it falls into good hands.

But all are agreed, that mercury, and several of its preparations, are efficacious in destroying worms, both by its weight and subtilty disposing it to pass through the minutest capillaries; and also by its globular figure, which no kind of change, by whatever menstruum or any other management it is dissolved, can alter ; and therefore I have given it with good success in various shapes to destroy vermin,- 
sometimes the crude, sometimes the calomel or mercurius dulcis, and in some very urgent cases of this kind I have exhibited a drachm, sometimes two drachms of the turbith mineral; but, whoever ventures upon these, and such like preparations, ought both to understand the nature of the medicine, and the constitution to which it is administered. I could relate many more cures of this kind, which I have made since, and particularly three very lately, which were all managed in the same manner, by giving their food and physic by way of glyster, and as they differed only in some few circumstances from those already related, I shall forbear to go into the particulars of them, but proceed to those convulsions which are owing to other causes.

When this distemper-does not proceed from vermin, as sometimes happens to old horses that have been strained in working, or after some very bad surfeit, then the mercurial preparations will be in a great measure unnecessary, or perhaps hurtful, and therefore recourse must be had to the cephalic drinks above inserted, to bleeding, and moderate purging, and proper alteratives. Rubbing, and the use of liniment externally, is here also of great use, and frequent glysters of the emollient kind. In this case a horse must be treated with great gentleness, because there is often some inward decay, which will admit of no rough dealing. I have seen, in horses that have died of this distemper, the midriff ulcerated, which being extremely full of branches and twigs from the phrenic nerves, that communicate with all the other nerves of the body, and being itself a kind of centre muscle, that acts in concert both with the muscles of the breast and lower belly, makes it, therefore, the more easy to account for this universal cramp, which, when it proceeds from hence, may be looked upon, for the most part, as the harbinger of death, unless the symptoms are so moderate, that there is room for administering medicines, and that the horse is able to take a sufficient quantity of food to sustain him; and if the symptoms do not increase, but abate, it is possible for him to recover; though, if the horse be old, or of a very weak constitution, he will scarce be worth the expence and 
pains. Some I have known recover and do very well, that have had all the symptoms of a diseased midriff; and in this case, besides the use of the cephalic medicines, rowels and good feeding are of great use, as soon as the horse's skin is loosened enough to bear them.

I have taken notice, that this universal convulsion may also take its rise from a faulty blood, in which case it may be removed without much difficulty, unless the horse be very old, as in the instance I am going to relate.

A horse in the third troop of guards was seized with this universal cramp or convulsion, which began in his hind parts, quite different from that which proceeds from vermin, or faulty midriff, both which seize suddenly. At first, nothing appeared but a cramp in his legs, to which some horses are often subject, and generally come well with moving until they are warm; and therefore, the groom that looked after him, trotted him twice a day in the riding house, after which, it went off for a time; but in a few days, he was all over convulsed, with his jaws set, yet not so close, but we could, with some difficulty, give him both balls and drinks.

The horse was about eight years old, and had been about three years in the troop. His blood was exceeding poor and viscid, resembling paste, and the loss of it gave him no relief. I concluded from hence, and from other circumstances, that his distemper proceeded altogether from a depraved weak sizy blood, and not from vermin; for, when the convulsions happen to young horses from vermin, their blood is indeed sizy, but at the same time rich and florid; but it was quite otherwise with this horse: the convulsions began in the limbs, where the motion of the blood and juices are most languid, and from the consent that all the muscles have one with another, ascended gradually, like a fire that begins in the bottom of a house, and rising upwards, would soon consume the whole fabric, unless speedily extinguished. This horse was cured without much difficulty, though it was some time before he came to a perfect statc of health. 
The medicines administered to him were the same that have been already inserted in the cure of epilepsies, and other cephalic disorders, with cinnabar balls, which were proper to attenuate and take off the siziness of his blood. In such cases a sinall quantity of wine may also be indulged, with saffron, Virginia snakeweed, and contrayerva roots, to be mixed with the drinks; and in some cases, a tincture of steel, to warm and invigorate the blood, viz.

\section{$\xi \frac{x}{2}$ Castor \\ $\zeta^{\frac{x}{2}}$ Asafoetida \\ 1 Handful Rue \\ 1 ditto Pennyroyal}

$\zeta 8$ Filings of Iron tied up in a Bag

Infuse these in two quarts of boiling water, and keep the infuision close covered by itself for use.

Also take

\section{$\zeta \frac{x}{2}$ Virginia Snakeweed \\ $\zeta \frac{x}{2}$ Contrayerva \\ $\zeta \frac{x}{2}$ Valerian \\ 32 Saffron \\ 32 Cochineal}

Infuse in a quart of White Wine; letting it stand in the sun, or by a warm fire, twenty four hours.

Take a pint of the first infusion, and a gill of this tincture, for a dose, which may be given once a day, or oftener, as the symptoms require.

If the horse's mouth continues pretty much locked up, that he receives his drinks with difficulty, sufficient intervals must be allowed between every hornful; and, indeed, this caution is as necessary here 
as in those cases where we suppose inflammations or imposthumations in the lungs. But good rubbing, and the use of nervous liniments externally, are no less necessary than internals; for such is the nature of all cramps and convulsive contractions, that unless the convulsed parts be kept continually warmed with stimulating things, and frequent frictions, the contractions will grow stronger and more obstinate. And further, because convulsed horses are apt to be exceedingly costive, it is necessary to give glysters often, till they come to the use of their jaws, and are able to feed tolerably well. After which, purges are exceedingly proper, not only to attenuate the blood, but to drain off the superfluous size, that clogs the muscles, and hinders the vibration of the nerves, or the free intercourse of the animal spirits. The following will be found the most beneficial in this case, wherein the common purges of plantation aloes would be hurtful, being more apt to create nervous disorders then to cure them :-

\section{Succotrine Aloes}

$3 \frac{x}{2}$ Myrrh

32 Asafoetida

32 Gum Ammoniacum

3 1 Saffron

Syrup of Marsh Mallows sufficient to make a ball.

These may be given one in a week; and continued three weeks or a month, or longer, if needful : they will just open the horse's body, and work as an alterative to cleanse and purify the blood, and so gently, that the horse may be used moderately in any kind of business, in the interval between the purges.

Having at full length given Mr Gibson's account of the symptoms of locked jaw and tetanus in the horse, and the mode of treatment he pursued in such cases, I shall now make some observations on his mode of treatment. 
It appears that Gibson has been pretty well acquainted with many of the symptoms indicating this disease; but it is somewhat singular that he does not advance the history of a single case, wherein the complaint originates from an external wound. Although he commences his observations on convulsions, with signifying that diseases of that nature may be brought on by injuries in the tendinous and ligamentous parts of the legs and feet, yet nothing is observed concerning the treatment of such wounds, or the progress the disease makes when it originates from such a cause; neither does he mention any thing concerning the state of the pulse.

And in treating of this complaint, he considers, that when it arises from any internal affection, it is generally owing either to an affection of the stomach or bowels, from bots or worms, or from an affection of the diaphragm : and when it arises from bots affecting the stomach, they produce inflammation and ulceration in that organ : he observes, they are bred there from their eggs, and generally come to their maturity in the months of April, May, and June, this being the season wherein this disease prevails among young horses; and when it happens at any other time of the year, or to horses about six years old, that are in work, it is then for the most part owing to other causes,-as imposthumations and ulcerations of the diaphragm, which he has seen; but these instances, he says, are not so frequent as those from bots in the stomach.

He then gives an account concerning the deposit of the eggs of those bots, and their generation.

It appears to me to be a very difficult matter to give a clear account concerning the generation of those bots; but certain it is, that they are sometimes found fixed very closely to the muscular coat of the 


\section{1}

stomach, producing inflammation and ulceration in that organ, which assumes, as Mr Gibson observes, much the appearance of a honey comb.

I have a very good specimen of it amongst my anatomical collection. It is a portion of the stomach of a mare, that belonged to the Second, or Queen's own regiment of Light Dragoon Guards, which died of tetanus, in consequence of the irritation produced by these destructive insects.

In this case the disease made a very rapid progress, - as I was informed by the groom, who looked after the mare, that she appeared as usual that day she was attacked, and eat her corn and hay; and in about six hours afterwards I was sent for to examine her, and found her jaws so much shut, and the muscles throughout the whole system so spasmodically affected and rigidly contracted, that no medicine could be administered by the mouth, and she died shortly afterwards.

The mare had received no injury in any part of her body, that could induce one to think was the cause of the complaint; and as the disease made such a rapid progress, I informed the captain of the troop, I suspected bots in the stomach to be the cause of the disorder, and that I had scarcely any hopes of her recovery,-therefore, after death, it was agreed to have her opened,

And on dissection the following morbid appearance was observed :-

On opening the abdomen or belly, the stomach and intestines were found to be considerably inflamed; and on making a section of the stomach, the internal coat, and even the muscular coat, was found to be deeply ulcerated with a number of these bots, fixed so closely and firmly to the ulcerated parts, that it was difficult to pull them off without breaking them.

So far it appears that Gibson is accurate concerning the description he has given of this disease making such a quick progress when it originates from bots in the stomach.

He then mentions, when the complaint arises from ulcerations in 
the diaphragm, there are always some previous symptoms by which it may be distinguished from the convulsions that proceed from bots.

When this is the case, he says, the horse first of all falls off his appetite, grows gradually weak, feeble, and dis-spirited in his work, and turns short breathed with the least exercise.

With respect to ulcerations in the diaphragm producing tetanus, I confess I never knew it originate from that cause; but it is probable it may arise from a diseased action in that part, it being a muscle of respiration, and being supplied greatly with nerves. If a horse be worked beyond his strength, particularly in pulling great weights, it will lay the foundation for this disease.

I have known an ulceration in the diaphragm of a draught horse, but it did not produce any tetanic affection.

When this disorder arises from any of the internal organs being affected, I consider it to be a matter extremely difficult, to point out, in the horse particularly, what organ is affected.

Although, if for sometime it is observed, that one or two of these bots, now and then, have been discharged with the excrements, and the horse should suddenly be seized with symptoms of locked jaw, attended with frequent startings; if at the same time there is no injury in the external parts of the body, particularly of the tendinous and ligamentous parts of the tail, legs, or feet; in this case I should consider the complaint to have originated from bots in the stomach.

In treating of this disease, Mr Gibson observes, when it proceeds from bots in the stomach, that mercurial medicines should be administered as quickly as possible, and that he has seen very extraordinary effects from the administration of a ball which he has prescribed.

Now, in cases of bots in the stomach, and other worms in the intestines, producing locked jaw, it is very probable that mercurial medicines may be of considerable utility; but I think the dose Gibson prescribes, should be considerably diminished, and combined with other 
medicines of an antispasmodic nature, and repeated according to the judgment of the practitioner.

The infusions he orders after the ball is given, I consider to have little effect in this complaint.

He next prescribes a drench made of a strong decoction of tobacco, and some other herbs, which, he says, may be given to horses of little value, on account of its cheapness : in regard to which, I consider that tobacco as an internal remedy, is attended with very pernicious consequences, as is clearly proved from an observation made by $\mathrm{Mr}$ White, an ingenious veterinary surgeon of Fxeter, in his Treatise on Veterinary Medicine, third vol. page 232, and the following is the account he gives of it:-

A gentleman, whose horse was in perfect health, but had not so smooth a coat as he wished, was advised, by a groom, to give him some tobacco steeped in beer. He accordingly procured, he believes, one ounce of the strongest tobacco, and infused it during the night in some beer. The next morning, the liquid part was strained off, and given to the horse; about two minutes after, he dropped down, and died.

Tobacco infusions, when properly made, may be used as an external remedy in cutaneous diseases; but as an internal remedy in the horse, I think they ought to be rejected, as the above circumstance sufficiently indicates.

Mr Gibson speaks much of friction, and the use of stimulating liniments, both of which I consider to be of some utility in tetanus.

He states, that in some cases, he has ordered rowels under the jaw, and in the breast, these being the only parts in which they can with propriety be inserted.

In regard to which, I consider, that in all cases of tetanus, rowels are very improper, as their insertion certainly produces great irritation, consequently they must increase the spasms of the muscles very much.

He next mentions a case, where the jaws were so much shut, that the horse could neither eat nor drink for three weeks, only by 
continually rubbing the jaw and neck, he could sometimes make a shift to suck about a handful of scalded bran, or sometimes a little oatmeal, moistened with a little warm water; and he thinks, that during the three weeks, he had not eaten as much as was sufficient to sustain him one day; and during all this time, he was supported by milk and oatmeal, injected by the fundament. He had also a glyster once a day, made of a decoction of some herbs, \&c.

Now, he observes, that during all this time, the contractions of the muscles of his jaws and mouth continued in some measure obstinate, and without some powerful relief, might have proved fatal, even though the original cause was in a great measure taken away.

Therefore, he caused half an ounce of crude opium to be given in one of his glysters, which was followed by these circumstances : that the horse soon lay down; he began to point his ears backwards and forwards, and could move his neck very freely; and his mouth was so far at liberty, that he took his drenches with little or no difficulty, and he could eat hay and bran sufficient to sustain him.

We have here a strong instance of the good effect of opium in this case of tetanus, which evidently shews it to be a most useful medicine in spasmodic affections, in bringing on a relaxation of the muscular system.

He next details a case of tetanus, where the spasms began in the muscles of the hind extremities of the horse, and afterwards, the whole muscular system became spasmodically affected, with the jaws set.

Now, I should wish to observe, that during my practice, which has been upwards of twenty years, and during that time I have attended about sixty cases of tetanus, I can with confidence assert, that I never knew the disease commence in that way; it invariably began with an affection of the muscles of the jaw ; and as the disease advanced, the muscles of the head, neck, back, and hind extremities became affected.

He then concludes with observing, that after a horse has got a free use of his jaws, and the action of the muscular system restored, so as the horse may occasionally be ridden, that a purge may be given once a week, for three weeks or a month. 
With respect to the administration of purges after the tetanic symptoms are removed, I consider that they only tend to do harm, as the system is generally much debilitated from the violence of the spasms, and the want of sufficient nutriment being got into the system during the progress of the complaint.

Therefore, if the bowels are become naturally open, and all the secretions and excretions of the body are going on in a regular way, instead of administering purges, I would recommend tonics combined with cordials; a generous diet, regular and moderate exercise, and not to omit considerable friction in dressing, and using moderately warm cloathing.

By this mode of treatment, it is very probable, the tone of the muscles will soon be restored.

But if costiveness should take place, a laxative ball or clyster may occasionally be administered.

Having pointed out what may be considered of utility, and at the sanıe time, what may be considered of no utility, and even pernicious, in $\mathrm{Mr}$ Gibson's treatment of locked jaw and tetanus in horses,-

I shall now proceed to mention a few more authors that have given a short account of this disease.

Mr. Bartlett, Clater, and Blunt, have each taken notice of this disease in their works, but the substance of what they observe, seems chiefly to be borrowed from Gibson.

Mr Delabere Blaine, in his second vol. page 550, of the Outlines of the Veterinary Art, in treating of tetanus, observes, that the jaws being much shut, it is unfavourable for the exhibition of internal remedies, and in this case, medicine may be given by the nose, without either danger or difficulty; and he recommends a trial of the following drench; and if a mitigation of the symptoms takes place, to repeat it :- 


\section{Drench.}

\section{Tincture of Opium \\ ₹ 1 B Vitriolic Ether \\ Half Pint Brandy \\ Three Gills Ale}

It is probable this medicine may be of considerable service, if administered by the mouth, before the jaws get locked; but I am persuaded, if it is attempted to be given by the nose, it will excite great irritation in the membrane lining the nose and trachea, which will tend greatly to increase the spasms of the muscles, and do harm.

Therefore, when it is found impracticable to administer medicine by the mouth, I should prefer it given as a clyster; but it should be observed, a greater quantity of it may be given in this way, than by the mouth.

Mr John Ferron, Veterinary Surgeon to the 13th Regiment of Light Dragoons, and author of a work, termed A New System of Farriery, page 193, in writing on locked jaw, considers the treatment to be confined to the most powerful antispasmodics, bleeding, and immersing the animal in a warm bath, at 90 degrees of heat, which, he says, he has known to be successful, provided the whole body be covered with the water for two or three hours; after which, the horse must be kept extremely warm and well cloathed, unless the symptoms should return with more violence.

Mr White, of Exeter, in his Treatise on Veterinary Medicine, 1st vol. 8th edition, page 348 , mentions a case of locked jaw, that proceeded from an injury in the foot, which he treated successfully by the administration of large doses of opium and camphor: 
A strong blister was applied to the spine, beginning at the withers, and continuing it the whole length of the spine, even to the basis of the tail.

A caustic was applied to the wound in the foot.

In this case, the system had been partially affected,-I mean the spasmodic affection had been confined to the muscles of the jaw, as $\mathrm{Mr}$ White observes, the muscles of the neck were in a natural state.

Now in my practice, as I have already had occasion to observe, I have invariably found, that before the jaws become considerably locked, the muscles of the neck, back, and hind extremities become much spasmodically affected and rigid.

However, it appears this case, which Mr White details, must evidently have been the same disease, but the spasms were confined to the muscles of the jaw; and such a tetanic affection goes under the denomination of trismus.

It appears again, that cases of trismus are very rarely met with in the horse.

$\mathrm{Mr}$ White, treating the case successfully, greatly corroborates the idea, that opium, combined with other antispasmodics, is much to be depended upon in the curing of tetanic affections.

Dr Benjamin Rush, Professor of Medicine in Philadelphia, in his 1st vol. page 255 and 263, of the Medical Inquirer, states, that tetanus often affects horses in the West Indies; and he has seen it twice cured by applying a potential caustic to the neck, under the mane, by large doses of the oil of amber, aud by plunging one of them into a river, and throwing buckets of cold water on the other.

Mr Moorcroft, Veterinary Surgeon, late of Oxford Strect, in London, but now in the service of the East India Company, is said to have cured a case of locked jaw, by the ruse of the cold bath. 
$\mathrm{Mr}$ Blanchard, Veterinary Surgeon to the 3rd Regiment of Dragoons, is said to have cured a case of locked jaw by extreme exposure to cold. It was in the winter season, and the weather was extremely cold and stormy. At night, the horse was turned into the barrack yard; and the next morning found perfectly free from the complaint.

Dr Parry, of Bath, in his Treatise on Tetanus, page 12, observes, that he has often known the disease be produced in lambs, by boring their ears with a red hot iron too near the root, for the purpose of marking them; and in page 20 , he observes, the same lambs were long kept in cold water, without the smallest relaxation of the spasms.

With respect to the effect of cold in tetanic cases, I never tried it but once, and that was in a case of a mare which had the disease from an overreach. It happened in the winter season, when there was a considerable quantity of snow on the ground: therefore, the mare's whole body, her nostrils excepted, was immersed in the snow for some time; but, on removing the snow, there was found no relaxation of the muscles; the symptoms gradually increased, and she expired the third day.

Having mentioned a few authors who have noticed this disease, and the modes of treatment they have pursued, I shall, in the next place, proceed to state the cause, progress, and termination of this dreadful complaint, and shall afterwards detail the mode of treatment I have found most successful towards its cure. 
ON

THE CAUSE,

PROGRESS, AND TERMINATION

OF THE

\section{LOCKED JAW AND TETANUS \\ IN}

\section{H O R S E S.}

$\boldsymbol{T}_{\text {HIS disease being one of the most desperate and fatal that is incident }}$ to the horse, demands early and great attention.

It is a spasmodic affection of some or all the muscles, which occasions them to become rigidly contracted.

It commences with an affection of the muscles of the jaw, and when the spasms are confined to these muscles, the complaint has been termed tiismus.

But when the disease has made a further progress, so as to affect the muscles of the neck, back, hinder extremities, and abdomen, it is then called tetanus; but it is evidently the same disorder at a inore advanced stage.

It is fortunate this disease does not often occur; but it is said to prevail more in hot than in cold climates, and is considered to be the most fatal when it arises from injuries in tendinous and ligamentous parts. 
I have found by close attention to the cases of this complaint which have come under my care, that the most common causes of this disorder in the horse are injuries in the extreme parts of the body, such as wounds in the tendinous and ligamentous parts of the feet, legs, and tail.

But it may arise from a wound in any part of the body, that produces much irritability; or it may originate from any sudden variation of temperature, as exposure to cold when the body is in a profuse perspiration, or when a horse has been long kept in a warm stable, and is afterwards exposed much to wet or damp weather; or it may come on without any apparent reason.

The greater number of cases which I have attended, have originated from the amputation of the tail, commonly called docking, although I have had several cases in which the disease was brought on by wounds in the feet: for instance, by a nail being driven into the sensible part of the foot in shoeing; and by overreaches. I have likewise known it proceed from castration, and from those species of worms called bots, which attack the stomach, producing inflammation and ulceration in that organ.

And it is astonishing, that injuries in tendons, which, in a state of health, are considered insensible, should sometimes, when injured, produce such a derangement in the system as to occasion a locked jaw.

Now, in investigating the nature and seat of this disorder, it seems necessary to mention what morbid appearances have been observed on the dissections that have been made on the bodies of those horses which have died of the complaint.

Therefore, I shall briefly state for the present, that I have generally found, on opening the spinal canal, that the membranes covering the spinal marrow exhibited a very inflamed appearance, and the spinal marrow itself was tinged of a darker colour; and, on opening the cranium or skull, the coverings of the brain were likewise found to exhibit some marks of inflammation. I shall afterwards give a more 
detailed account of those appearances which occurred to me on dissections.

It appears evidently a disease of the nervous system, affecting particularly the medulla spinalis, and the nerves that are distributed from it.

It may be necessary to observe, that a Dr Reid, of Dublin, has published a work on the Nature and Treatment of Tetanus in the Human Subject, whose ideas, in many respects, correspond with mine, particularly with regard to the seat of this dreadful disease.

But I can with confidence assert, that before I read Dr Reid's work, I had discovered by my own dissections in the horse, that the coverings of the spinal marrow, in tetanic cases, exhibited a very inflamed appearance; at the same time, the nervous substance itself put on a darker tinge, which Dr Trotter, an eminent physician in Newcastle upon Tyne, and who is author of a work, termed A View of the Nervous Temperament, and some other valuable publications on the human body, can testify, as he was so condescending as to do me the honour of perusing my work as I wrote it, for which I consider myself greatly obliged.

At the same time, I shewed him a specimen of the inflamed state of the coverings of the spinal marrow, which I had removed from the spinal canal of a mare that died of tetanus, which specimen I have now among my anatomical collection.

Now, when we consider that the muscles derive their sensation from the nerves, which are distributed from the medulla spinalis, when that important part becomes affected in the manner we have observed, it is no wonder to find the muscular system thrown into a convulsed state, when the source from whence the muscles receive their sensation is so much deranged.

And I am greatly induced to think that the convulsed or contractile state of the muscles does not come on until the spinal marrow and its membranes become affected.

But what seems most astonishing is, when the disease originates from a trifling wound, as for instance, an overreach in the foot, or some 
slight injury of a tendon, and when to appearance there is very little pain or inflammation attending the part; and the wound shall be nearly healed, and sometimes quite healed, before symptoms of tetanus appearI say, it is astonishing, that such a wound should give rise to this terrible disorder, and excite such a morbid appearance within the spinal canal.

But it is probable this is owing to the degree of sympathy that exists between the one part and the other, there being at the same time a great predisposition in the body, which renders it extremely irritable, and peculiarly liable for the whole nervous system to be affected by such a cause.

In Dr Parry's Treatise on Tetanus, page 19, a strong instance is mentioned, of the sympathy that exists between the extremities and the back, in a case of a boy twelve years old, who had tetanus in consequence of a laceration of the flexor muscles of his little finger, from the bursting of a small cannon. In this case, Dr P. says, the parts principally affected were the dorsal muscles, - a power remaining of opening the mouth in a certain degree, and of swallowing a little.

He observes again, it is curious, that in this case, on the first day, and that only, touching the sore part would bring on a spasm of the dorsal muscles. This evidently shews the sympathy that existed in this case between the extreme parts of the body and the back.

Consequently, it must become a matter of the utmost importance to use means to diminish that increased irritability as quickly as possible, as the complaint frequently makes a very rapid progress; and when the jaws become completely locked, there is but little chance of recovery.

Whereas, if medical aid is called in when the jaws may be got open, so as a drench may be administered with a small horn, or a ball may be given on the end of a cane, or a piece of whalebone, a cure may very probably be performed.

The great evil in cases of this disorder is, the proprietor of the horse, or the groom who looks after him, frequently is ignorant of the symptoms indicating the complaint when it is commencing, as it is a 
disease that does not often occur, it is not generally known : the malady then goes on progressively until the jaws are completely locked, and the whole muscular system spasmodically affected and rigidly contracted, before a professional person is called in.

It therefore becomes a matter of the greatest importance to be well acquainted with the first symptoms of this disease, so as to administer a medicine early to reach the stomach, whereby we stand a greater chance of completely arresting the progress of the disease, and making a cure.

This disorder makes such a rapid progress in some constitutions, that I have known a horse's jaws completely locked, and the muscles of the whole frame become violently rigid, in the course of little more than six hours from the commencement of the attack; and the danger is generally in proportion to the violence of the attack.

At other times I have known the progress of the disease so slow, that the symptoms have not commenced for a month after the amputation of the tail.

But in a general way, when this disease originates from docking, or from an injury of the foot, the symptoms come on about a week, ten days, a fortnight, or three weeks, after the part has been injured.

I shall now proceed to point out the symptoms.

\section{SYMPTOMS OF TETANUS.}

When this complaint commences, a stiffness may be observed about the muscles of the jaw: the horse does not masticate his food with that freedom he used to do ; neither is he inclined to move his body as before; and there is frequently an increased secretion of saliva. Costiveness gुenerally takes place; and the secretion of urine is often somewhat diminished. On elevating the head, the membrana nictitans, commonly called the haw, covers more of the ball of the eye than in the natural 
state. Pulse and respiration are frequently very little altered; the appetite generally good, and the jaws very little shut.

But shortly after, the muscles of the head and neck become spasmodically affected, - a stiffness, and some degree of rigidity, may be observed in those parts, his nose becomes a little thrown out from his chest, his head is frequently somewhat raised, and upon elevating it a little more, the membrana nictitans, or what is commonly called the haw, still covers more of the ball of the eye than it does in the natural state, his ears are rather erect or pricked up, his nostrils are somewhat expanded, and upon a slight fatigue, the pulse becomes a little hurried and irregular, and respiration is accelerated, his tail is a little cocked, with a shaking of it; appetite good, but there is some difficulty in masticating hay.

As the disease advances, the muscles of the back and hind extremities become more or less stiff and rigid, and as the horse moves, he straddles much, and even in a state of inaction he stands with his hind legs much asunder, and if you attempt to turn him, he turns with his body in a straight line, as he can neither move the vertebræ of the neck nor back; his nose is more thrown out, his nostrils are more expanded, his ears are more erect, his jaws become considerably shut, his tongue is a little swelled, and there is still an increased secretion of saliva. Upon elevating his head, the membrana nictitans covers more of the ball of the eye, his tail is more elevated, and shakes much upon the least fatigue, the abdominal muscles become rigidly affected, and the abdomen is much drawn in; appetite good, but cannot masticate hay; the pulse and respiration much more hurried upon very little fatigue.

If the complaint has made a further progress, his jaws become nearly locked, the spasms of the muscles greatly increase, and are attended with great pain, his pulse becomes much hurried and irregular, and his breathing is more accelerated; but at times the pain is not so severe; then the pulse and respiration become more calm; but neither is of long duration. His nose is thrown out more in a line with his 
body, his ears are more erect and immoveable, his tail more elevated, and frequently shakes much; the vertebræ of the neck and back become excessively stiff from the rigid state of the muscles; some difficulty in swallowing comes on, from the throat and cesophagus being spasmodically affected; at the same time there is often an inflammation about the pharyux, and a kind of groan after drinking, or in attempting to drink, may frequently be observed: the case is then very dangerous.

Now, during all this time, the animal has considerably more use of his fore extremities than his hind ones.

But if the complaint be allowed to make a little further progress, the muscles of the fore extremities become rigid and stiff, and the muscles of the whole frame get violently contracted and rigid, his jaws become completely locked, his tongue swells more, his pulse is excessively quick and irregular, his breathing is still more accelerated, a tremour of the whole system takes place, at length a violent convulsion comes on, which puts a period to his existence.

But it may happen, when the symptoms throughout the course of the disease, have increased in a mild way, that even when the jaws have become completely locked, the horse may have sufficient nutriment conveyed into the system by means of injections by the fundament, so as to support nature many days.

And it may likewise happen, that the medicines being administered in the same maniner, may be conveyed into the system, so as to bring on a general relaxation of the muscular system.

But when the disease has got so far advanced, I should wish to imprint on the mind, that a cure is very rarely performed.

Having given a description of the different causes producing tetanus in the horse, together with the symptoms indicating the complaint, in its different stages,-

We shall now proceed to point out a mode of treatment for it. 
TREATMENT OF TETANUS.

With respect to the treatment of this disorder, it is of the utmost importance to use means at its commencement, whereby we have a much greater chance of administering medicines to reach the stomach, so as to arrest the progress of the spasmodic affection of the muscles; and performing a cure.

Various modes of treatment have been adopted : some practitioners have preferred the cold bath, with a free administration of opium; others, the warm bath, with the use of opium, bark, \&c. \&c.

Opium, camphor, musk, \&c. have long been considered as the principal medicines to be administered internally in this dreadful disease in the human subject.

And I must acknowledge, that in the course of my practice in the horse, I have greatly depended upon the use of opium, combined with other antispasmodics, after the bowels have been properly opened.

And during twenty years experience I have successfully treated about thirty cases of tetanus, which were well marked.

An illustration of many of these cases I shall afterwards give.

This disease being a spasmodic affection of the muscles, occasioning them to become violently contracted and rigid, it appears that it is an essential part of the treatment to produce as quickly as possible a relaxation in those parts, without much injuring the strength of the system.

And as the horse is generally very costive, a purgative drench should be given, when the jaws can be got sufficiently open to give it with a small horn: or the purge may be given in the form of a ball, in small pieces, on the end of a piece of whale bone or cane.

As soon as a purgative drench or ball is administered, an emollient clyster should be given, which greatly facilitates the action of the purge.

It must be remarked, that the stomach and intestines in this complaint are not very susceptible of being acted upon, therefore they will 
bear more than a horse in other complaints, and that is the reason I order a drench and clyster at the same time.

And the following formulas may be administered with a good effect :-

$$
\begin{aligned}
& \text { Purgative Drench. } \\
& \text { NO. I.-FOR A PONY. }
\end{aligned}
$$

36 Barbadoes Aloes

33 Soap

32 Ginger

$\overrightarrow{3} 1$ Treacle

20 Drops Oil Anniseeds

NO. II.-FOR A MIDDLING SIZED SADDLE HORSE.

58 Barbadoes Aloes

34 Soap

33 Ginger

- 32 Treacle

30 Drops Oil Anniseeds

NO. III.-FOR A CARRIAGE HORSE.

59 Barbadoes Aloes

34 Soap

34 Ginger

32 Treacle

40 Drops Oil Anniseeds
Emollient Clyster.

NO. I.-FOR A PONY.

$\overrightarrow{3} 6$ Olive Oil

3 Pints Water Gruel, warm

NO. II.-FOR A MIDDLING SIZED SADDLE HORSE.

38 Olive Oil

2 Quarts Water Gruel, warm

NO. III.-FOR A CARRIAGE HORSE.

310 Olive Oil

2 Quarts Water Gruel, warm 
Purgative Drench.

NO. IV.-FOR A STRONG DRAUGHT HORSE.

311 Barbadoes Aloes

34 Soap

34 Ginger

40 Drops Oil Anniseeds

34 Treacle
Emollient Clyster.

NO. IV.-FOR A STRONG DRAUGHT IIORSE.

$\zeta 12$ Olive Oil

5 Pints Water Gruel, warm

In making the drenches, first beat the aloes, soap, and ginger well, then make it into an electuary with the treacle and oil of anniseeds; afterwards mix the whole in a pint of warm water, and give it.

By giving a purgative drench and an emollient clyster immediately after, we not only relieve the system quickly by unloading the stomach and intestines of their contents, but by increasing the secretion from their glands, it is probable that a general relaxation of the muscular system in some measure takes place, as it appears that the stomach and bowels and external muscles of the body discover strong associations in many diseases.

If the horse is in a plethoric state, and his pulse and respiration have become much hurried, a moderate quantity of blood may be drawn from the jugular vein, and this operation may be repeated according to circumstances.

But it must be observed, we cannot bleed in this disorder as we would in some acute internal inflammations, such as an inflammation of the lungs, \&c. originating from a different cause, as the animal, from his complaint, is often prevented in a great measure from taking sustenance by the mouth. 
Therefore, if a large quantity of blood be drawn from a vein, and very little nutriment be received into the stomach afterwards, it may produce such a shock to nature as may not be recovered; and strongly indicates that venesection should be performed with great caution, particularly as blood, when drawn from a vein, in this disease, and allowed to coagulate, does not exhibit an inflammatory appearance so much as in other inflammatory diseases. Although I certainly have observed in some tetanic cases, when the pulse has been strong and frequent, a considerable coat of buff on the blood; but this blood was not often of a tough consistence, it was generally very loosely connected.

The diet in this disorder should principally consist of thin bran mashes, oatmeal gruel mixed with milk, or any thing brought to a solution that affords much nutriment; and a little good clover hay may frequently be offered when the jaws have not got much shut, as by keeping the muscles of the jaw considerably in action, it may retard the progress of the spasms; at the same time, considerable friction over those parts, should not be omitted.

Having before observed, that I consider it an essential part of the treatment, to use means to bring on, as quickly as possible, a relaxation of the muscles, without materially injuring the strength of thesystem, every effort, therefore, in the mode of treatment, should co-operate to answer this purpose.

And I have found, that after using considerable friction to the whole body, that stimulating liniments well rubbed over the muscles of the jaw, head, neck, and back, and immediately afterwards covering the body with sheep skins, as recently taken of the sheep as possible, have had a good effect in reducing the spasms of the muscles.

I wish the skinny part of the sheep skin to be in contact with the horse's skin.

By this means we bring on sensible perspiration in a short time, which continues as long as the sheep skins remain moist; and when they get the least dry, or offensive in smell, they ought to be renewed. 
I have always considered, during my practice, that the sensible perspiration brought on by this mode of treatment, greatly contributed to the curing of the disease, and I think, may be considered preferable to the warm bath, as there is not that risk of the animal receiving cold, as there is when the bath is used.

And I have often found, that if the symptoms, before the jaws become much shut, can be kept stationary forty eight hours, that there is great probability of a cure.

The following liniment may be applied over the muscles of the jaw, head, neck, and back :-

\section{Liniment.}

\section{$\xi_{z^{-}}^{x}$ Oil Turpentine \\ $\xi \frac{1}{2}$ Water of Pure Ammonia \\ $\zeta 2$ Mustard Powder \\ 1 Quart Olive Oil}

This liniment should be well rubbed over the muscles of the jaws, head, neck, and back, and the body covered immediately afterwards with sheep skins as recently taken off the sheep as you can.

It ought not to be repeated more than once : if it be repeated often, it may produce too much irritation, which would only tend to increase the spasms, as the heat of the horse's skin being so much increased by the use of the sheep skins, it is made very susceptible of being acted upon.

Whereas, if we use only a sufficient stimulus to determine the blood in a mild way to the surface of the body, the application of the skins generally brings on a very copious perspiration, which has been attended with the most salutary effects.

But great caution should be used, when it is applied, in removing the sheep skins, not to expose too much of the body to cold at a time, 
as it may materially obstruct the process of perspiration, and prevent that relaxation of the muscles which is one of the most important points to be obtained in the curing of this disease.

In fact, it appears in this disorder, that the action of most of the secretory organs in the body becomes considerably diminished, consequently it is a matter of great importance to restore the natural action of those parts.

Hence the necessity of keeping the bowels open, and of promoting the process of perspiration, particularly over the head, neck, and back.

I consider the combined effect of this treatment tends greatly to lessen the inflammatory state of the contents of the spinal canal, which appear's to me to be the seat of this terrible disease.

Dr Rush, in his first vol. of Medical Inquiries, page 258, states that a case of tetanus in the human subject was cured by a miliary eruption on the skin.

And in Mr Cooper's Dictionary of practical Surgery, page 817, a case of locked jaw in the human subject is recorded, which was cured by a copious perspiration.

This case originated from a piece of fish bone, which had lodged in one of the sinuses of the fauces, and was under the care of Monsieur Larry, a French surgeon.

Nature curing one of these cases by an eruption on the surface of the body, and in the other, a copious perspiration being brought on, curing the complaint, greatly strengthens the idea, that determining' the blood to the surface of the body is a very important point, and that promoting perspiration must be of considerable utility in tetanic affections, particularly when the disease originates from exposure to cold.

It is extremely difficult to bring on sensible perspiration in the horse, by administering medicines internally.

But when the body is covered with sheep skins, after considerable friction and the liniment has been applied, it seldom fails of bringing on a most copious perspiration. 
If it should happen that sheep skins cannot be procured at the time this disorder occurs, a blister may be applied to the spine, beginning at the withers and continuing it backwards the whole length of the spine, and even to the basis of the tail ; but previous to its application, let the hair be clipped bare.

And if the disease has made much progress, let a blister be applied over the cranium or skull also, and about eight inches backwards from the occipital bone on each side of the neck, in the direction of the vertebræ; and the following formula may be used, excepting in the blister that is applied to the cranium the euphorbium may be omitted, as it sometimes gets into the eyes, and produces considerable inflammation.

\section{Blister.}

\section{$\zeta 1$ Cantharides powdered \\ 32 Euphorbium powdered \\ $\zeta 1$ Oil Turpentine \\ 36 Hog's Lard}

As soon as the blister has done operating, and the swelling subsided that the blister occasioned, begin the use of the liniment and sheep skins, in the manner I have pointed out.

Now, from what has been said concerning the membranes of the spinal marrow in tetanic cases exhibiting an inflammatory appearance, and the nervous substance itself assuming a darker colour, it is obvious that there are two things essentially necessary to be attended to in the beginning of the treatment of this complaint.

The one is, to alter the state of the intestines, which are generally constipated.

And the other is, to induce a copious and constant perspiration over those parts I have previously mentioned. 
We by this means determine the blood from the spinal canal, and thereby take off the distention of the vessels of its contents, so as to diminish the inflammatory state of those parts so essential to life.

Having made some observations concerning the utility of keeping the bowels open, and of the mode of procuring sensible perspiration in the horse, and the probability of relieving the spasmodic affection of the muscles by such means,-

We shall now proceed to the administration of some of the most powerful antispasmodics, which I have found from experience, tohave a good effect in this disease; but great care is required in giving them, when the jaws are much shut, so as to get them to reach the stomach.

After the purgative drench has done operating, I recommend one of the following balls to be given in small pieces, on the end of a piece of whalebone or cane.

Or the ball may be dissolved in a pint of a decoction of rue, and given as a drench, morning and evening, with a small horn; and considerable time ought to be taken in the administration of it. The horse's head ought not to be kept too high, and should frequently be allowed to rest a little; for, if his head is kept too high, or is kept too long up at a time, it tends greatly to increase the convulsions, and he becomes very unruly, and it is probable the greater part of the medicine will be lost.

\section{Antispasmodic Balls.}

NO. I.-FOR A PONY.

31 Crude Opium

31 Camphor

31 Asafoetida 
NO. I1.-FOR A MIDDEING SIZED SADDIE HORSE.

31 B. Crude Opium

51 B Camphor

32 Asafoetida

NO. III.-FOR A CARRIAGE HORSE.

32 Crude Opium

32 Camphor

32 Asafoetida

NO. IV.-FOR A STRONG DRAUGHT OR WAGGON HORSE.

32 B Crude Opium

32 B Camphor

32 B Asafoetida

Dissolve the Opium in Water, and the Camphor and Asafoetida in Spirits of Wine, then add Anniseed Powder sufficient to make each Recipe into Balls.

And immediately after the ball or drench has been administered, Let one of the same balls be dissolved in three pints of a decoction of rue, and given as a clyster, morning and evening.

\section{Decoction.}

Three Handfuls Rue

Three Quarts Water

Boil it down to two quarts, and strain it off. 
But it must be observed, that the quantity of opium in each succeeding dose must be increased or diminished, according to the violence of the spasms, and the effects it is observed to produce in the system.

In some constitutions, after being repeated a few times, it.may occasion some degree of restlessness : the quantity of opium then ought to be diminished; but I do not wish any diminution of the camphor and asafoetida.

But in a general way, in cases of tetanus, the system can bear considerably larger doses of opium than in any other disease, therefore it must be administered in such a manner as to have its effects constant in the system, without producing much restlessness; and great attention is required of the practitioner engaged in such cases, in prescribing a proper dose of this useful medicine.

At the same time it should occasionally be combined, when given in the form of clyster, with such medicines as will prevent it acting too powerfully as an astringent; and for this purpose I recommend three or four drachms of common soap to be dissolved in the clysters, as the necessity of the case may demand.

But if the bowels should become obstinately costive, the purgative drench should be repeated at intervals of about a week.

It now and then happens, when the disease has made some progress, that when the horse lies down, he is incapable of rising again, from the contractile state of his muscles, although it is not often a horse attempts to lie in this complaint.

When such a circumstance occurs, it becomes necessary to have sufficient hands to raise the horse, and have him slung. In fact, I think it better to have him slung, even if he has not fallen, if his muscular system is found to be very rigid, as it may prerent a great deal of trouble.

If he be properly slung, the person who gives the medicines lias a better chance of giving them so as to reach the stomach, as the horse is kept in a fixed situation. 
Whereas, if otherwise, when you elevate his head in administering a drench or ball, you increase the spasms, and he rushes forward, and becomes very resolute; and it is very probable the one half of the medicine will be lost.

Therefore it becomes a matter of importance to give the medicine in such a manner as to reach the stomach, at the same time to increase the spasms as little as possible.

I have sometimes found, that when the jaws are not so much locked as to prevent the power of mastication, the horse will eat a dose of opium amongst a bran mash; and if his jaws are more locked, it may be mixed in water gruel, and it is probable he will drink it.

When it is found he will take the opium in this way, it ought always to be given so; and the asafœetida and camphor may be given in the form of drench or ball, as is found most convenient.

If the medicine is administered as a ball, on the end of a cane, great care should be used in getting the ball as far up the mouth as possible, by putting a little of it up at a time, and continuing to work it for some time, as near the gullet as you can. When this is done, if the horse do not swallow it immediately, it is very probable it will adhere to the roof of the mouth, or grinders, and be swallowed by degrees, as it dissolves.

I am convinced, from practice, that opium, is a most powerful medicine in this complaint, after having unloaded the intestines, therefore, every means should be used that can be suggested, to get it to enter the stomach.

If it is combined with camphor and asafoetida, and mixed with a mash or gruel, it is probable the smell will occasion some horses to refuse it, and that is the reason I have mentioned giving the opium alone, in a mash or gruel.

But, as the appetite is generally uncommon eager throughout the whole course of this disease, it may happen, the horse may take to eat or drink even when the camphor and asafoetida are joined with the opium, and mixed in a mash or gruel. 
I have known an instance of this, and the horse recovered.

If the complaint has made such a progress as to completely lock the jaws, the medicines, as well as the food, must be administered in the form of clysters.

But the quantity of medicine given in each clyster must be considerably more, and the following formulas may be given two or three times a day, according to the violence of the spasms :-

Antispasmodic Clysters.

NO. I.-FOR A PONY.

32 Crude Opium

32 Camphor

32 Asafoetida

NO. II.-FOR A MIDDLING SIRED SADDIE RTORSE.

33 Crude Opium

33 Camphor

33 Asafoetida

NO. III.-FOR A CARRIAGE HORSE.

33 B Crude Opium

33 \& Camphor

53 B Asafoetida 
NO. IV.-FOR A STRONG DRAUGHT OR WAGGON HOLSE.

5. 4 Cirude Opium

34 Camphor

34 Asafoetida

Dissolve the Opium in Water, and the Camphor and Asafotida in Spirits of Wine, and mix each Recipe in a decoction of Rue. No. 1 may be mixed in one quart of it, and all the others in three pints.

The quantity of opium in each succeeding clyster should be increased or diminished, according to the effects it is observed to produce.

And at intervals, about one gallon of strong oatmeal gruel, or gruel mixed with milk, may be injected by the fundament.

By this mode of treatment, it is found an animal may have sufficient nutriment conveyed into the system to support nature a considerable time.

If it be found after the medicines have been administered a few times in the form of clysters, that some relaxation in the muscular system has taken place, and particularly if the muscles of the jaw are so far relaxed, that the horse's mouth may be got open so as to give a drench with' a small horn, or a ball on the end of a piece of whalebone or cane, this plan must be resorted to.

He should frequently be tried if he will drink gruel, or eat a thin bran mash.

It is necessary to observe, that the cause of this dreadful disease should always be taken into consideration, whether it originates from exposure to cold, or worms, \&c. \&c. And such medicines must be combined with opium as are most likely to relieve the system under such circumstances. 
But I am of opinion, that the opium must always be considered as a most useful medicine in all tetanic affections, after the bowels have been properly opened.

Having pointed out the internal treatment to be pursued in the cure of tetanus in horses,-

I shall now proceed to indicate a mode of treatment to the wounded part, when the disease is symptomatic, or originating from a wound.

And as little has been said concerning this subject by authors who have written on the veterinary art, it may not be amiss, in the first place, to mention the opinions of a few of the authors who have written concerning the treatment of such wounds, when they have produced this terrible disease in the human body.

Dr Rush, of Philadelphia, in his Medical Inquiries, 1st vol. page 256, when the complaint arises from a wound in the human subject, recommends the wounded part to be dilated, if small or healed, and afterwards inflamed, by applying to it, turpentine, common salt, corrosive sublimate, or Spanish flies, which treatment has, he says, in many instances, been attended with the most salutary effects.

Dr Thomas, in his Practice of Physic, fourth edition, page 308, when this disease originates from a wound or puncture, recommends the wound to be dilated, and afterwards to pour a small quantity of a solution of opium into it, dressing it afterwards with a little lint dipped in the same, and laying a pledget spread with some digestive ointment over the whole. Every time the dressings are renewed, the wound is again to be wetted with the solution.

Mr Samuel. Cooper, in his third edition, page 113, of the first lines of the Practice of Surgery in the Human Subject, observes, when tetanus 
arises in consequence of a wound, it does not commonly make its appearance for many days after the accident, very often when there is neither pain nor uneasiness in the wounded part, and very frequently when the wound is even quite healed. The disorder is said to be more common in situations near the sea, than in inland countries. If a wounded person in a warm climate expose himself to the cold nocturnal air, he is particularly subject to the disease. In the majority of cases, tetanus is the consequence of wounds, generally of stabs in tendinous parts, and of injuries of the fingers and toes.

Sometimes, however, we see it, even in this country, produced by amputations, castration, and other operations; and likewise by gunshot wounds, compound fractures, \&c. It must be clear, however, from the preceding remarks, that the wound is not always the sole cause, and that the disorder would, in general, not take place, if the wound were not in a particular situation, the patient of a peculiar temperament, nor under the influence of climate, \&c.

In regard to the treatment of this disease, when it originates from a wound, he says, as the disorder frequently makes its attack after the wound is healed, and most commonly when there is no great pain or local irritation, as also topical means, and amputation of the part, seem sometimes to have very little, if any, influence over the constitutional disturbance, we might conclude, that after the symptoms have once come on, the connexion now existing between them and the original local cause, is not such, that its annihilation is likely to arrest the course of the disease. Against removing the wounded part, it has been argued, that if certain constitutional means only avail in a limited proportion of cases ; if only the same degree of success attend the combined effect of removing the wounded part, and administering internal medicines, we, must infer, that the operation had no influence whatever, and as causing superfluous pain, and the loss of a finger or limb, it ought not to have been undertaken. It has also been objected to many of the cases which have been brought forward to prove the efficacy of removing the part, 


\section{1}

or enlarging the wound, that nothing more is proved, than that the cure was accomplished in this way in a limited number of instances, and generally with the assistance of internal medicines; that perhaps the proportion of success is not greater than when only constitutional means were adopted; and that though these operations probabiy do not diminish the chance of preservation, except when a limb is amputated, yet, there is no positive evidence of their being at all useful. Upon the whole, however, he believes, that experience and authority are in favour of attempting either to alter the state of the wound, or else of amputating the injured part.

Drs Rush and Darwen recommend the wound to be dilated and dressed with oil of turpentine, in order to make it infiame : others have applied caustic. Larry, a judicious surgeon, who saw many cases of this disease among the French soldiers wounded in Egypt, is a strong advocate for the removal of the part. He tried, but without success, the application of tobacco leaves to the wound; moxo, and the actual cautery, were equally unavailing; blisters did not produce more good effect, except when the tetanus was preceded by a cessation of suppuration from the wound, in which circumstance they proved advantageous, the benefit being accompanied with a renewal of the suppuration. M. Larry was led to recommend amputation, by the event of a case of tetanus of an officer, who was shot in the foot, and apparently cured by such operation, after opium, tobacco, camphor, \&c. had been tried in vain.

This author's success tends to the conclusion, that in all cases of tetanus from wounds of the limbs, it is advisable to amputate as soon as the symptoms commence.

In the case just now cited, the symptoms ceased almost as soon as the operation was performed ; and even in cases which did not ultimately get well, the symptoms were always relieved by such practice. In one instance of tetanus, from a gun-shot wound in the arm, dilating and scarifying the wound were followed by speedy relief and a cure. 
The symptoms of tetanus being of a spasmodic nature, antispasmodic remedies have been given with the most sanguine hopes of success. Opium, together with the employment of cold bathing, or the cold shower bath, is the principal one. It is generally prescribed in unusually large doses, in the quantity of at least a grain every two hours. It is curious, that although this medicine is given so liberally in these cases, it never produces any propensity to sleep, and very seldom ill consequences. If the spasms abate, the opium must not be suddenly relinquished.

$\mathrm{Mr}$ Cooper again observes, as far as he can judge, the facts and observations adduced by Clark, in his Treatise on Diseases of the West Indies, and particularly by M. Larry, shew, that in cases of symptomatic tetanus from local injuries, more good is to be expected from a removal of the wounded part than any other means. But supposing this practice not to be acceded to, then the principal plans of treating tetanus may be reduced to three, which, in his opinion, seem to claim a preference in the order in which they are placed :-

1st,-Dr Chalmers, in his Treatise on the Diseases of South Carolina, orders repeated cold bathing, and reiterated doses of opium.

2ndly,-Dr Rush, of Philadelphia, prefers the liberal use of wine and bark, and making the wound inflame: the exhibition of other stimulants may be classed with this mode of treatment. Of a similar nature also is the practice advised by Darwin.

Thirdly,-Dr Donald Monro, in the Edinburgh - Physical and Literary Essays, vol. 3rd, describes a plan of treating tetanus by bringing on a rapid salivation. This method was communicated to him by a gentleman, who had adopted it with success in the West Indies. There it was found to answer in idiopathic cases of tetanus: its inefficacy in tetanus following wounds, was observed by M. Larry, in attendance on the French wounded in Egypt.

He lastly says, it may not be improper to add, that when the wounded part has been removed, the surgeon is not to forget that medicines may yet be useful, and ought to be prescribed. 
Having taken notice of the different modes of treatment used by physicians in the human subject, to the wounded part in symptomatic tetanus, I will now proceed to state the mode of treatment I adopt in symptomatic tetanus in the horse.

When tetanus has originated from a wound, as for instance, from the amputation of the tail of the horse, commonly called docking, or from a wound in the legs, feet, or any part of the body, the wound at that time generally assumes a flabby, pale, unhealthy appearance, with very little discharge, and what is discharged is of a serous nature; but frequently the wound is nearly healed, and sometimes quite healed, before tetanus commences.

On being called in to such cases, my mode of treatment has been to use fomentations of warm water as hot as the hand can bear it, and dressings of digestive ointment to the wounded part, at the same time using constitutional means.

And I frequently found, that after pursuing this plan a few days, the discharge was more copious and of a better nature, and the wound itself put on a much more healthy appearance.

But I consider the suppuration of the wound to be more influenced by the general relaxation of the muscular system, brought on by the free administration of the medicines I have mentioned to be used internally.

Therefore the internal treatment must be strictly attended to; and, in my opinion, is of considerably more importance than any local means to the injured part, in the cure of this dreadful disease, as it is evident in this disorder, that the action of most of the secretory organs in the body is much suppressed; and until the functions of these organs are considerably restored, the vessels of the wounded part have not the power of secreting or forming matter of a good consistence, owing to the sympathy or consent that one part of the body has with the other. 
From what has been advanced by Mr Larry, in the treatment of symptomatic tetanus in the human subject, some practitioners may be great advocates for the amputation of the injured part in the tail, when the disease originates from docking, in order to cut off the communication between the nerves of that part and their origin.

In regard to which, I never but once amputated the injured part, and this was a case of a two year old filly, who had tetanus from docking: the tail had been taken off about ten days previous to tetanic symptoms commencing, and the wound assumed, as it generally does, a flabby unhealthy appearance; and as much had been said in favour of the removal of the injured part, for the cure of symptomatic tetanus, I was determined to try the effect of amputation in this case.

Accordingly the operation was performed, and about one inch of the tail was removed, and the wound dressed with equal parts of oil of turpentine and digestive ointment; but the removal of the part did not tend to diminish the spasmodic affection of the muscles, and the case proved fatal on the fourth day.

The unfortunate termination of this experiment convinced me that a more mild mode of treatment was likely to be attended with greater success, and I therefore pursued the other plan which I have previously mentioned, and the result is, that a great many more cases have been successfully treated.

An illustration of which I shall shortly give.

But if the disease proceeds from an accidental wound or puncture, and suspicion arises, that some extraneous body is lodged in the wound, the wound must be dilated, and carefully examined, to ascertain whether there is any thing lodged therein: if so, it ought to be extracted as quickly as possible, and the part fomented and dressed with digestive ointment.

The success I have met with in the treatment of symptomatic tetanus, in the manner above described, I consider justifies me in pursuing the same plan, and particularly as this complaint is considered one of the most fatal that is incident to the horse. 
Those practitioners who are advocates for the amputation of the wounded part of the tail, when the disease originates from docking, are no further off performing the operation, at the same time, administering the medicines internally, and applying the liniment and sheep skins externally to the body, or a blister to the spine, \&c. in the manner I have pointed out.

When the complaint originates from a wound in any other part, as in the legs or feet, the wound may be dilated and dressed with equal parts of oil of turpentine and digestive ointment.

If it is wished that the wounded part should be destroyed, caustic may be used, and a poultice applied over all.

But I confess I am no advocate for the amputation of the injured part in the tail, when the disease originates from docking, nor yet am I partial to incisions or caustics, when the complaint arises from a wound in any other part of the body; and I have always believed, that the more quiet the horse is kept the better, as any sudden noise, or suddenly exposing him to a strong light, tends to increase the spasms; therefore, the stable should be moderately light, and as free from noise as possible, as it is clear that both the organs of hearing; and those of the sight, are in a very irritable state, and very susceptible of being stimulated from a slight cause.

Having mentioned the local treatment to be used to the wounded part in symptomatic tetanus in the horse,

I shall now proceed to give the history of several cases of this disease, which I have successfully treated. 


\section{CASE I.-March 7th, 1802.}

ORIGINATING FROM A NAIL BEING DIIVEN INTO TIIE SENSIBIE PART OF THE FOOT IN SHOEING.

This was the case of a saddle mare, five years old, and about fourteen hands high, the property of Mr Mather, a traveller.

On being called in to examine this case, I found the symptoms were a spasmodic affection of the muscles of the jaw, head, neck, back, hinder extremities, and abdomen, which occasioned them to become rigidly contracted, and the abdomen was much drawn in; the pulse was about fifty beats in the minute, with some irregularity, the respiration a little accelerated, the jaws were considerably shut, but not so but medicine inight be administered as a drench with a small horn; the appetite not diminished, but she could not masticate hay; the head somewhat raised, and on elevating it a little more, the membrana nictitans, or what is commonly called the haw, covered great part of the ball of the eye; the nose was thrown out from the chest, the nostrils expanded, the ears erect or pricked up, a great stiffness of the neck and back, the tail a little elevated, and upon a little fatigue, a shaking of it; a straddling of the hinder extremities; the animal was very costive, and the secretion of urine was somewhat diminished.

On inquiring into the cause of the disease, the proprietor of the mare informed me, that she had been shod about three weeks previous to coming to Newcastle, and that the farrier had driven a nail into the sensible part of the foot in shoeing, and she shortly after was lame, and was examined by a Mr Thompson, a fellow student of mine at the college, who soon detected the cause of the lameness, and used the necessary means under such circumstances, which relieved the animal, and in a few days she got sound. Mr Mather shortly after proceeded on his journey, and the mare performed very well as far as Durham, a distance 
of about ninety-four miles; but on coming from Durham to Newcastle, he found her action different, as he could scarcely get her out of a walk, and when he arrived at Newcastle, he halted at Mr Loftus's, the Shakespear Tavern. The spasmodic affection of the muscles during this time had become so great, that it was with some difficulty the hostler got her into the stable; and shortly after I was sent for to examine her, and found her labouring under the above symptoms.

Having examined the case, I ordered about two quarts of blood to be drawn from the jugular vein ; the bowels being constipated, the purgative drench, No. 2, was administered with a small horn; and the emollient clyster, No. 2, was likewise given; considerable friction was used over the muscles of the jaws, head, neck, and back, particularly where they were found to be most rigid; the liniment I have previously mentioned, was well rubbed over those parts, which were afterwards covered with sheep skins, as recently taken off the sheep as they could be procured, which soon brought on sensible perspiration.

The diet was principally thin bran mashes and oatmeal gruel, of which she frequently took a little.

On the 8th, the pulse about fifty beats in the minute, the breathing a little accelerated, jaws not more locked; the mare has been in a constant perspiration under the sheep skins ever since yesterday : the purgative drench not operating, another emollient clyster was administered, which assisted its action : the liniment was repeated.

On the 9th, the spasmodic affection of the muscles much about the same, as likewise the pulse and respiration ; she still perspires copiously; the purging having subsided, the antispasmodic medicine was begun, and the drench, No. 2, was administered with a small horn morning and evening; and one of the same drenches was mixed in three pints of a decoction of rue, and given as a clyster, morning and evening.

This drench and clyster were repeated morning and evening until the 14th, and during this time, the quantity of opium in each succeeding dose, was increased or diminished, according to the violence of the 
spasms, which at times were rather severe, and occasioned the pulse to beat about sixty in the minute, and the breathing to become a good deal accelerated. It was always administered in such a manner as to have its effects constant in the system, without producing much restlessness : during this time, there was likewise a most copious perspiration going on under the sheep skins. The bowels becoming costive again, another purgative drench and emollient clyster were administered.

On the 15th, the drench not operating, an emollient clyster was given, which facilitated its action; pulse a little hurried and irregular, as also the breathing; jaws 'not more locked; she still perspires under the sheep skins; and the appetite is good, but cannot masticate hay.

On the 16th, the pulse more regular, and respiration more calm; she perspires freely under the sheep skins; the purging having subsided, the antispasmodic medicine was again administered, both by the mouth and fundament, and continued in the same manner as above described until the $21 \mathrm{st}$, when another purgative drench and emollient clyster were given. The jaws, at this time, might be got more open, and the muscles of the jaw had so far recovered their action, that the mare could masticate hay; and the muscles of the head, neck, back, and hinder extremities became considerably relaxed, and on elevating the head, the membrana nictitans did not cover so much of the ball of the eye.

On the 23rd, the purging having subsided, the antispasmodic medicine was again had recourse to, and administered in the same way until the 10th of April, when another purge was given. The muscular system at this time was greatly relaxed, as the mare could open her jaws nearly as well as ever : she could move her ears backwards and forwards, and get her nose more to her chest; nostrils contracted; could move the muscles of the eye; bend her neck so as to look round in the stall; the vertebræ of the back had likewise more motion, as the muscles became more relaxed; the hinder extremities not so much asunder; tail not so much cocked; and on elevating the head the membraná nictitans covered very little of the ball of the eye. 
On the 12th, the purging having subsided, the antispasmodic medicine was again used a few days longer, when the mare was completely cured of the complaint.

The only remaining thing to be attended to, was to strengthen the system,- - therefore tonics combined with cordials were administered, which, together with a generous diet, regular and moderate exercise, considerable friction in dressing, and moderately warm clothing, soon restored the tone of the muscles, and the animal became as strong and as active as ever.

The quantity of crude opium administered during the course of the disease was 39 .

N. B. It may be necessary to observe, that I never used any local means, such as making incisions to divide the nerves in that part of the foot that was injured in shoeing, and yet I treated the case successfully.

\title{
CASE II.-June 5th, 1803.
}

\author{
ORIGINATING FROM THE AMPUTATION OF THE TAIL, COMMONLY \\ CALLED DOCKING.
}

This was a case of a post horse, six years old, and about fifteen hands high, the property of Mr Charles Turner, a respectable innkeeper in Newcastle upon Tyne.

On examining this case, I found the muscles of the jaw, head, neck, back, and hinder extremities rigidly contracted; the abdominal muscles were likewise much affected, and the belly was much drawn in ; on elevating the head, the membrana nictitans covered great part of 
the ball of the eye; the nose thrown out from the chest; the nostrils expanded; the ears erect and immoveable ; a great stiffness of the vertebræ of the neck and back; a straddling, with great stiffness of the hinder extremities; tail elevated, and a shaking of it; the jaws were much shut, but not so but medicine might be administered with some difficulty with a small horn; the appetite was good, but the horse could not masticate hay, although he could get down a little thin bran mash, and drink gruel; his pulse was about sixty beats in the minute, with some irregularity; the respiration was accelerated; his bowels were constipated, and the secretion of urine somewhat diminished.

This horse had been docked about a week previously to tetanic symptoms commencing, and the wound assumed a pale flabby unhealthy appearance, with very little discharge from it, and what was discharged was of a thin serous nature.

After having examined the case, and finding the heart and arteries hurried in their action, I ordered a moderate quantity of blood to be drawn from the jugular vein, and two quarts were taken.

The bowels being obstinately costive, the purgative drench, No. 3, and emollient clyster, No. 3, were administered, considerable friction was used to the whole body, and the liniment was well rubbed over the muscles of the jaw, head, neck, and back, which were afterwards covered with sheep skins, that soon brought on sensible perspiration.

On the 6th, the pulse about sixty-five beats in the minute, with some irregularity; the breathing quickened; he perspires under the sheep skins, his jaws are no more shut; the purgative not operating, another emollient clyster was given, which assisted its action; he eat some bran mash, and drank a littlè gruel.

On the 7 th, the pulse about sixty beats in the minute; respiration liurried; he is in a copious perspiration under the sheep skins; jaws no more shut; the purging being subsided, the antispasmodic medicines were begun, and the drench, No. 3, and clyster, No. 3, were administered and repeated every day in the manner I have pointed out, until 
the 12 th, when some little relaxation of the muscular system might be observed; the bowels getting costive, another purgative drench and emollient clyster were given.

On the 14th, the pulse about fifty beats in the minute; respiration not so much hurried; he still perspires freely under the sheep skins; jaws more open, and the rigidity of the muscular system somewhat further diminished; the purging having subsided, the antispasmodic medicine was again administered. About this time, a considerable cedematous swelling took place in the prepuce, commonly called the sheath, and a swelling likewise of considerable extent took place in the lower part of the abdomen or belly, which I think was in consequence of standing in the stable, together with some swelling dropping down from the back, which was occasioned by the friction used, together with the stimulus of the liniment, to remove which, scarifications and emollient fomentations were used, and the scarifications were anointed with a little digestive ointment.

On the 15th, the pulse about forty-eight beats in the minute, with a little irregularity; respiration very little hurried; he still perspires under the sheep skins; jaws more open; the horse now could so far use the muscles of his jaws, that he could masticate hay, and more relaxation might also be observed in the muscles of the head, neck, back, and hinder extremities; the swellings in the prepuce and abdomen much subsided; the fomentation and anointing repeated, as also the antispasmodic medicine, and continued every day, both by the mouth and fundament, in the manner I' have pointed out, until the 23rd. During this time the animal daily recovered the use of the muscular system; the swellings in the prepuce and abdomen nearly gone.

On the 24th, the pulse about the natural standard, that is, about forty beats in the minute; respiration calm; the intestines inclining to be costive, another purgative drench was given, as also an emollient clyster; the jaws at this time might be got so much open, that the purge was administered as a ball with the hand; he could 
move his ears backwards and forwards, bend his neck so as to look round in the stall ; his nose was very little thrown out from his chest, and his nostrils very little expanded, and upon elevating the head, the membrana nictitans covered very little of the ball of the eye; his tail was not near so much elevated, and very little shaking of it; his hinder extremities not near so much asunder; the swellings in the prepuce and abdomen totally subsided.

After the operation of the purge, the antispasmodic medicine was again had recourse to, and continued until the 5th of July, when the horse was perfectly cured of the complaint.

The local application to the wound in the tail was a fomentation of warm water and a dressing of digestive ointment, applied every day, and the wound in the course of a few days put on a much more healthy appearance; but as I have already observed, I consider the healthy state of the wound to be more influenced by the internal treatment than any local means.

From the combined effect of this treatment the wound soon began to granulate, and instead of having that pale flabby appearance, the granulations that arose were firm and florid, with a discharge of matter of a good consistence, and continued so until the wound was quite healed.

The quantity of crude opium administered during the course of the disease was $\overline{3} 8$.

N. B. In this case there was no amputation of the wounded part in the tail, or yet incisions, or the application of caustic, and the case was successfully treated. 
CASE III.-August 23rd, 1803.

IDIOPATHIC.

This was a case of a colt three years old, and about fifteen hands high, the property of the late Mr Thomas Holmes, of High Heaton, near Newcastle, and as no cause could be traced that could give rise to the disease, it may be termed an idiopathic case.

The symptoms that appeared on my being called in to this case, were a spasmodic affection of the muscles of the jaws, head, neck, back, and hinder extremities; the muscles of the abdomen were likewise much affected, and the belly was much drawn in. On elevating the head, the membrana nictitans covered great part of the ball of the eye; the nose thrown out from the chest; the nostrils expanded; ears erect; a great stiffness of the vertebræ of the neck and back; a straddling, with great stiffness of the hinder extremities; tail a little elevated; pulse and respiration not much altered, although, upon very little fatigue, the pulse became hurried and irregular, and respiration became accelerated; his bowels were constipated, and the secretion of urine a little diminished; his jaws were considerably shut, but not so but medicine might be administered as a drench with a small horn; his appetite was not diminished.

Having examined the case, the purgative drencl No. 2, and emollient clyster No. 2, were administered.

The liniment was used with considerable friction over the muscles of the jaw, head, neck, and back, particularly where they seemed most rigid; and the parts were afterwards covered with sheep skins, which soon brought on sensible perspiration.

The diet consisted principally of thin bran mashes and water gruel. 
On the 24th, the bowels freely opened; the spasmodic affection of the muscles much about the same; pulse and respiration at times a good deal hurried.

The liniment was repeated, and a copious perspiration is going on under the sheep skins.

On the 25th, the purge having done operating, the antispasmodic medicine was begun, and the drench and clyster No. 2, were-administered in the manner I have pointed out; jaws no more shut, and the muscular system much about the same as on the preceding day; pulse about fifty beats in the minute, with some irregularity; respiration a little hurried: he perspires freely under the sheep skins.

On the 26th, the symptoms stationary; the antispasmodic medicine repeated, and continued every day both by the mouth and fundament, until the 12th of September, when the colt was nearly well; he could move his jaws freely; his nose was very little thrown from his chest; his nostrils very little expanded; he could move his ears backwards and forwards, bend the vertebir of the neck and back, so as to look round in the stall, and move more freely from side to side; the membrana nictitans, on elevating the head, covered very little of the ball of the eye. During this time a constant perspiration was going on under the sheep skins, and they were renewed every third or fourth day.

On the 13th, the intestines inclining to be costive, another purge was adminisiered.

On the 15th, the purging subsided, and the colt was cured of the disease.

There was some debility remaining, and to strengthen the system, a generous diet was used, which, together with moderate exercise, soon restored the powers of the body.

The quantity of crude opium adininistered during the course of: the disease was 37 . 
CASE IV.-February 24th, 1804.

\author{
ORIGINATING FROM AN INJURY IN THE FORE FOOT, COMMONIY \\ CALLED AN OVERREACH.
}

This horse was a hunter, about fifteen hands and a half high, the property of the Rev. Mr Ridley, then residing at Blagdon, about nine miles from Newcastle.

On examining this case, the symptoms that appeared were a spasmodic affection of the muscles of the jaw, head, neck, back, and hinder extremities, as also of the muscles of the abdomen, causing them to become rigidly contracted; the head a little raised, and on elevating it a little more, the membrana nictitans covered great part of the ball of the eye; the nose thrown out from the chest; the nostrils expanded; the ears erect and almost immoveable; a great straddling and stiffness of the hinder extremities; the tail elevated, and upon the least fatigue a shaking of it; his jaws were considerably shut, but not so but medicine might be administered with some difficulty with a small horn; pulse and respiration not much altered, although upon the least fatigue both became much hurried; his bowels were constipated, and the secretion of urine diminished; appetite good, but could not masticate hay.

After having examined the case, and making a little inquiry into the cause of the disease, I ascertained that the horse had got an injury in the fore foot, about three weeks previous to tetanic symptoms coming on, and the wound was then healed: I immediately considered the complaint to have been brought on by that wound.

The intestines being in a state of constipation, the purgative drench No. 3, and emollient clyster No. 3, were administered, and considerable friction was used to the whole body. 
The liniment was well rubbed over the muscles of the jaw, head, neck, and back, and those parts afterwards covered with sheep skins, which quickly brought on sensible perspiration.

On the 25th, the pulse and respiration much about the same as on the preceding day, as also the spasmodic affection of the muscles, the bowels are pretty freely opened, and there is a constant perspiration going on under the sheep skins.

The liniment was repeated.

On the 26th, the spasms of the muscles much about the same; the purging having subsided, the antispasmodic medicines were begun, and the drench and clyster No. 3, were administered, and repeated every day in the manner I have pointed out, until the 8th of March, when the rigidity of the muscular system was greatly diminished; his jaws were more open; he could masticate hay; move his ears backwards and forwards; he acquired more motion of the vertebræ of the neck and back; his nostrils not so much expanded; and on elevating his head, the membrana nictitans covered very little of the ball of the eye; the hinder extremities not so much asunder, and considerably more action of their muscles; but his bowels getting costive, another purgative drench was given; and as soon as its operation had subsided, the antispasmodic medicine was again resorted to, and continued until the 13th, when the horse was cured of the complaint, and during this time he was in a constant perspiration under the sheep skins, which were renewed every third or fouth day.

The quantity of crude opium administered during the course of the disease was $\bar{\zeta} 5$.

N. B. In this case there were no local means used, such as dividing the nerves, or applying caustic to that part of the foot which was injured, and which gave rise to the complaint, and still the case was treated successfully. 
CASE V.-November 16th, 1804.

ORIGINATING FROM THE AMPUTATION OF THE TAII.

This was the case of a draught mare, seven years old, and between fourteen and fifteen hands high, the property of Edward Major, Esq. of Monkton, about six miles from Newcastle.

The symptoms that appeared on examining this case, were a rigid contraction of the muscles of the jaw, head, neck, back, and hinder extremities, as also of the abdomen or belly; on elevating the lead, the membrana nictitans covered great part of the ball of the eye; the nose thrown out from the chest; the nostrils expanded; the ears erect or pricked up; a great stiffness of the vertebræ of the neck and back, from the rigid state of the muscles; a straddling, with great stiffness of the hinder extremities; the pulse and respiration not much altered, but upon a little fatigue, the pulse became hurried and irregular, and the respiration accelerated; appetite good; the bowels were costive, and the secretion of urine somewhat diminished; her jaws were much shut, but not so but medicine might be administered as a ball on the end of a piece of whalebone or cane.

The tail of this mare had been amputated about ten days previous to the symptoms of tetanus commencing.

The case being examined, the treatment that was pursued in the first place, was to unload the intestinal canal, and afterwards to administer the antispasmodic medicine, in the manner I have pointed out.

The liniment was applied over the muscles of the jaw, head, neck, and back, and the parts afterwards covered with sheep skins, which soon induced a copious perspiration.

The diet was thin bran mashes, oatmeal gruel, \&c. 
This treatment was followed up until the 14th of December, when the mare was completely cured of the disorder. During this time the spasms were often severe, which caused her pulse to become hurried and irregular, and the breathing to be accelerated.

Much attention was paid to the administration of the medicine, and great pains were taken in giving it on the end of a cane. It was given in small pieces at a time, and every exertion used to get it as far up to the gullet as possible, by working each piece gently up for some time.

The wound in the tail was fomented every day with warm water, as hot as the hand could bear it, and a dressing of digestive ointment applied.

The combined effects of the internal treatment with the local application to the wound in the tail, in the course of a few days brought the wound to assume a more healthy appearance, and the matter that was discharged from it to be of a better consistence, and it continued so until it was quite healed.

The quantity of crude opium administered during the course of the disease was 3834 .

N. B. In this case there was no amputation of the injured part in the tail, nor any incisions, nor the application of caustic, and yet the case was treated successfully. 


\section{CASE VI.-March 27th, 1804. \\ ORIGINATING FROM THE AMPUTATION OF THE TAIL.}

This was the case of a filly two years and a half old, and about fourteen hands high, the property of Mr John Anderson, late of Scots House, about three miles from Newcastle.

The symptoms that occurred were a spasmodic affection of the muscles of the jaw, head, neck, back, hinder extremities, and abdomen; on elevating the head, the membrana nictitans covered a considerable portion of the ball of the eye; the nose was thrown out from the chest; the nostrils expanded; the ears erect; a great stiffness of the vertebræ of the neck and back; pulse about sixty beats in the minute; respiration was likewise quickened; appetite good, but could not masticate hay; the bowels were costive.

This filly had been docked about three weeks previous to symptoms of tetanus commencing, and the wound assumed that pale, flabby, unhealthy appearance, which generally takes place in tetanic cases: there was very little discharge from it, and what was discharged was of a thin serous nature.

Having taken the case into consideration, about five pints of blood was drawn from the jugular vein, and the purgative drench No. 2, and emollient clyster No. 2, were administered.

The liniment was applied over the muscles of the jaws, head, neck, and back, with considerable friction, and the parts afterwards covered with sheep skins, which soon brought on a copious perspiration.

The diet was bran mashes and oatmeal gruel.

On the 28th, the pulse and respiration were a little hurried; the spasmodic affection of the muscles much about the same; the bowels 
pretty open; and she perspired under the sheep skins; appetite good, and she got down a little bran mash, and drank oatmeal gruel.

On the 29th, the symptoms stationary.

The liniment repeated.

On the 30th, the pulse and respiration at times hurried; the spasms of the muscles much about the same; she perspires freely under the sheep skins.

The purging having subsided, the antispasmodic medicine was begun, and the ball No. $\mathcal{2}$, was given in small pieces, on the end of a piece of cane, and great pains were taken to work each piece up as near to the gullet as possible: when this is done, if the horse does not swallow it immediately, it is probable it will adhere to the roof of the mouth or grinders, and be swallowed by degrees, as it dissolves : too much attention cannot be paid to this circumstance, in order to get the medicine to reach the stomach, so as to arrest the progress of the disease. 'The antispasmodic clyster No. 2, was also administered in the manner I have pointed out. This treatment was continued until the 14th of April, when the filly: was cured of the complaint.

Some debility remaining, a few tonic medicines; combined with cordials, were given, which, together with a generous diet, regular and moderate exercise, and moderate cloathing, soon' restored the strength of the system.

The local treatment to the wound in the tail was a fomentation of warm water, and a dressing of digestive ointment applied every day, which, combined with the effect of the internal' treatment, in the course of a few days brought the wound to assume a healthy florid appearance, attended with a good suppuration, which continued until it was healed:

The quantity of crude opium administered during the course of the disease was $\zeta 5,34$.

N. B. In this case there was no amputation of the injured part in the tail, nor incisions, nor the application of caustic, and yet the case was treated successfully. 
CASE VII.-December 24/h, 1805.

ORIGINATING FROM TIE AMPUTATION OF THE TAIL.

This was the case of a draught horse, eight years old, and about sixteen hands high, the property of $\mathrm{Mr}$ Christopher Fairs, of Gateshead Fell, near Newcastle.

On being called in to this case, the symptoms that appeared were a spasmodic affection of the muscles of the jaw, head, neck, back, hinder extremities, and abdomen; on elevating the head, the membrana nictitans covered a great part of the ball of the eye; nose thrown out from the chest; nostrils expanded; ears erect; a great stiffiness of the vertebræ of the neck and back, as also of the hinder extremities; the pulse not much altered, nor yet the breathing, but upon a little fatigue the pulse became hurried and irregular, and respiration was accelerated; the bowels were costive; the jaws were considerably shut, but not so but that medicine might be administered with a small horn.

The tail had been amputated about a fortnight previous to tetanic symptoms commencing, and the wound assumed that unhealthy appearance I have described in the preseding cases.

The case being examined, the treatment consisted in the first place, in opening the intestines, and afterwards, in the free use of the antispasmodic medicine, administered in the manner I have pointed out, and continued until the 24th of January, when the horse was cured of the complaint:

The liniment was applied over the muscles, of the jaws, head; neck, and back, and the parts covered with sheep skins, which soon brought on a copious perspiration.

The local treatment to the wound in the tail was by fomentations of warm 'water, and a dressing of digestive ointment applied every day. 
During this time the spasms were sometimes severe, which caused the pulse to become hurried and irregular, and the breathing to be accelerated. There was a constant perspiration going on under the sheep skins, which were renewed as they became dry or offensive in smell.

The quantity of crude opium administered during the course of the disease was $\bar{\zeta} 6$.

N. B. In this case there was no amputation of the injured part in the tail, nor any incisions, nor the application of caustic, and yet the case was treated successfully.

\section{CASE VIII.-November 18th, 1806. \\ ORIGINATING FROM EXPOSURE TO COLD.}

The horse was a hunter, seven years old, and between fifteen and sixteen hands high, the property of Dixon Brown, Esq. of Long Benton, about three miles from Newcastle.

The symptoms that appeared on examining this case were a quick and irregular pulse, about sixty beats in the minute; respiration accelerated, and attended with a cough; the muscles of the jaw, head, neck, back, hinder extremities, and abdomen, were spasmodically affected, which caused them to become rigidly contracted; the head a little raised, and on raising it a little more, the membrana nictitans covered great part of the ball of the eye; nose thrown out from the chest; nostrils expanded; ears erect, and immoveable; tail rather elevated, and upon a little fatigue, shook much; a straddling of the hinder extremities, with great stiffness; the vertebræ of the neck and back were likewise very 
stifi, and if you attempted to turn him, he could neither bend his neck nor back, but turned in a straight line; the jaws were considerably shut, but not so but that medicine might be administered with some difficulty in the form of a ball, by giving it in small pieces on the end of a cane, or as a drench, with a small horn; his bowels were constipated, and the secretion of urine diminished.

On inquiring into the cause of the disease, I ascertained that the horse was affected with a cold, and had coughed four or five days previous to tetanic symptoms commencing; and as there was no injury in any of the external parts of the body, nor yet any symptoms of worms affecting the stomach and intestines, I considered the complaint to have originated from exposure to cold, suppressing the process of perspiration.

Having examined the case, and finding the heart and arteries hurried in their action, about five pints of blood were taken from the jugular vein ; the bowels being very costive, the purge No. 3, and emollient clyster No. 3, weré administered.

The liniment was applied over the muscles of the jaws, head, neck, and back, with considerable friction, and the parts covered with sheep skins, which soon brought on sensible perspiration.

The diet was bran mashes, oatmeal gruel, \&c.

On the 19th, the pulse and respiration much about the same; the jaws not more locked; the purge not operating, two emollient clysters were administered, which facilitated.its action.

On the 20th, the spasmodic affection of the muscles much about the same, as also the pulse and respiration; the purging having subsided, the antispasmodic medicine No. 3, combined with an antimonial, was given as a drench; and immediately after, the antispasmodic No. 3 was administered.

The liniment was repeated.

On the 21 st, the pulse about sixty-five beats in the minute, and the breathing still hurried; the jaws not more shut; the antispasmodic 
medicine, combined with an antimonial, was given morning and evening, in small pieces in the form of a ball, on the end of a cane; and the antispasmodic clyster was also administered morning and evening.

On the 22nd, the pulse about seventy beats in the minute; the respiration very much accelerated, although the jaws were not more locked; the pulse and respiration being so much hurried, the bleeding was repeated, and about five pints of blood were drawn from the jugular vein : the same ball was given morning and evening.

About this time some odematous swellings came on about the prepuce or sheath, abdomen, and fore arms, to relieve which, scarifications and emollient applications were used.

On the 23rd, the pulse about sixty-five beats in the minute; the respiration not quite so much accelerated; the jaws somewhat more open, and the rigidity of the muscles in general not quite so great; the swellings in the sheath and belly a good deal subsided; the ball and clyster were repeated morning and evening, and continued in the same manner every day until the 27 th, when the jaws were still more open, and the system in general more relaxed.

On the 28th, the horse appeared to have a great affection of his bowels, which I thought originated from the astringent effect of the opium ; his pulse was about seventy beats in the minute, and his breathing considerably hurried: I therefore ordered the bleeding to be repeated, and about five pints were drawn, and mild cathartic drenches, such as castor oil, were administered, and emollient clysters were given, and repeated until a free passage of the intestines was obtained.

On the 29th, he was considerably easier, and his bowels were pretty open; his pulse and respiration not so much hurried; but his extremities becoming cold, an embrocation was used to determine the blood to those parts, which had the desired effect.

On the 30th, the pulse still less hurried and more regular, and his breathing more calm; his bowels pretty open, and the extremities warm; in short, the whole system was very much relieved: as the spasmodic 
affection of the muscles had greatly subsided, the antispasmodic medicine was again administered in the same manner as on the 27th, and repeated every day until the 14 th of December, when the horse was cured of the complaint.

But the system being debilitated, a few tonic medicines, combined with cordials, were administered, with a generous diet; regular and moderate exercise, with considerable friction in dressing, and moderately warm cloathing, soon restored the strength of the body.

Mr Brown afterwards hunted the horse seven seasons, and I understand, during that time, he carried him as well as ever.

N. B. The quantity of crude opium administered during the course of the disease was $\overline{3} 934$.

CASE IX.-January 23rd, 1807.

ORIGINATING FROM THE AMPUTATION OF THE TAIL.

This was the case of a filly three years old, and about fourteen hands high, the property of Mr Swan, of North Shields, about eight miles from Newcastle.

On examining this case, the symptoms that appeared were a rigid contraction of the muscles of the jaw, head, neck, back, and hinder extremities; the abdominal muscles were likewise much affected, which occasioned the abdomen to be much drawn in ; on elevating the head, the membrana nictitans covered great part of the ball of the eye; the nose thrown out from the chest; the nostrils expanded; the ears erect; a great stiffness of the vertebræ of the neck and back; a straddling of the hinder extremities; pulse a little hurried and irregular; respiration 
accelerated; appetite good, but could not masticate hay; the bowels were constipated, and the secretion of urine diminished.

Having examined the case, about two quarts of blood were drawn from the jugular vein : the internal treatment consisted in opening the primæ viæ, that is, in unloading the intestines, and afterwards administering the antispasmodic medicine in the manner I have pointed out.

The liniment was applied over the muscles of the jaw, head, neck, and back, with considerable friction, and the parts covered with sheep skins, which soon brought on sensible perspiration.

The tail had been amputated about three weeks previous to tetanic symptoms commencing, and the local treatment to the wound was fomentations of warm water, and dressings of digestive ointment, which, combined with the effect of the internal treatment, in the course of a few days, brought it to assume a much more healthy appearance, which continued until it was quite healed.

The internal treatment was continued until the 19th of February, . when the mare was cured of the complaint.

During this time the pulse was often hurried and irregular, and the breathing quickened; there was a constant perspiration going on under the sheep skins, which were renewed as they became the least dry or offensive in' smell.

The quantity of crude opium administered during the course of the disease was $\bar{\zeta} 34$.

$\mathrm{N}$. B. In this case there was no amputation of the injured part in the tail, nor incisions, nor the application of caustic, and yet the case was treated successfully. 


\section{CASE X.-July 14th, 1807.}

ORIGINATING FROM AN INJURY OF THE HINDER EXTREMITY.

This was the case of a draught mare, six years old, and fourteen hands high, the property of Mr George Cutter, of Kenton, near Newcastle.

The symptoms that appeared on examining this case, were a spasmodic affection of the muscles of the jaw, head, neck, back, hinder extremities, and belly, which caused them to become rigidly contracted; the head somewhat raised, and on elevating it a little more, the membrana nictitans covered a great part of the ball of the eye; the nose thrown out from the chest; the nostrils expanded; the ears erect, and immoveable; a great stiffness of the vertebræ of the neck and back; a straddling, with great stiffness of the hinder extremities; tail elevated, and a shaking of it; the jaws were much shut, but not so but that medicine might be administered with some difficulty with a small horn; the appetite good, but she could not masticate hay, although she could get down a thin bran mash, and drink oatmeal gruel; the pulse and respiration not much altered; the bowels were costive, and the secretion of urine diminished.

This mare had received an injury in the hind leg a little above the fetlock joint, which lacerated the flexor tendon of the foot; the wound was about four inches in length; she had received it about a fortnight previous to symptoms of tetanus commencing; and the wound had a very flabby unhealthy appearance, with very little discharge from it, and what was discharged was of a thin serous nature.

Having examined the case, the treatment consisted, in the first place, in opening the intestinal canal, and afterwards in the free use of the antispasmodic medicine, administered in the manner I have pointed 
out, and continued until the 24 th of January, when the mare was free from the complaint.

The liniment was applied over the muscles of the jaw, head, neck, and back, and the parts covered with sheep skins, which soon brought on a copious perspiration.

During the course of the disease the spasmodic affection of the muscles was sometimes severe, which caused the pulse to become hurried and irregular, and the breathing to be quickened : there was a constant perspiration going on under the sheep skins, which were renewed when they became the least dry or offensive in smell.

The local treatment to the wound in the leg, was a fomentation of warm water, as hot as the hand could bear it, and dressings of digestive ointment every day.

From the combined effects of this treatment, the wound soon began to granulate, and instead of having that pale flabby appearance, the granulations that arose were firm and florid, with a discharge of matter of a good consistence, and continued so until the wound was quite healed.

The quantity of crude opium administered during the course of the disease was $\zeta 8$.

N. B. In this case there was no incision, so as to divide the nerves in the part affected, nor was any caustic applied, and yet the case was successfully treated. 


\title{
CASE XI.—January 12th, 1808.
}

\author{
IDIOPATHIC.
}

This was the case of an aged draught horse, about fifteen and a half hands high, the property of Thomas Burdon, Esq. now Sir Thomas Burdon, Knight.

The symptoms that appeared on examining this case, were a spasmodic affection of the muscles of the jaw, head, neck, back, hinder extremities, and abdomen, causing them to become rigidly contracted; on elevating the head, the membrana nictitans covered a great part of the ball of the eye; nose thrown out from the chest; nostrils expanded; ears erect; a great stiffness of the vertebræ of the neck and back; hind legs much asunder; tail a little elevated, and upon the least fatigue a shaking of it; pulse not much altered, nor yet respiration, but upon a little fatigue, his pulse became quick and irregular, and his breathing also became accelerated; his bowels were constipated; his jaws were considerably shut, but not so but that medicine might be administered with some difficulty on the end of a cane.

Having examined the case, the treatment consisted in unloading the intestines, and afterwards administering the antispasmodic medicine in the manner I have pointed out.

The liniment was applied over the muscles of the jaw, head, neck, and back, and the parts covered with sheep skins, which quickly brought on sensible perspiration.

This treatment was continued until the 16th of February, when the horse was cured of the complaint.

But during the course of the disease, the spasms of the muscles were often severe, which caused his pulse to become hurried and irregular, and respiration at the same time was much accelerated : there was a 
constant perspiration going on under the sheep skins, which were renewed as they became dry or offensive in smell.

N. B. The quantity of crude opium administered in this case during the course of the disease was $\zeta 7$.

\section{CASE XII.-March $24 t h, 1808$.}

\section{ORIGINATING FROM A PUNCTULE IN THE EXTENSOR TENDON \\ OF THE FOOT.}

This was the case of a hunter, six years old, and between fifteen and sixteen hands high, the property of Richard Wright, Huntsman to the Newcastle Hunt.

On being called in to this case, the symptoms were a spasmodic affection of the muscles of the jaw, head, neck, back, hinder extremities, and belly, which caused them to become rigidly contracted; his head rather raised, and on raising it a little more, the membrana nictitans covered a great part of the ball of the eye ; nose thrown out from the chest ; nostrils expanded ; ears erect ; a great stiffness of the vertebræ of the neck and back; hinder extremities much asunder; tail a little elevated, and a shaking of it ; the pulse and respiration not much altered, but upon a little fatigue his pulse became hurried and irregular, and his breathing increased; his appetite good, and he could get down thin bran mashes and oatmeal gruel; his bowels were costive, and the seçretion of urine diminished; the jaws were considerably shut, but not so but that medicine might be administered with some difficulty on the end of a cane. 


\section{1}

The horse had received the puncture in hunting, about ten days previous to my being called in, and the wound was healed, but left a little indurated substance about the size of a hazel nut, unattended with any pain or inflammation.

Having examined the case, the treatment consisted in keeping the bowels open, and afterwards administering the antispasmodic medicine in the manner I have pointed out.

The liniment was applied over the muscles of the jaw, head, neck, and back, and the parts covered with sheep skins, which soon induced a free perspiration.

The internal treatment was continued until the 23rd of April, when the horse was free from the complaint.

He was afterwards sold to Thomas Fenwick, Esq. banker, in Newcastle, who hunted him three seasons, and I understand he performed his work as well as ever.

During the course of the disease, the spasmodic affection of the muscles was frequently severe; which caused the pulse to become hurried and irregular, as also the breathing to be quickened. There was a constant perspiration going on under the sheep skins, which were renewed as they became'dry or offensive in smell.

The quantity of crude opium administered during the course of the disease was $\overline{3} 8$ :

N. B. In this case I never used any local means to the part that gave rise to the complaint, and yet the case was treated successfully. 
CASE XIII.-December 29th, 1808.

IDIOPATHIC.

This was the case of a draught mare, ten years old, and about sixteen hands high, the property of $\mathbf{M r}$ George Cutter, of Kenton, near Newcastle.

On inspecting this case, the symptoms that appeared were a spasmodic affection of the muscles of the jaw, head, neck, back, hinder extremities, and abdomen; on elevating the head, the membrana nictitans covered great part of the ball of the eye; nose thrown out from the chest; nostrils expanded; ears erect; great stiffness of the vertebræ of the neck and back; hinder extremities much asunder; tail elevated, with a shaking of it; pulse and respiration not much altered, but upon a little fatigue the pulse became hurried and irregular, as also the breathing; the appetite good, but she could not masticate hay; the bowels were constipated; the jaws were considerably shut, but not so but that medicine might be administered with some difficulty on the end of a cane.

Having examined the case, the treatment consisted in the first place, in opening the intestines, and afterwards administering the antispasmodic medicine in the manner I have pointed out.

The liniment was applied over the muscles of the jaw, head, neck, and back, with considerable friction, and the parts covered with sheep skins, which soon brought on a most copious perspiration.

The internal treatment was continued in the manner I have pointed out, until the 18th of January, when the mare was cured of the complaint.

During this time the spasms of the muscles were sometimes greater than at other times, which hurried the pulse and respiration; there was a constant perspiration going on under the sheep skins; which were renewed as occasion required. 
The quantity of crude opium administered during the course of the disease was 33,36 .

N. B. About a month after this mare's recovery, it was observed she was pregnant; and she went her full time, and foaled a fine healthy filly foal, which, with the mare, did well.

\section{CASE XIV.-January 24th, 1809.}

ORIGINATING FROM THE AMPUTATION OF THE TAIL.

This was the case of a colt two years and a half old, and about fourteen hands high, the property of Mr Charles Turner, of Newcastle.

On examining this colt, the symptoms were a spasmodic affection of the muscles of the jaw, head, neck, back, abdomen and hinder extremities, which caused them to become rigidly contracted; head rather raised, and upon raising it a little more the membrana nictitans covered great part of the ball of the eye ; nose thrown out from the chest ; nostrils expanded; ears erect; tail elevated, and upon a little fatigue a. shaking of it; hind legs much asunder; pulse and respiration not much altered, but upon the least fatigue the pulse became hurried and irregular; the breathing was also quickened; the bowels were costive, and the secretion of urine somewhat diminished.

Having examined the case, the treatment consisted in keeping the bowels open, and administering the antispasmodic medicine in the manner I have pointed out.

The liniment was used over the muscles of the jaw, head, neck and back, and the parts covered with sheep skins, which soon brought on a free perspiration. 
The internal treatment was followed up to the 12th of February, when the colt was cured of the complaint.

This colt had been docked about a month previous to tetanic symptoms commencing, and the wound in the tail was very small, but assumed an unhealthy appearance, with that thin serous discharge which I have previously described.

The local treatment to the wound was a fomentation of warm water, and a dressing of digestive ointment applied every day, which, combined with the effect of the internal treatment, soon brought the wound to put on a more healthy appearance, and the matter that was discharged from it to be of a better consistence, and it continued so until it was quite healed, which was in the course of a few days.

During this time the spasmodic affection of the muscles was sometimes great, which quickened the pulse and respiration; there was a constant perspiration going on under the sheep skins. The skins were renewed as they became dry or offensive in smell.

The quantity of crude opium administered during the course of the disease was $\overline{3} 8, \hat{3} 3$.

N. B. In this case I did not amputate the injured part in the tail, nor make any incisions, or apply caustic, and yet I treated the case successfully. 


\section{CASE XV.-January 28th, 1811.}

ORIGINATING FROM A NAIL BEING DRIVEN INTO" THE SENSIBI.E

PART OF THE FOOT IN SHOEING.

This was the case of a draught horse, five years old, and nearly sixteen hands high, the property of $\mathrm{Mr}$ Francis Anderson, of Bent House, near South Shields, and about eleven miles from Newcastle.

On examining this case, the symptoms that appeared were a spasmodic affection of the muscles of the jaw, head, neck, back, hinder extremities, and abdomen, which caused them to become rigidly contracted; on elevating the head the membrana nictitans covered great part of the ball of the eye; nose thrown out from the chest; nostrils expanded; ears erect; great stiffness of the vertebræ of the neck and back; tail elevated, and a shaking of it on the least fatigue; pulse and respiration not much altered, although upon the least fatigue both became much quickened; the bowels were costive; his jaws were considerably shut, but not so but that medicine might be administered with some difficulty on the end of a cane.

On inquiry into the cause of the disease, I ascertained that the horse had been shod about six days previous to tetanic symptoms commencing, and that the farrier had driven a nail into the sensible part of the foot in shoeing, which caused lameness; but by removing tbe shoe and opening the part with a drawing knife, where the nail had been driven, and applying a little ointment to the part, the horse got sound in about four days; and on the firth day he was put to work, but did not perform as he had done, as he seemed to have a stiffness all over him, and incapability of exerting his muscular system with freedom, and as the driver termed it, he seemed "mazed." The next day I was sent for and found him in the situation above described. 
The treatment in this case consisted in keeping the intestines open, and using the antispasmodic medicine in the manner I have pointed out.

The liniment was applied over the muscles of the jaw, head, neck, and back, and the parts covered with sheep skins, which soon brought on a copious perspiration.

The internal treatment was continued until the 6th of March, when the horse was cured of the complaint.

The severity of the spasms were sometimes greater than at other times, which caused some alteration of the pulse and respiration : there was a constant perspiration going on under the sheep skins, which were renewed as they became dry or offensive in smell.

The quantity of crude opium administered during the course of the disease was $\zeta 10$.

N. B. In this case there were no incisions made so as to divide the nerves in that part of the foot that was injured in shoeing, nor any application of caustic, and yet the case was treated successfully.

\section{CASE XVI.-March 7th, 1812.}

\section{IDIOPATHIC.}

This was the case of a draught horse, about five years old, and about sixteen hands high, the property of the late owners of Fawdon Colliery, about three miles from Newcastle.

The symptoms that appeared on my being called in to this case, were a spasmodic affection of the muscles of the jaw, head, neck, back, hinder extremities, and abdomen, which caused them to become rigidly contracted; on elevating the head, the membrana nictitans covered a 
great part of the ball of the eye; nose thrown out from the chest; the nostrils expanded; ears erect; a great stiffness of the vertebræ of the neck and back; a straddling, with great stiffness of the hind legs; tail elevated, and upon the least fatigue a shaking of it; pulse and respiration not much altered; his bowels were constipated, and the secretion of urine diminished; his jaws were considerably shut, but not so but that medicine might be administered with some difficulty on the end of a cane.

Having examined the case, the treatment pursued was, in the first place, to unload the intestinal canal, and afterwards to administer the antispasmodic medicine in the manner I have pointed out.

The liniment was well rubbed over the muscles of the jaw, head, neck, and back, and the parts covered with sheep skins, which quickly brought on perspiration.

The internal treatment was continued until the 21st of April, when the horse was free from the complaint.

During this time the pulse and respiration were sometimes hurried according to the severity of the spasms, and a constant perspiration was going on under the sheep skins.

The quantity of crude opium administered during the course of the disease was $\zeta 12$. 


\section{CASE XVII.-March 23rd, 1813.}

ORIGINATING FROM THE AMPUTATION OF THE TAIL.

This was the case of a filly, three years old, and about fourteen hands high, the property of Mr Kyle, of Ponteland, about seven miles from Newcastle.

In this case the symptoms of tetanus commenced about ten days after the tail had been amputated, and the wound assumed a pale flabby unhealthy appearance, with very little discharge.

On examining the filly, the muscles of the jaw, head, neck, back, hinder extremities, and abdomen, were found to be spasmodically affected, which caused them to become rigidly contracted; on elevating the head the membrana nictitans covered great part of the ball of the eye; nose thrown out from the chest; nostrils expanded; ears erect; great stiffness of the vertebræ of the neck and back, and when she turned her body it was in a straight line, as she could neither bend her neck nor back; a straddling of the hinder extremities; tail elevated, and upon the least fatigue a shaking of it; the pulse and respiration very little altered; the bowels were constipated; appetite good, and she could get down thin bran mashes, and drink oatmeal gruel, although the jaws were considerably shut, but not so but that medicine might be administered with some difficulty on the end of a cane.

The treatment in this case consisted in keeping the intestines open, and administering the antispasmodic medicine in the manner I have pointed out.

The liniment was applied over the muscles of the jaw, head, neck, and back, and the parts covered with sheep skins, which soon induced a free perspiration. 
The internal treatment was continued until the 29th of April, when the filly was free from the disorder.

During this time the spasms of the muscles were sometimes severe, which caused the pulse and the breathing to be hurried. A constant perspiration was going on under the sheep skins.

There were some swellings came on about the fore arms and knees, which gave way to fomentations and sedative applications.

The local treatment to the wound in the tail was a fomentation of warm water and dressings of digestive ointment applied every day, which, combined with the effect of the internal treatment, soon brought the wound to a more healthy appearance, and it so continued until it got well.

The quantity of crude opium administered during the course of the disease was $\zeta 8$.

N. B. In this case there was no amputation of the injured part in the tail, nor incisions, nor any application of caustic, and yet the case was treated successfully.

\section{CASE XVIII.-April 19th, 1813.}

ORIGINATING FROM THE AMPUTATION OF THE TAIL.

This was the case of a colt, two years old, and about fourteen and a half hands high, the property of Mr Gallon, of Low Weatslet, about seven miles from Newcastle.

The colt had the tail amputated about three weeks previous to the commencement of tetanic symptoms, and the wound assumed a pale 
flabby unhealthy appearance, with very little discharge, and what was discharged was of a thin serous nature.

On examining this case, the symptoms that appeared were a spasmodic affection of the muscles of the jaw, head, neck, back, hinder extremities, and abdomen, causing them to become rigidly contracted; on elevating the head the membrana nictitans covered great part of the ball of the eye; nose thrown out from the chest; nostrils expanded; ears erect; a great stiffness of the vertebræ of the neck and back; a straddling; with great stiffness of the hinder extremities; tail elevated; pulse and respiration very little altered; his bowels were constipated, and the secretion of urine somewhat diminished; appetite good, but could not masticate hay, as the jaws were considerably shut, but not so but that medicine might be administered with some difficulty on the end of a cane.

The treatment in this case consisted in keeping the bowels open, and the free use of the antispasmodic medicine, in the manner I have pointed out.

And after continuing this treatment about a fortnight, the colt so far recovered the use of his jaws that he could masticate hay; and his appetite was so uncommonly eager, that he eat his mashes with the antispasmodic medicine mixed with them.

This treatment was continued until the 20th of May, when the colt was cured of the complaint.

The liniment was applied over the muscles of the jaws, head, neck, and back, and the parts covered with sheep skins, which soon brought on a copious perspiration.

During this time the spasmodic affection of the muscles was better and wurse, which caused some variation of the pulse and respiration: there was a constant perspiration going on under the sheep skins.

Some swellings came on about the prepuce and lower part of the abdomen, which gave way to scarifications and emollient fomentations. 
The local treatment to the wound in the tail was a fomentation of warm water, and dressings of digestive ointment applied every day, until it was healed.

The quantity of crude opium administered in this case was $z 733$.

N. B. In this case there was no amputation of the injured part in the tail, or incisions, or the application of caustic, and yet the case was treated successfully.

\author{
CASE XIX.-January 4th, 1814. \\ COMMENCING ON THE RECOVERY OF AN INFLAMMATION \\ OF THE I.UNGS.
}

This was the case of a draught mare, five years old, and about fifteen hands high, the property of Edward Hetherington; Esq. of Newcastle.

About a month previous to tetanic symptoms coming on, this mare had a desperate attack of inflammation of her lungs. I attended her, and used the necessary means under such circumstances, and got-her well; but she had not been recovered more than a week of this complaint when symptoms of tetanus appeared.

These symptoms were a spasmodic affection of the muscles of the jaw, head, neck, back, hinder extremities, and abdomen, which caused them to become rigidly contracted; on elevating the head, the membrana nictitans covered great part of the ball of the eye; the nose thrown out from the chest; nostrils expanded; ears erect, a stiffness of the vertebræ of the neck and back; hinder extremities much asunder; the pulse hurried and irregular; mouth hot; respiration accelerated; 
jaws considerably shut, but not so but that medicine might be administered with some difficulty on the end of a cane.

Having examined the case, and finding the pulse about sixty beats in the minute, with some degree of strength, hot mouth, and other febrile symptoms, I ordered a moderate quantity of blood to be taken from the jugular vein, and about three pints were drawn.

The internal treatment consisted in keeping the intestines open, and administering the antispasmodic medicine in the manner I have pointed out.

This treatment was pursued until the 18th, when the mare was cured of the complaint.

The liniment was applied over-the muscles of the jaw, head, neck, and back, and the parts covered with sheep skins, which quickly brought on perspiration ; and it was constant during the use of the sheep skins.

The spasms at times were more severe than at other times, which occasioned some variation in the pulse and respiration.

In the course of six weeks after this mare's recovery of tetanus, it was observed she was pregnant; and she went her full time, and foaled a fine healthy filly foal, which, with the mare, did well.

The quantity of crude opium administered during the course of the disease was $\frac{3}{3} 4$.

N. B. This mare must have had an uncommonly strong constitution to recover from two of the most desperate diseases that can attack the horse, and afterwards to have a fine healthy foal. The case greatly indicates what nature can withstand in some constitutions, and shews if the disease is properly understood, and medical aid properly used, that there is a great probability of frequently making a cure, if means are used in time. 
CASE XX.-April 13th, 1815.

ORIGINATING FROM THE AMPUTATION OF THE TAIL.

This was the case of a two years old filly, about fourteen hands high, the property of $\mathrm{Mr}$ Gilhespy, late of Higham Dykes, about ten miles from Newcastle.

The filly had been docked about ten days previous to tetanic symptoms commencing, and the wound put on a pale flabby unhealthy appearance, with very little discharge, and that of a thin serous nature.

On inspecting the case, the symptoms that appeared were a spasmodic affection of the muscles of the jaw, head, neck, back, hinder extremities, and belly, whicl caused them to become rigidly contracted; on elevating the head the membrana nictitans covered great part of the ball of the eye; nose thrown out from the chest; nostrils expanded; ears erect; the vertebræ of the neck and back very stiff; a straddling, with a stiffness of the hinder extremities; the pulse and respiration not much altered, but upon the least fatigue the pulse became hurried and irregular; and the breathing became accelerated; the bowels were costive ; the jaws were considerably shut, but not so but that medicine might be administered as a drench with a sinall horn.

liaving examined the case, the treatment consisted in unloading the intestines, and afterwards in the administration of the antispasmodic medicine in the manner I have pointed out.

This treatment was continued until the 30th, when the filly was cured of the disease.

The liniment was applied over the muscles of the jaw, head, neck, and back, and the parts covered with sheep skins, which soon brought on a most copious perspiration, which was constant as long as the sheep skins were applied. 
The local treatment to the wound in the tail was fomentations of warm water, and dressings of digestive ointment applied every day, which, combined with the effect of the internal treatment, soon brought the wound to assume a healthy appearance, attended with a discharge of matter of a good consistence, which so continued until the wound got well.

The quantity of crude opium administered during the course of the disease was $\xi 4$.

N. B. In this case there was no amputation of the injured part in the tail, nor any incision, nor application of caustic, and yet the case was successfully treated.

\section{CASE XXI.-March 7 th, 1818.}

ORIGINATING FROM EXPOSURE TO COLD.

This was the case of a mare twelve years old, and about fourteen and a half hands high, the property of Mr Urwen, of Backworth, about six miles from Newcastle.

On examining the case, the symptoms that appeared were a spasmodic affection of the muscles of the jaw, head, neck, back, hinder extremities and abdomen, which caused them to become rigidly contracted; on elevating the head the membrana nictitans covered great part of the ball of the eye; nose thrown out from the chest; nostrils expanded; ears erect; great stiffness of the vertebræ of the neck and back; great stiffness of the hinder extremities, and she straddied much; tail much elevated, and upon the least fatigue a shaking of it; pulse about 
seventy beats in the minute, but not strong; respiration accelerated, attended with a cough; appetite good; the bowels were costive and the secretion of urine diminished; the jaws were considerably shut, but not so but that medicine might be administered with a small horn.

Having examined the case, the purgative drench No. 2, and emollient clyster No. 2, were administered.

The liniment was well rubbed over the muscles of the jaw, head, neck, and back, and sheep skins applied, which quickly brought on a copious perspiration; considerable friction was likewise used to the hinder extremities, which were excessively stiff.

Diet-bran mashes, oatmeal gruel, \&c.

On the 8th, the pulse becoming stronger and more frequent, at the same time respiration being much accelerated, about two quarts of blood were drawn from the jugular vein, and upon letting it stand to coagulate, it exhibited a coat of about one inch and a half of size, of a buff colour, but the blood had not that tough or firm consistence that we generally find in acute inflammatory cases; such as in an inflammation of the lungs, \&c., the particles were very loosely connected; she perspired freely under the sheep skins; jaws rather more shut; the purgative drench not operating, an emollient clyster was given every four hours until it operated, which was after the third had been administered.

On the 9th, the jaws were not more shut; the pulse still beating about seventy-five in the minute; and respiration much accelerated, the bleeding was repeated, and about three pints were drawn, and on letting it stand to coagulate, it exhibited the same appearance as on the 8th. She was in a copious perspiration under the sheep skins; the purging having subsided, the antispasmodic medicine, combined with an antimonial, was begun, and the drench No. 2, with the addition of 32 of antimonial powder, was administered in the manner I have pointed out; the antispasmodic clyster No. 2 was likewise given.

On the 10th, the jaws were not more shut; the pulse about sixtyfive beats in the minute, with some irregularity; the breathing quick; 
she coughed more; the antispasmodic medicine, combined with an antimonial, was repeated by the mouth, and the antispasmodic clyster was also repeated. Some difficulty in swallowing coming on, a blister was applied to the external part of the throat: she was in a copious perspiration under the sheep skins.

On the 11th, the jaws much about the same; the pulse about seventy beats in the minute; respiration quick; she perspired freely under the sheep skins; the difficulty in swallowing still great; the blister was repeated to the throat; and an antispasmodic, combined with an antimonial, according to the following formula, was administered every three hours for twelve hours, and great attention was paid in increasing or decreasing the quantity of opium, according to the violence of the spasms, and the effects it was observed to produce in the system; the antispasmodic clyster was likewise repeated :-

\section{Drench.}

\section{B Crude Opium}

51 Camphor

31 Antimonial Powder

31 Linseed Powder

3 1 Olive Oil

34 Treacle

Dissolve the Camphor in the Oil, and the Opium in a little Water; then mix the whole into an Electuary; afterwards mix it in one pint of thin Oatmeal Gruel, and give it.

On the 12th, the spasmodic affection of the muscles much about the same; the pulse about sixty five beats in the minute, and the breathing quick; she is in a constant perspiration under the sheep skins; the 
difficulty in swallowing not so great; the antispasmodic medicine, combined with the antimonial, continued as on the 11th, and the antispasmodic clyster repeated.

On the 13th, the pulse about sixty beats in the minute; respiration not quite so much accelerated; cough more loose; she perspires freely under the sheep skins; the difficulty in swallowing much less; jaws rather more open; drenches and clysters repeated as on the 12th.

On the 14th, the pulse about sixty beats in the minute; respiration hurried; the spasmodic affection of the muscles much about the same as on the preceding day; an increased secretion of saliva took place; perspiration is going on copiously under the sheep skins; drenches and clysters repeated.

On the 15th, the bowels getting costive, the purgative drench No 2, and the emollient clyster No. 2 were administered; the jaws rather more open; she perspires freely under the sheep skins; the pulse and respiration much about the same as yesterday.

On the 16th, the pulse about fifty-five beats in the minute; respiration more calm; the purgative drench operating well; no medicine was administered this day; she is still in a perspiration under the sheep skins.

On the 17th, the pulse about fifty beats in the minute; respiration easy ; the jaws considerably more open, and a general relaxation of the muscular system has in some measure taken place; she is in a copious perspiration : the purgative drench having done operating, the antispasmodic medicine, combined with an antimonial, was administered as before, and likewise the antispasmodic clyster.

On the 18th, the pulse about sixty beats in the minute; respiration quickened; she coughs more, and a considerable quantity of thickened mucus is discharged with the fæces; she drinks freely of a strong infusion of linseed; the jaws much about the same; drenches continued, and emollient clysters administered; she is in a constant perspiration under the sheep skins. 
On the 19th, the pulse about fifty beats in the minute; and the breathing quite calm in the morning, but in the evening the pulse became hurried, about seventy beats in the minute, and respiration quickened; she perspires under the sheep skins; drenches and clysters continued as yesterday.

Diet principally strong infusions of linseed, and strong oatmeal gruel, of which she drank very freely.

On the 20th, the pulse about fifty beats in the minute; respiration easy; she perspires freely under the sheep skins; drenches and clysters as on the preceding day.

On the 21 st, the pulse about sixty-five beats in the minute; respiration hurried; jaws not more shut; she is in a copious perspiration; drenches and clysters continued.

On the 22nd, the pulse about sixty-three beats in the minute; the breathing accelerated; the spasmodic affection of the muscles rather increased; drenches and clysters repeated; she still perspires freely under the sheep skins.

On the 23rd, in the morning the pulse about fifty beats in the minute; respiration calm; the spasmodic affection of the muscles greatly diminished. In the evening an increased secretion of saliva came on ; and she appeared restless from the effects of the opium, with a quick pulse.

On the 24 th, the pulse about sixty beats in the minute, and she is not so restless; the spasms of the muscles much about the same as yesterday; the sheep skins becoming dry, and as fresh ones could not be procured that day, a blister was applied to the spine, its whole length, beginning at the withers and ending at the croup ; drenches and clysters repeated, but the quantity of opium was diminished.

On the 25th, the pulse about fifty-five beats in the minute, and the breathing pretty calm in the morning, and the blister operated well. In t' afternoon she lay down but could not rise again of herself; she 7 much, which increased the spasms, and hurried the pulse to 
about one hundred beats in the minute, with great acceleration of respiration; sufficient hands were got to raise her, and she was got up and slung; drenches repeated, and also the antispasmodic clyster.

On the 26 th, the pulse about fifty-five beats in the minute; the respiration considerably easier; the spasms of the muscles greatly abated; drenches and clysters as on the preceding day.

On the 27 th, the pulse about fifty beats in the minute, and the breathing calm in the morning; but in the evening the pulse about sixty-seven beats in the minute, and respiration quickened; there was some degree of restlessness; drenches repeated, but the quantity of opium was diminished; the bowels inclining to be costive, a laxative clyster was administered.

On the 28th, the pulse about fifty beats in the minute; the respiration easy; the jaws considerably more open, and the muscular system much more relaxed; the antispasmodic drenches and clysters repeated.

On the 29th, the pulse about fifty beats in the minute; the breathing easy in the morning; but in the evening the pulse became hurried to about eighty beats in the minute, and respiration much accelerated; the bleeding was repeated, and about five pints were drawn from the jugular vein. Upon letting it stand to coagulate, it exhibited a coat of size of a buff colour, about one inch thick, which was of a more tough consistence than the blood that had been previously drawn.

On the 30 th, the pulse about sixty beats in the minute, and the respiration not so much accelerated; the bowels becoming costive, and when the excrements were evacuated, a quantity of thickened mucus was discharged with them; therefore, the following opening drench was given, and an emollient clyster was likewise administered.

\section{Opening Drench.}

1 Pint cold drawn Linseed Oil

to $\frac{1}{2}$ Treacle

1 Gill Oatmeal Gruel 
On the 31 st, the pulse about forty seven beats in the minute; the breathing quite calm; bowels open ; the mare has now acquired a great use of the muscles, and can bend her neck and back, looks round in the stall, and moves pretty actively from side to side; the nose is not near so much thrown out from the chest; the nostrils not so much expanded; she moves her ears backwards and forwards; and upon elevating the head, the membrana nictitans does not cover near so much of the ball of the eye; tail not near so much elevated, and the shaking of it greatly subsided; she has so far recovered the use of her hinder extremities, that if her back is touched where she was blistered, she kicks very powerfully; and her jaws are so much opened that a ball might be administered with the hand.

On the 1st of April, the pulse about 55 beats in the minute; the breathing calm; the opening drench having done operating, the antispasmodic medicine, combined with the antimonial, was again administered, as likewise the antispasmodic clyster, and continued until the 9th, when the mare was quite free from the complaint.

Some debility remaining, tonics, combined with cordials, were administered, which, together with a generous diet, good dressing, and moderate cloathing, regular and moderate exercise, about half an hour or an hour every day, soon restored the strength of the system.

The quantity of crude opium administered during the course of the , disease was 315 . 
CASE XXII.-March 14th, 1818.

IDIOPATHIC.

This was the case of a colt, four years old, and about fourteen hands high, the property of Mr Davidson, of Crawcrook, about eight miles from Newcastle.

On examining this colt, the symptoms that appeared were a spasmodic affection of the muscles of the jaw, head, neck, back, hinder extremities, and abdomen; the pulse about sixty-five beats in the minute; the respiration a good deal accelerated; the nose thrown out from the chest ; the nostrils expanded ; the ears erect ; and upon elevating the head, the membrana nictitans covered great part of the ball of the eye; great stiffness of the vertebræ of the neck and back; the jaws were considerably shut, but not so but that medicine might be administered as a drench with a small horn; the bowels were costive, and the secretion of urine diminished.

This colt was observed to have a stiffness of his body a few days previous to the proprietor consulting me about him, and during that time, he said he had been twice bled, and the first time he was bled, about two quarts were drawn from the jugular vein, and upon letting it stand to coagulate, he observed it exhibited a thickish coat of size of a buff colour, but the blood was not of that tough or firm consistence that we generally find in most acute inflammatory cases; about four days afterwards the bleeding was repeated, and about three pints of blood were drawn, which exhibited the same quantity of size, and was of the same consistence.

Having taken the case into consideration, the purgative drench and emollient clyster No. 3, were administered. 
The liniment was applied over the muscles of the jaw, head, neck, and back, and the parts covered with sheep skins, which soon induced a copious perspiration.

On the 15th, the jaws were not more shut; the purgative not operating in the morning, another emollient clyster was given, and in the evening the purge began to operate: he is perspiring under the sheep skins.

On the 16 th, the pulse about sixty beats in the minute; respiration hurried; jaws not more shut; the purgative operating freely; he is in a perspiration under the sheep skins; no medicine given this day.

On the 17th, the pulse and respiration much about the same as yesterday; jaws not more shut; the purgative drench having done operating, the antispasmodic medicine was administered, and the drench and clyster No. 3, were given in the manner I have pointed out: a copious perspiration is going on under the sheep skins.

On the 18th, the pulse about sixty-five beats in the minute, with some irregularity; the breathing considerably hurried; about five pints of blood were drawn from the jugular vein, and upon letting it stand to coagulate, it exhibited a thick coat of size which appeared rather of a more tough consistence than the blood that had been drawn a few days previous; he is in a copious perspiration under the sheep skins; drenches and clysters repeated.

On the 19th, the pulse about seventy beats in the minute; respiration much accelerated; the jaws not more shut; the bleeding was repeated, and about five pints of blood were drawn from the jugular vein, which did not exhibit so much size nor yet was it so tough as the blood that was drawn yesterday; a copious perspiration is still going on under the sheep skins; drenches and clysters continued.

On the 20th, the pulse about sixty beats in the minute; respiration hurried; there is some relaxation in the muscular system; drenches and clysters repeated, and continued every day until the 24th, during this time he has gradually acquired more action of the muscles; and a free perspiration has been going on under the sheep skins. 
On the 25th, the pulse about fifty beats in the minute; respiration pretty calm; the sheep skins becoming dry, and not being able to procure more that day, a blister was applied the whole length of the spine; the bowels getting costive, another purgative drench and emollient clyster were given.

On the 26th, the symptoms still favourable; the purge operating well, as also the blister; no medicine given this day.

On the $27 \mathrm{th}$, the pulse about fifty beats in the minute; respiration calm, and the colt seemed quite composed; the physic having done operating, the antispasmodic medicine was again administered as before; jaws more open.

On the 28th, the symptoms still favourable; drenches and clysters repeated.

On the 29th, the drenches and clyters repeated; the pulse and respiration considerably more hurried; he appears restless from the effects of the opium.

On the 30th, he is not so restless; the quantity of opium in the drenches and clysters is moderated; pulse and respiration not so much hurried.

On the 31 st, the pulse about fifty-five beats in the minute; the breathing a little hurrried; a considerable relaxation in the muscular system has taken place; drenches and clysters repeated as on the 28th, and continued until the 4th of April, during which time he was in a gradual way of recovery.

On the 5th, the pulse about fifty beats in the minute; respiration easy; jaws still more open; the bowels inclining to be costive, another purgative drench and emollient clyster were given.

On the 6th, the purgative operating well, symptoms favourable.

On the 7 th, the purging being subsided, the antispasmodic medicine was again used, and continued in the manner I have pointed out until the 13th, when the animal had acquired a great deal more use of the muscular system. 
On the 14th, the bowels being again constipated, another purgative drench and emollient clyster were given; the pulse about forty-five beats in the minute; breathing pretty calm; the nose not near so much thrown out from the chest; the nostrils very little expanded; ears not near so erect, he moves them backwards and forwards; and on elevating his head, the membrana nictitans covered very little of the ball of the eye; he has considerably more motion of the vertebræ of the neck and back.

On the 15th, the purgative operated well, symptoms favourable.

On the 16th, the purging being subsided, the antispasmodic medicine was again had recourse to, and continued in the manner I have pointed out until the 20th, when the colt was cured of the complaint.

The quantity of crude opium administered during the course of the disease was 31635 .

CASE XXIII.-March 31st, 1818.

ORIGINATING FROM THE AMPUTATION OF THE TAIL.

This was the case of a colt of the draught kind, about three years old, and nearly sixteen hands high, the property of Mr Summerbell, of Milkup, near Blagdon, about eight miles from Newcastle.

This colt had been docked about three weeks previous to tetanic symptoms commencing, and the wound had very little discharge, and was of a thin serous nature.

His jaws were not so much shut as any of the preceding cases, although the muscles of the head, neck, back, and hinder extremities, were spasmodically affected; the pulse about forty-seven beats in the 


\section{5}

minute; the respiration a little hurried; nose thrown out from the chest; nostrils expanded; ears erect; and on elevating the head the membrana nictitans covered great part of the ball of the eye; a stiffness of the vertebrx of the neck and back; and a stiffness, with great straddling, of the hinder extremities; tail elevated, and upon the least fatigue a shaking of it.

Having examined the case, the treatment consisted, in the first place, in opening the intestines, and afterwards in the free use of the antispasmodic medicine, administered in the manner I have pointed out.

The liniment was applied over the muscles of the jaw, head, neck, and back, and the parts covered with sheep skins, which was soon followed by a copious perspiration.

The internal treatment was continued until the 15th of April, when the colt was cured of the complaint.

The spasmodic affection of the muscles was sometimes more severe than at other times, which caused some variation of the pulse and respiration: there was a constant perspiration going on under the sheep skins, which were renewed as they became dry or offensive in smell.

The local treatment to the wound in the tail, was a fomentation of warm water, and dressings of digestive ointment every day, which, combined with the effect of the internal treatment, soon brought the wound into a healing state, and it continued so until it got well.

The quantity of crude opium administered during the course of the disease was $\zeta 5,34$.

N. B. In this case there was no amputation of the injured part in the tail, nor incisions, nor application of caustic, and yet the case was successfully treated. 


\section{CASE XXIV.—May 22nd, 1818.}

ORIGINATING FROM CASTRATION, COMMONLY CAILED GELDING.

This was the case of a thorough-bred colt, three years old, and about fifteen hands high, the property of Sir Matthew White Ridley, Bart. of Blagdon.

This colt had been castrated about three weeks previous to tetanic symptoms commencing, and the wound was considerably healed when those symptoms came on, but there was very little discharge from it.

On examining the case, the symptoms that appeared were a spasmodic affection of the muscles of the jaw, head, neck, back, and abdomen, which caused them to become rigidly contracted, and the abdomen to be much drawn in ; on elevating the head, the membrana nictitans covered great part of the ball of the eye; the nose thrown much out from the chest; the nostrils greatly expanded; the ears erect; a great stiffness of the vertebræ of the neck and back; the bowels were constipated, and the secretion of urine diminished; the pulse and respiration not much altered, but upon the least fatigue, the spasms were increased, which caused the pulse to become hurried and irregular, and the breathing much accelerated, with a shaking of the tail; his tongue was a little swelled; his jaws were considerably shut, but not so but that medicine might be administered with a small horn.

Having examined the case, the purgative drench No. 2, and emollient clyster No. 2, were administered.

'The liniment was applied over the muscles of the jaw, head, neck, and back, and the parts covered with sheep skins, which soon brought on a copious perspiration.

On the 23d, the jaws not more shut; pulse about fifty beats in the minute, with some irregularity; respiration increased: the purge not 
operating in the morning, another emollient clyster was given to facilitate its action, which had the desired effect, and it operated briskly all that day and night; he perspires under the sheep skins.

On the 24th, the pulse about fifty-five beats in the minute; mouth hot, with some degree of fever; respiration considerably hurried; the purging nearly subsided; his jaws are not more shut; he perspires freely under the sheep skins; about two quarts of blood were drawn from the jugular vein, which, upon coagulating, exhibited a thick coat of size, of a buff colour, and rather of a tough consistence.

On the 25th, the pulse about sixty beats in the minute, with some irregularity; the breathing much accelerated, although the jaws are not more closed; the purging having subsided, the antispasmodic drench and clyster No. 2 were administered morning and evening, in the manner I have pointed out; he perspires freely under the sheep skins.

On the 26th, the pulse about sixty-four beats in the minute, with some irregularity; respiration much hurried; jaws not more shut; a constant perspiration is going on under the sheep skins; the antispasmodic drenches and clysters repeated.

On the 27th, the symptoms stationary; the drenches and clysters repeated.

On the 28th, the pulse about fifty-four beats in the minute; respiration a little hurried; the spasmodic affection of the muscles much about the same; he perspires copiously under the sheep skins: drenches and clysters continued.

On the 29th, the pulse and respiration much about the same as yesterday, as likewise the spasms of the muscles; he now begins to tire of the drenches, and turns very resolute, which causes great part of them to be lost, therefore a drachm or two of opium powdered is given him among his mash, two three times a day, which he eats to make up for that part of the drench which is lost; he is in a copious perspiration under the sheep skins; clysters repeated.

On the 30 th, symptoms stationary. 
On the 31 st, the pulse about fifty beats in the minute; respiration hurried; jaws rather more open; a copious perspiration is going on under the sheep skins; the antispasmodic drenches, powder, and clysters repeated.

Some swellings came on about his extremities; his neck and back were likewise a good deal excoriated with the heat of the skins and the effect of the liniment, to relieve which the parts were bathed with a saturnine lotion, and rubbed with a saturnine ointment, and the woolly part of the sheep skins was well wet with the lotion made warm, and applied next the horse's skin where it was excoriated.

On the 1st of June, the pulse about fifty beats in the minute; respiration a little hurried; jaws much about the same as yesterday; drenches, clysters, and powder continued; he is in a copious perspiration under the sheep skins; the neck and back not so much excoriated; and the swellings in the extremities a good deal subsided.

On the 2nd, the pulse about forty-eight beats in the minute; the breathing hurried; jaws more open; he perspires freely under the sheep skins; the swellings in the extremities greatly reduced; and the neck and back not near so much excoriated; drenches and clysters continued.

On the 3rd, the pulse and respiration much about the same as on the preceding day; the spasmodic affection of the muscular system not so great; he is in a constant perspiration; drenches and clysters repeated.

On the 4th, the pulse about forty-eight beats in the minute; respiration pretty calm; he perspires freely under the sheep skins: his bowels becoming costive, another purgative drench and emollient clyster were administered.

On the 5 th, the pulse and respiration much about the same as yesterday; the purge operating well ; the swellings in the extremities nearly gone, and the parts on the neck and back that were excoriated quite well ; no medicine administered this day; he perspires under the sheep skins. 
On the 6th, symptoms still favourable; the purgative drench having done operating, the antispasmodic medicine was again resorted to, in the manner I have pointed out; he is in a copious perspiration under the sheep skins.

On the 7 th, symptoms favourable; the antispasmodic medicine repeated; he is in a constant perspiration under the sheep skins.

On the 8th, the pulse about forty beats in the minute; respiration easy; the spasmodic affection of the muscles-greatly diminished, as the jaws could be got considerably more open; his nose not-so much thrown out from his chest; nostrils not near so much expanded; the vertebræ of the neck and back not near so stiff; he perspires under the sheep skins: drenches and clysters repeated, and continued until the 12th, when the opium made him a little restless, although the spasms of the muscles. were still greatly abated.

On the 13th, he is not so restless; the antispasmodic drenches and clysters repeated, but the quantity of opium is moderated.

On the 14th, the pulse about thirty-three beats in the minute, which is about seven pulsations below the natural standard; respiration not the least disturbed; his jaws might be got open nearly as far as in the healthy state; he moves his whole body a great deal better; lies down and gets up of himself: drenches and clysters repeated as on the 11th, and continued until the 19th; during this time he has been in a gradual way of recovery, and his diet has been very liberal, and of the most nutritive kind; his pulse, on the 19th, was about forty-three beats in the minute; respiration very regular; on elevating his head, the membrana nictitans covers very little of the ball of the eye; nose not near so much thrown out from the chest; nostrils very little expanded; he moves his ears backwards and forwards.

His bowels getting costive, another purge and emollient clyster were administered, and the jaws could be got so far open, that the purge was given as a ball with the hand.

There was still a considerable stiffness about the vertebræ of the 2 F 
back, therefore a blister was applied to the spine, beginning at the withers, and ending at the croup.

On the 20th, the purge operated well, and continued to operate until the $21 \mathrm{st}$; the blister likewise operated well; no medicine given during the operation of the purge.

On the 22nd, the purging being subsided, the antispasmodic medicine was again given, and administered in the manner I have pointed out, until the 2nd of July, when the colt was cured of the complaint.

There being some debility remaining, a generous diet was continued, which, together with moderate exercise, soon restored the strength of the system.

The local treatment to the wound in the scrotum, was a dressing of warm digestive ointment every day, which, combined with the effect of the internal treatment, soon brought the wound into a healthy state, and it continued so until it was quite healed.

The quantity of crude opium administered in this case during the course of the disease was 315,34 .

N. B. In this case there were no incisions used to the wounded part in the scrotum, nor the application of caustic, and the case was treated successfully.

Now, it may be observed, that in all the cases of symptomatic tetanus which I have successfully treated, I have not had recourse to amputations, incisions, or caustics, to cut off the communication between the nerves of the injured part and their origin.

I never amptuated the injured part that gave rise to the disease but once, and that was in the case of a two years old filly that had tetanus from docking, and, as I have previously stated, the case was unsuccessfully treated.

Therefore, whatever may have been the success of M. Larry, the 


\section{1}

French surgeon, in dividing the nerves of the wounded part in symptomatic tetanus in the human subject in curing this disease, I must candidly observe, I am no advocate for such treatment in the horse; and I consider the success which I have met with in adopting a more mild mode of treatment justifies me in continuing the same plan.

And I am greatly inclined to think, that when tetanus is once produced from a wound, that the disease goes on independent of its cause, and that any local treatment avails nothing, unless constitutional means are used; as we very often find, that when tetanus is produced from a wound, that the wound may be healed before tetanic symptoms come on, and at that time there is neither inflammation, swelling, nor pain in the part. Such circumstances naturally induce one to think, that the amputation of a part, or incisions, or caustic, must avail little; and as the performance of an operation, or making incisions, or the application of caustic, must be attended with considerable pain, I consider it tends much to aggravate the complaint, by increasing the spasms.

Having given the history of several cases of tetanus in the horse, which were successfully treated, I shall now proceed to state a few cases of this disease that were unsuccessfully treated, at the same time I shall mention the morbid appearances I observed after death, on dissection. 


\section{CASE I.}

OF IDIOPATHIC TETANUS.

This was the case of a draught mare, the property of Mr Errington, carrier, near Heddon on the Wall, about eight miles from Newcastle.

On being called in to this case, the symptoms that appeared were a spasmodic affection of the muscles of the jaw, head, neck, back, hinder extremities, and abdomen, which caused them to become rigidly contracted; the pulse was hurried and irregular; respiration greatly accelerated; the nose thrown much out from the chest; the nostrils much expanded; the ears erect and immoveable; the head a little raised, and on elevating it a little more, the membrana nictitans covered much of the ball of the eye; the vertebræ of the neck and back were excessively stiff, owing to the rigid state of the muscles, as also were the hinder extremities, with great straddling; the tail was very much elevated, and there was a shaking of it; the jaws were so much shut that no medicine could be administered by the mouth; the tongue was swelled; the bowels were constipated, and the secretion of urine was diminished; she was much inclined to drink oatmeal gruel, but the difficulty in swallowing was so great, that she got little or none down, and when she attempted to drink, the spasms were inuch increased.

Having examined the case, about two quarts of blood were drawn from the jugular vein; a laxative clyster was administered, and after its operation, the antispasmodic clyster I have directed to be given when the jaws are completely locked, was administered, and repeated according to the violence of the spasms.

The liniment was applied over the muscles of the jaw, head, neck and back, and the parts covered with sheep skins, which soon brought on perspiration. 
The next day the spasms increased; the pulse and respiration became excessively quick, with a tremour of the whole system, and a violent convulsion coming on, put a period to her existence.

\section{MORBID APPEARANCES ON DISSECTION.}

On opening the abdomen or belly, the stomach and intestines exhibited an inflammatory appearance, with gangrenous marks; and on opening the large intestines, particularly the rectum, the freces were found very dry, black and hard, and adhering very strongly to their villous coat; the liver likewise had some marks of inflammation.

On opening the thorax or chest, the lungs were found much inflamed, with gangrenous marks; and the membrane that lines the chest, called the pleura, had a gangrenous appearance.

The membrane that lines the trachea and nose had an inflammatory appearance.

And the mucus membrane of the pharynx likewise exhibited an inflammatory appearance.

On opening the cranium or skull, the membranes that cover the brain, called the dura and pia mater, exhibited some marks of inflammation, with the blood vessels greatly distended.

On opening the medullary canal of the cervical vertebræ, the coverings of the medulla spinalis, or spinal marrow, which in fact are a continuation of the same membranes that cover the brain, were found to have marks of inflammation.

On opening the medullary canal of the dorsal vertebræ, the membranes that cover the spinal marrow were found highly inflamed, and the spinal marrow itself had a darker appearance. 


\section{CASE II.}

OF IDIOPATHIC TETANUS.

This was the case of an aged horse of the draught kind, the property of Mr Coulson, of Bullock Steads, about four miles from Newcastle.

On examining this case, the horse had all the symptoms I have before described, to a great height, with his jaws so much shut, that no medicine could be administered by the mouth.

Having examined the case, the treatment pursued was similar to that used in the preceding case.

He died on the third day.

\section{MORBID APPEARANCES ON DISSECTION.}

On opening the abdomen, the stomach and intestines were found to be inflamed, as likewise the liver.

The mucus membrane of the pharynx, and that of the larynx, were found to have marks of inflammation.

On opening the cranium, the dura and pia mater exhibited marks of inflammation, with the blood vessels much distended.

On examining the contents of the medullary canal of the cervical vertebræ, the coverings of the medulla spinalis, or spinal marrow, had some slight marks of inflammation.

But of that part of it which enters the canal of the spina dorsi, the coverings exhibited a most violent inflammation to its whole extent, and the nervous substance itself had a darker tinge than in the natural state. 


\section{CASE I.}

OF SYMPTOMATIC, OR TETANUS ORIGINATING FROM A WOUND.

This was the case of a two years old colt, which had the complaint from the amputation of the tail : he was the property of $\mathrm{Mr}$ Hewison, of Benton Place, near Newcastle.

On being called in to this case, the colt had all the symptoms of the preceding cases, with his jaws so close, that no medicine could be administered by the mouth.

The treatment was similar to the preceding cases.

He died on the third day.

\section{MORBID APPEARANCES ON DISSECTION.}

On examining the viscera of the abdomen, the stomach and intestines were found to be highly inflamed; the liver likewise had some marks of inflammation.

- On examining the thoracic viscera, the lungs exhibited a very inflammatory appearance, with gangrenous marks; the pleura likewise had marks of inflammation.

On examining the contents of the cranium, the dura and pia mater showed some marks of inflammation, with great distention of the blood vessels ; on cutting into the substance of the brain, there was some effusion of water in the ventricles.

On examining the contents of the medullary canal, the covering of the medulla spinalis was found to be inflamed; but of that part of it which runs along the canal of the spina dorsi, or dorsal vertebræ, the inflammation was found to be more violent, and the nervous substance itself showed a more dark tinge. 


\section{6}

\section{CASE II.}

OF SYMPTOMATIC TETANUS.

This was the case of a two years old filly, which had the disease from the amputation of the tail : she was the property of $\mathrm{Mr}$ Arthur, of Newburn Hill Head, about four miles from Newcastle.

The symptoms were similar to the preceding cases, and the treatment was also similar.

The filly died on the fourth day.

$$
\text { MORBID APPEARANCES ON DISSECTION. }
$$

On inspecting the contents of the abdomen, the stomach was found to have considerable marks of inflammation of the external coat, but the internal coat was very little affected; the intestines exhibited great marks of inflammation in places, throughout their whole extent, attended with gangrene.

The liver likewise shewed marks of inflammation, with a gangrenous appearance.

On inspecting the contents of the thorax, the lungs were found to be highly inflamed.

On inspecting the contents of the cranium, the dura and pia mater shewed marks of inflammation, with the blood vessels greatly distended.

On inspecting the contents of the medullary canal of the cervical vertebra, the coverings of the medulla spinalis exhibited some marks of inflammation.

But on examining the coverings of the medulla spinalis, which enters the canal of the spina dorsi, they were found to be highly inflamed, and the nervous substance itself to have a darker tinge. 
And besides those appearances, within the skull, medullary canal, thorax, and abdomen, I observed the pharynx and oesophagus to have an inflammatory appearance.

The internal part of the trachea likewise had marks of inflammation.

Now, it appears to me, as I have already stated, from the dissections I have made, that this disorder is seated in the spinal canal, affecting the medulla spinalis and its coverings; and in proportion as those parts, so essential to life, take on a morbid action, in proportion does the disease make a slow or a rapid progress. This will depend greatly upon the predisposition in the system to be acted upon.

And I think that the morbid state of the viscera of the thorax, and of those of the abdomen, in a general way, is the effect of the disease, from sympathy or consent of parts, and may be considered as a secondary symptom, after the complaint has made some progress in the nervous system.

But there is no doubt that the inflammation and ulceration, which are brought on in the stomach by that species of worms termed bots, sometimes give rise to the disease; but when the complaint originates either from an affection of the extremities or any of the viscera of the abdomen, the effect is the same upon the contents of the spinal canal, and ultimately causes a spasmodic affection of the muscular system. How ever, when the complaint originates from the above cause, viz. an ulceration of the stomach, it generally, as I have already had occasion to observe, makes a very rapid progress, and the danger must always be considered in proportion to the violence of the attack.

When tetanus takes place in the horse, the spasmodic affection of the muscular system does not abate quickly; it is often a week or ten days, or even longer, before any considerable relaxation can be observed in the muscles; and it may be considered a favourable appearance if the disease can be kept stationary forty-eight hours, when the jaws are not 
so much shut but that a medicine may be given as a drench with a small horn ; and it ought to stimulate the practitioner to exert himself in the treatment of the case, which certainly requires as much attention, judgment, and medicine, as any disorder which is incident to the horse.

It also requires great attention on the part of the groom, in frequently offering the horse strong oatmeal gruel, thin bran mashes, milk, or any thing brought to a solution, which affords much nutriment; and when the jaws have not got so much closed as to prevent the power of mastication, a little good clover hay should frequently be offered him, as keeping the jaws in action tends greatly to retard the progress of the spasms; and considerable friction should frequently be used over the muscles of the jaw with the hand, and the head, neck, and back should always be kept well covered with sheep skins. Too much attention cannot be paid to these circumstances; and the animal should be kept in a stable moderately light, and should be disturbed as little as possible. 


\author{
$\boldsymbol{A}$ \\ PRACTICAL TREATISE \\ ON THE \\ EP I DEM I C D I SEASE, \\ or \\ CATARRHAL AFFECTION, \\ IN HORSES.
}




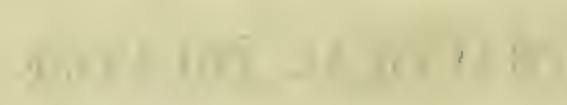

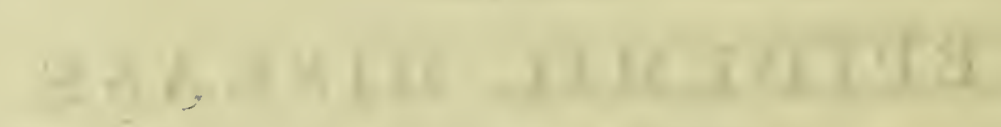

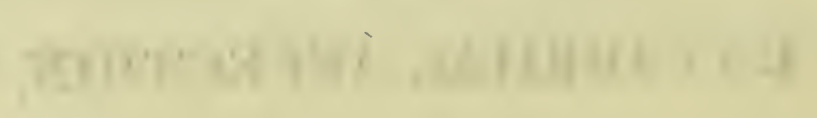

$$
\begin{aligned}
& \text { thented }
\end{aligned}
$$




\section{INTR ODUCTION.}

$W_{\text {I'тн respect to Epidemical Diseases, we frequently find the symptoms }}$ vary, according to the nature of the constitution, so that the disorder is often found to attack different parts of the body, and consequently requiring some little alteration in the mode of treatment.

An Epidemical Disease is a complaint that attacks many horses, at the same season, and in the same place, and is generally considered contagious. It often rages with great violence in many parts to a considerable extent.

The Epidemic we are going to treat of, generally assumes much the appearance of a common cold or catarhal affection.

Indeed, Catarrh arising from cold, and that from contagion, are in most respects so similar, that when this Epidemic rages, it is almost impossible to determine in a horse having symptoms of Catarrh, after exposure to cold, whether the disease proceeds from the one cause or the other; and generally, it requires, for the most part, the same mode of treatment for its cure.

There is this difference, however, to be observed, that Catarrh from contagion comes on with more cold shivering than the Catarrh arising from cold alone; and the former does also, not only sooner shew febrile symptoms, but to a more considerable degree.

As this is a subject of some importance, it may not be amiss to proceed in the same manner as we have done in treating of tetanus, - that is, in the first place, to mention what has been said by those authors who have had considerable practice, and have entered into a detailed account concerning this disease. 
I shall afterwards state my opinion concerning the cause, progress, and different terminations of the complaint, together with the mode of treatment for it.

Mr Gibson, in his Treatise on the Diseases of Horses, 1st. vol. 2nd edition, page 375, gives the following account of the Epidemic he attended :-

About the end of the year 1732, there was a very remarkable distemper of this kind among the horses:in London, and in several other parts of the kingdom; they were seized suddenly with a vehement dry sounding cough, which shook them so violently; that some of them were often ready to drop down with hard straining and want of breath; their throats were raw and sore; many of them had their kernells swelled, and painful to the touch. For the first two days most of them refused all manner of food, as well as water, and had so many other bad symptoms, that when this distemper first broke out, many were afraid of a mortality coming among them ; and indeed the only good sign they had, was the vehemence of their cough, which both kept their blood in motion, and speedily set them a running at the nose, which generally began the third day, and continued in so profuse a manner for five or six days, that some of them in that time discharged as much as two or three pails would hold of purulent matter, which however was generally of a laudable colour and good consistence.

While the running at their noses continued, they could not feed much, though their appetites were craving, because the matter mingled so much with their food, as to render it altogether disagreeable, so that. they lost their flesh exceedingly; but that loss of their flesh proved a benefit to them rather than a detriment, and as soon as the running abated, they eat voraciously and soon recovered their flesh. This distemper, though no ways mortal, yet was so very catching, that when any horse was seized with it, I observed those that stood on each hand of him were 


\section{3}

generally' affected as soon as he began to run at the nose; in the same manner as the small pox communicate the infection when they are upon the turn.

While this sickness lasted, above a hundred of the troop horses under my care, were seized with it. I always caused the sick horses to be removed from the sound, as soon as they were taken ill, and put by themselves as in an hospital; and in one troop of the Horse Grenadiers, I filled a stable of thirty-six standings, in three days, an infirmary of five standings, and another of eighteen standings, in three or four days more: nevertheless, all of them recovered in a short time. Also many gentlemen's horses'where I was concerned, did well, without any remaining taint from the distemper; and it was observable, that some who had been subject to a dry cough before this sickness, continued more free from it for some time afterwards, though I do not remember any of them were absolutely cured of this defect; notwithstanding their great purgation from the nose; which plainly sheweth me the difficulty of removing an obstinate dry cough, by the common and usual means of promoting a discharge that way. The horses which chiefly escaped the distemper, were those that had been in constant strong exercise, or full aged old horses, many of which were no ways infected, though very much exposed to it.

The method I followed in curing this malady was simple and easy ; for having observed by their dung and manner of staling, that neither the stomach, guts, nor kidnies were in any degree injured, but only their lungs and the glands about their throat very much stuffed, I ordered them as soon as they were seized, to be bled plentifully, which gave them a sensible relief; for at first many of them were feverish and very short breathed, and by somewhat emptying their vessels, helped the sooner to bring on the running at their noses, which in a horse, ansivers the same end as expectoration in a man; afterwards $I$ gave them soft balsamics mixed with detersives, which are always necessary for horses, because they require more pungent and stimulating medicines than men, their 
fibres being more strong and rigid, and therefore the following drinks were generally administered with good success.

One Handful of Coltsfoot

One ditto of Hyssop

One ditto of Camomile Flowers

$\zeta \frac{x}{2}$ Linseed

$\zeta \frac{x}{2}$ Garlic

$\zeta \frac{\pi}{2}$ Liquorice Root

$\xi \frac{x}{2}$ Saffron

Infused in two quarts of boiling water : one half for the morning, and the other half for the afternoon.

With these were given, balls made of the warm aromatic pectoral powders mixed with honey, balsam of sulphur, and oil of anniseeds; and in cases where the phlegm appeared to be more than ordinarily tough and viscid, a small portion of about $\zeta 4$ linseed oil was added to some of their drenches; and in some cases it was necessary to give about half a pint of white wine, with a few ounces of oxymel of squills. I did not perceive any of them costive, or very hot and feverish, after they took to run at their noses, otherwise it would have been also necessary to have administered emollient clysters ; and therefore, as soon as they looked lively, and eat up their allowance, which was chiefly scalded bran and hay, I left off the use of the medicines, and allowed them plenty of water, which had a good effect in thinning and diluting their blood, which was extremely sizy, and the cure was perfected by air and moderate exercise.

The continuance of this distemper among our horses was but short. It began in some places in the country, near London, about the middle of September, for I did not hear it was universal over the whole kingdom; and in London, it began in October, the weather being unusually foggy, but was quite over in about six weeks or two months, and made so swift 
a progress, that in the space of one week, there was scarce a stable without the infection. Some horses were perfectly recovered in a week or ten days, some in a fortnight, and few continued under it longer than three weeks or a month before they recovered their flesh and their usual strength and vigour; and I observed scarce any did amiss, except those that had been unskilfully treated by cleaning and syringing their noses with sharp stimulating things, which by irritating those parts too much, brought on a continued running of purulent matter on some, that could not be stopped afterwards, with swellings under their jaws, which ended in a waste and rottenness; whereas if they had been left more to nature, scarce any of them would have done amiss. But I have known the same thing happen in a common cold, and in the strangles especially, when they have met with the like treatment, as will be shewn more fully when I come to treat of those distempers.

About two years after this, viz. in 1734, another epidemical distemper happened in the spring, that proved more fatal than this, though by reason of its short continuance, it was much less taken notice of than the first, for many horses recovered so far as to be out danger in two or three days. In the one, the horses coughed so vehemently in the streets, and many of the hackney coach horses and cart horses that were obliged to work, had their noses in so nasty a condition, and so much exposed to open view, that they could not avoid being seen by every body. But this other distemper was not so universally talked of, though vast numbers -were seized with it, and some died suddenly of it. In one week I had nearly a hundred of the Guard and Grenadier horses, besides many belonging to gentlemen, taken so bad, and with such violent symptoms, that I was at first afraid of its proving very dangerous, but of the great numbers that were under my care not one did amiss.

They were seized suddenly with a hot burning fever, and their flesh apparently seemed so sore and tender, that they could scarce bear to be touched; they were generally costive, staled but little, and that with pain and straining, and of a very high colour; they refused all manner of 
food, and were so extremely sick, that they would not drink, neither did I perceive any of them offer to lie down till their distemper came to a crisis; upon treating them with cooling and opening medicines, with plentiful bleeding, they generally recovered.

I was confirmed in this method by several symptoms that appeared upon the turn of the distemper; some of them having very hot and inflamed eruptions, which broke out in several parts, with blisters resembling the St Anthony's fire: those that came to maturity appeared generally on the inside of the arm or fore leg, near the elbow, or towards the hock; and some of them had several large bags of water, which gathered on the sides of their bellies, or towards their flanks, near the inguinal glands, which the farriers called a water farcy, but indeed was the effect of a very hot inflamed blood. Some had been costive before this distemper seized them, for their dung was extremely hard and black.

In this case soft and oily clysters were made use of to relax their bowels, and in some the bleeding was repeated; cooling infusions, with sal prunella, and cream of tartar, saffron, and such like things, were also given to open them, both by dung and urine, and by that means to abate the heat and effervescence of their blood, which not only took off their fevers, but caused the critical discharges from the boils, which at first had but a very indifferent aspect, to digest into good matter, without leaving any taint behind them, so that none of the horses that were treated in this manner did amiss; and where some died in the hands of unskilful persons, it was generally owing to their giving them hot inflaming things under the notion of cordials, and cloying them with sugar sops before their fevers were abated, and their stomachs in a condition to receive food; and, indeed, this is the true reason why so many horses miscarry in fevers, because most people are apt to force them to feed by administering food with a horn, when it is altogether improper, neglecting to bleed sufficiently in the beginning, giving hot medicines inwardly, with wines, and other spiritous liquors, which only add fuel to the fire; which things are always pernicious in inflammatory distempers, especially to horses, that are used to a simple diet. 
This distemper did not continue in its full force in London above three weeks or a month; and those that were seized about the latter end of that time, had it more favourably, and required little more than bleeding; those that looked any ways surfeited were purged, and had antimonial powders given them, which generally perfected their cure; and some were sent to the salt marshes, or other spring grass, the sickness happening just before the grass season.

I have known single horses seized with the same symptoms at other times, when the distemper was neither infectious nor epidemical; and these were always successfully relieved with bleeding, and other evacuations, especially with diuretics and diluters, giving them plenty of water gruel, or white water.

Mr Osmer, in his Treatise on the Diseases of Horses, 3rd edition, page 131, gives the following account of the epidemical disease, that occurred in his time, in the year 1750 :-

He says, from the observations I have made on the various diseases of horses for many years, and from the nature, sameness, and simplicity of their food, I have been heretofore inclined to think that those animals were not subject to malignant fevers as men are.

But the epidemical disease that has occassionally raged among them some few years past, and which still shews itself at times, has taught me the contrary.

In this disease, which I own is new to me, they are seized with a variety of symptoms that require very different treatment. On this account particular regard is to be had to the symptoms attending it, as the proper criterion or direction how you are to act, and with such attention, the methods here directed will seldom fail to answer your purpose.

This disease begins in general with great debility of the limbs, and many horses are so much weakened as to reel and stagger about when led along, and that almost as soon as they are taken ill. 
It is attended too, in general, with loss of appetite, a dry short cough; their eyes become suddenly dim, and glazed, and lifeless; and they are particularly free from all inclination to drink.

But there being, I think, five different classes or degrees of this disease, I shall endeavour to distinguish them as clearly and concisely as I can, for the information of the reader.

1 st. Besides the symptoms already mentioned, some of them are taken with a coldness of the external parts : these are chiefly affected with a weakness behind; they have no fever or token of inflammation; and there seems to be a tendency towards a general stagnation of the fluids.

2ndly. Amongst others are great tokens of inflammation; the fever is high, and the external parts are hot and burning; these are most affected in their head and sight.

3rdly. In others, the disease falls on the throat, with manifest tokens of great soreness; these seldom have any feverish heat, are not so much affected in their limbs or sight as some are; their appetite, too, and inclination to eat and drink seems better than in those of the first and second class. They are in general miserably reduced before this soreness goes off, though their falling away ought not to be imputed solely to their fasting, because almost all horses in this disease, that have it much, are reduced in a very few days, almost to the degree and leanness of a dog horse.

4thly. Others there are which are seized at first with a cough only, and shew little or no symptoms of illness, nor any unusual heat or cold: these in general soon have a discharge of a serous fluid from the nostrils, as in the inflammatory fever; these are least affected, and recover soonest of any, and frequently, too, without any assistance at all.

5thly. In others there appears, soon after the cough, the phlegmon or boil in some part of the head or body; in some of whom the vital heat is sufficient, without any art or assistance, speedily to bring on a critical imposthumation; in others the vital heat is so little that their lives 
are manifestly endangered before any imposthumation can be obtainèd, even with the assistance of art.

But when we talk about vital heat, it may perhaps be more proper to say, that the different progress of the critical boil in different horses, is owing to the difference of their fluids, and the more brisk or languid circulation thereof, as they happen to be more or less viscid.

If this be not the true cause, from whence, I pray you, arise the two extreme sensations of cold and heat in different horses affected with the same epidemical disease? It may be observed too, that those horses are most affected with cold and shivering in whose blood is found the least serum.

Having described the different symptoms of this disease, I shall subjoin the proper methods of treatment.

For those of the first class, bleeding is particularly found to do harm; and if it be done in any great quantity, the horse soon drops, a violent palpitation of the heart succeeds, and death most probably follows soon. The blood of these when taken away, and exposed to the air twenty-four hours, has not a drop of serum in it, but remains a coagulated sizy mass; nor do these, when costive, bear the evacuations by clysters with advantage, but rather with the contrary effect; and rowels also seem to do harm to horses under the circumstances here described. For those, the following medicine will generally produce in a few days the desired effect :-

$\zeta 1$ Crude Sal Ammoniac

31 Nitre

$3 \frac{x}{2}$ Castile Soap

32 Camphor, rubbed with a little cold drawn Linseed Oil

Mucilage of Gum Arabic, a sufficient quantity to make it the consistence of a ball for one dose, and give it three times a day. 
But if on the use of these medicines for a few days, the urinary secretions appear not to be enlarged, or the symptoms do not abate, then the quantity of nitre and sal ammoniac ought to be increased according to your horse's size, strength, and habit of body.

His proper food, at the beginning, is hay and scalded bran, if he will eat it; his drink should be moderately warm, and whatever he likes best, and as much as he chooses.

By the continuance of this medicine for a few days, as the stagnated fluids become thinner, the bodily warmth and strength increases; and soon after as the urinary secretions appear to be augmented, he begins to drink freely, upon which he generally becomes suddenly well, recovers his limbs and his appetite at once, and is free from all complaints but his cough, which perhaps leaves him not entirely till he has recovered his flesh.

When those symptoms appear, and the horse's appetite is good, leave off these medicines, lest the fluids become too much attenuated, and so a dropsy ensue, and all other medicines too, for nature now will, in general, best do her own work without art. Bran and scalded oats together, are now his proper food. During his whole illness, he should not be taken out of the stable on any account, nor afterwards, till he has recovered his flesh and been purged, which most probably he will not be able to bear for a considerable time; and as in the inflammatory fever, keeping the horse cool is very beneficial, so in this disease keeping him moderately warm with good rubbing, if he is inclined to be cold and stiff in his motions, is very necessary.

For those of the second class, bleeding, in a moderate quantity, is very beneficial, more especially at the beginning of the disease: here evacuations too, by clysters, will be found of use, and the medicines before directed should be given in like manner. If the heat and fever continue twelve hours, and the vessels on the membranes about the eye appear red, inflamed, and distended, a second bleeding, in a moderate quantity, may be necessary, and will be generally sufficient; but in this 
and future blood lettings, you are to be directed solely by the tokens of inflammation, remembering that the horse in this disease can bear the loss only of a small quantity at one time, respect being had also to his size and strength.

The blood in horses, with these symptoms, is very sizy, of a buff colour, and has but little serum in it when it has stood for a time. In this case, therefore, rowels will be found improper, because the lymph and finer fluids are hereby discharged, of which there appears to be already a deficiency, or rather some degree of stagnation in the circulation thereof:

For such as are affected with a soreness of the throat, bleeding, clysters, and rowels, are all improper, unless there be manifest tokens of fever and inflammation; in either case the medicine before directed is proper : these will eat bread and water gruel made thin.

For those which have a discharge at the nostrils, bleeding is highly prejudicial, because this is an effort of nature, and is a kind of crisis to get rid of the disease. Clysters here are seldom wanted, because the horse has, in these circumstances, generally an appetite to eat a quantity of scalded bran sufficient to keep his body open; but rowels here, with the medicines before directed, help to assist nature in unloading the surcharged vessels, and getting rid of the extravasated fluids : for though many horses do well under these circumstances, by the help of nature alone, without any assistance, yet I have seen many instances, both in this fever, as well as in the inflammatory, where for want of these artificial helps, the extravasated fluid discharged at the nostrils, has been of so sharp a nature as to corrode the soft membrane, which lines the internal cavity of the nose, and there produce ulcers, which lying out of the reach of topical applications, often turn to the real glanders.

For the fifth class, a poultice of bread and milk, with lard, should be applied twice a day to the boil, and it might reasonably be deemed very proper, where the pulse is low, the circulation languid, and the external parts cold, to give the horse some warm alexipharmic medicines 
to enable nature to bring on the work of suppuration. But I have found in several instances, that such medicines are, on this occasion, of no account at all; for when I have perceived the boil to stand still many days, and not advance in the least to maturation, and the horse has been in manifest danger, I have left off the use of. warm medicines, and have given the medicines before directed, with camphor, thinking by this means to thin the fluids, and so to carry off the disease by the other common secretory ducts, and this has succeeded; but what is remarkable, and I believe, contrary to speculative reasoning, the phlegmon or boil, which before stood still and would not advance at all, has soon after, when the urinary secretions have been enlarged, come to suppuration ; and though this may appear somewhat strange to the learned, yet it ought to be remembered, that bleeding has occasionally brought the phlegmon in men to suppuration, which before made no advances thereunto.

By these different methods I have saved the lives of many horses, having lost a few only, out of a great number, though I am ready to acknowledge, that when this disease first made its.appearance, I endangered the lives of many; but this last circumstance has, I dare say, never happened to any of the farriers from the use of their remedies, because they have approved receipts to cure all diseases without the trouble of reasoning about them.

Mr James White, of Exeter, in his Treatise on Veterinary Medicine, 4th vol. page 158, makes the following observations concerning the Epidemical Disease in horses.

He states, that the first epidemic he had an opportunity of seeing, occurred in the summer of 1798, when, in some parts of that country, it proved very destructive, generally however, there is reason to believe, from its being improperly treated.

The most common symptoms of the disease, were a cough, dullness of the eyes, and disinclination for food or water: seldom, however, was 
the appetite for either altogether lost. These symptoms were soon followed by a discharge from the nostrils, and soreness of the throat, causing more or less difficulty in swallowing, sometimes to such a degree, that in attempting to drink, the water would return through the nostrils, and some of the horse's food might be seen mixed with the matter discharged from the nose. This was more conspicuous when grass was given to the horse, as the discharge would then be of a greenish colour.

Sometimes a horse would appear extremely weak nearly at the commencement of the disorder; and almost in every case the strength declined very quickly: there was also, in general, a proportionate loss of flesh.

When called in at the first appearance of the disease, I generally, says he, found it necessary to bleed, sometimes freely, that is, to the extent of a gallon: this was thought particularly necessary when the horse breathed quickly, which might be seen by the motion of the flanks and nostrils; had a quick pulse, and the inner surface of the upper eye-lid was unusually red. If in such cases the above symptoms had not abated much in six or eight hours, and particularly if the blood that had been drawn was sizy, that is, if its surface was of a yellowish or buff colour, the bleeding was repeated. But this was not often found necessary. If the bowels were rather costive, a mild laxative was given and a clyster; but when these did not appear necessary, nitre was given morning and evening.

In cases where there was such soreness of the throat as to cause difficulty in swallowing, no medicine was exhibited unless there were symptoms which urgently demanded, and then only in a liquid form. To relieve the soreness of the throat, blistering ointment was applied under the ears and throat; a rowel under the jaw was also tried with the same view, and found useful ; blistering, however, appeared to be the most active remedy, though it sometimes proved inconvenient from the horse 
rubbing the blistered part against the manger ; when considerable weakness was obseived, the horse was freely supplied with oatmeal gruel or malt mashes; if the throat was not sore, tonic and cordial medicines were given. It is necessary here to observe, that it is seldom, if ever proper, to give cordials or tonics at the commencement of the disease, and even when they appear proper at a later period, it should first be ascertained that there are no inflammatory symptoms; nor should the use of these ever be persisted in when they appear to cause uneasiness in the horse, to diminish the appetite, or increase the frequency of the pulse.

We generally find, that during the spring and the early part of summer, a Catarrhal Disease is very common, particularly among young horses, which has some resemblance to that just described.

$\mathrm{Mr}$ White then gives an account of the Epidemic that occurred in the year 1815 .

He observes, that the most serious epidemic which has occurred for several years to horses, made its appearance about the latter end of April, in the year 1815, and during the months of May and June, raged with great violence in many places. Though the symptoms have been alarming, and much inconvenience has been suffered from the suspension of the animal's labour, and the expence of medical attendance, it does not appear to have destroyed many horses, while in others its fatality has been more considerable; but in the metropolis it is said to have been highly destructive.

Though much has been written on the Epidemical Diseases of Cattle, and many conjectures suggested as to their origin or causes, it does not appear that much light has been thrown upon the subject. It must be allowed, however, that such attempts were highly laudable, as they were considered the only probable means of discovering a mode of prevention, or such a method of treating the disease, as might effectually arrest its progress before its calamitous effects were materially or generally felt.

With respect to the contagious nature of Epidemics, perhaps much may be said, both for and against the opinion; and though no great ad- 


\section{5}

vantage has hitherto resulted from the inquiry, it is certainly a subject of high importance.

If we read the accounts of Ramazzini, Lancisi, and other ancient writers, scarcely a doubt will be felt of the contagious nature of such diseases : so destructive, indeed, have they been at some periods, as to cause the most serious alarm, particularly about the beginning of the last century. According to Lancisi, there died in the Ecclesiastical states, from October, 1713, to April, 1714,-8,466 oxen used for ploughing, 10,125 white cows, 2,816 red cows, 108 breeding bulls, 427 young bulls, 451 heifers, 2,362 calves, 862 buffaloes (male and female), 635 young buffaloes-in all, 26,252 cattle in seven months. This writer thinks, that if the computation had begun from the 2nd of August, the number of cattle that perished would have amounted to 30,000 .

It is fortunate for mankind that so dreadful a pestilence has not happened for many years, though epidemical diseases of a much less formidable nature have several times appeared.

By referring to a meteorological journal of the months of May and June, 1815, it will be seen, that the weather has been extremely variable, and that rain and cold winds have been more prevalent than usual, and the preceding winter unusually mild. It should be observed also, that it was a part of the year when Catarrhal complaints or colds are very common among young horses.

How far the combined effect of these causes may have produced and continued the late epidemic independent of contagion, I shall not pretend to determine. It appears, however, from the inquiry I have made, as well as from my own experience, that the disease greatly abated when the warm weather set in; while wet and cold weather has uniformly aggravated it, or proved favourable to its production.

In page 171 , he observes, in the late epidemic, though several horses were attacked in the same stable, and sometimes even a whole team, either nearly at the same time or in succession, he does not think it was contagious, as many horses escaped that stood in the same stable with such as were diseased. 
Draught horses appeared to suffer more from the distemper than others, particularly where they were exposed to sudden change, as in post or coach work; hot ill ventilated stables seemed particularly favourable to its production and progress, and horses that were fed high appeared more susceptible of the disease than others; young horses were more frequently attacked than old ones; horses in regular, but not immoderate work, and fed accordingly, appeared to suffer less than any others; and I have been informed by a person who lately came from Woolwich, that among the horses of the Royal Artillery in that barrack, the disease had not been observed.

Horses, however, in all situations, appeared at times to be attacked by this distemper, nor were those at grass always secure from it.

The first symptoms were generally a troublesome cough ; dullness of the eyes; quick pulse and loss of appetite; sometimes it began with a violent shivering; quick pulse and laborious breathing; a discharge from the nostrils generally took place within a week from the commencement of the disease, which sometimes was very copious, though not so abundant as in the epidemic described by Gibson, about the year 1732, nor did it in any instance smell offensively, or prevent the horse's feeding, though it frequently had a very disgusting appearance, not unlike the discharge from the nose of a horse badly glandered.

When the attack was slight, the disease often disappeared gradually without any discharge taking place, though horses generally appeared to be relieved in some degree, soon after the nostrils began to discharge matter : this was by no means uniformly the case. In several instances I have seen them very seriously attacked after that period, so often indeed, and so suddenly did it happen, that $\mathrm{I}$ am inclined to consider it as a characteristic symptom of this distemper. 
THE FOLLOWING CASES OF DISTEMPER MAY SERVE AS EXAMPLES.

No. I.

A waggon horse had been labouring under this disorder, and for two or three days had been discharging freely from the nose. About this time he was seized suddenly with a quickness of breathing, as if inflammation of the lungs were approaching. He refused his food; pulse about ninety, and a remarkably strong pulsation of the temporal artery : four quarts of blood were taken, and about an hour after, as the horse did not appear to be relieved, or the pulse altered, there being likewise a very thick coat of buff or size upon the blood, the operation was repeated to the same extent as at first: from this time the horse gradually recovered, the medicines and treatment to be described hereafter having been employed after the bleeding. It may be proper to observe, that the quantity of blood drawn in this case was more considerable than is usually found necessary at so late a period of the complaint. I was induced, however, to repeat the operation, by seeing no abatement of the symptoms, by the continuance of that remarkably strong pulsation of the temporal artery, and by the sizy state of the blood. It has been generally held as a maxim in farriery, that bleeding should be avoided either in the epidemic or common cold, as soon as the nostrils discharge freely. In this distemper, however, I had often occasion to bleed in such circumstances, and the immediate relief it afforded, and the gradual recovery that followed, certainly prove the propriety of the practice. 


\section{No. II.}

A draught horse, about seven years old, had the distemper about a week : he had recovered his appetite, the cough appeared to be getting better, and the discharge from the nostrils was considerable; at this time, he was suddenly attacked with violent shivering, quick pulse, and laborious breathing; about one gallon of blood was taken away, which quickly relieved him, and by adopting the treatment to be described, he gradually recovered. Cases like the foregoing often occurred, and it is sufficient to state, that in every instance, the animal was relieved by bleeding.

In some horses, troublesome abscesses formed under the jaws, as in strangles, but this symptom did not often occur.

It is remarkable, however, that three cases of this kind happened in one concern; and I can only account for it, by the proprietor having given them some stimulating powders mixed with beer. In one of these cases the swelling was so considerable, as nearly to prevent the horse from swallowing, and so impeded respiration; that in attempting to move him from the stall, he fell, and was immediately killed by the blow.

On examining the body, two abscesses were found near the top of the gullet, full of white matter, and the surrounding parts were considerably thickened by inflammation; but the most remarkable appearance was a tumour about two pounds in weight, attached to the outside and posterior part of the stomach ; it consisted of a membranous sac, completely filled with white matter : the other two horses gradually recovered. From the description I have given of this distemper, it will appear, that it does not differ materially from those epidemics described by Gibson and Osmer, except that the latter observes, whenever there was a discharge from the nose, bleeding appeared to do harm. In this, however, 
several horses were bled freely when there was a copious discharge from the nose, and were uniformly relieved by it, as in the cases before stated.

The sudden attack of shivering, laborious breathing, and other symptoms of fever, and approaching inflammation of the lungs, which often happened unexpectedly, after a discharge from the nose had taken place, and the horse was thought to be doing well, seem also to constitute a peculiar feature in this distemper. From a careful consideration of the writings of Gibson, Osiner, and other respectable writers, on this subject, as well as from my own experience, I am satisfied that the only remedy to be relied upon in the epidemic diseases of horses, is early bleeding, not in the small quantities sometimes recommended, but to the extent of three, four, or even five quarts, and this may be as freely repeated after a short period, should a continuance of the symptoms render it necessary.

Cases may sometimes occur, which require only moderate bleeding, and some perhaps, though rarely, in which bleeding is improper, but these are easily distinguished : the general weakness of the animal, which may be seen, when he is led from the stable, the feebleness of the pulse, which is seldom much more frequent or quick than in liealth, the light or almost white colour of the inner surface of the upper eye-lid, in short, the absence of all febrile symptoms cannot fail of pointing out such cases to a careful observer.

The blood should always be preserved for examination; for when it is slow in coagulating, and has a thick coat of buff or size on its surface, we generally find a second bleeding necessary, and should carefully avoid all stimulating or heating medicines. If the dung is at all hard, a dose of opening medicine is proper, such as the oily laxative, in vol. 2nd, page 247. After the operation of the laxative, or should that medicine be found unnecessary, from the bowels being already open, the following ball may be given morning and evening, so as to increase the secretion of urine in a moderate degree. When green food can be procured, it should be given with moderation: tares and vetclies 
should be preferred; but if nothing of this kind can be had, bran mashes are most proper. When the horse appears much weakened, and the inflammatory symptoms have in a great measure subsided, a small quantity of oats may be given twice or three times a day. Should swellings appear under the throat or other parts, fomentations and poultices are proper, in order to promote suppuration; and when it is ascertained that matter has formed, the tumours should be opened.

When the weather is favourable, convalescents may be turned out for a short time during the day; but on no account should they be exposed to rain, cold winds, or an intense heat.

Horses recovering from the distemper require considerable attention, as the cough is very apt to return, and often proves difficult of cure by neglecting this circumstance. I have only now to add, that in this epidemic, like that we have before described, when soreness of the throat occurred, blistering was resorted to, and the exhibition of medicines suspended until swallowing became less painful and difficult, and then it was first given in a liquid form.

\section{Ball for the Distemper.}

Nitre from $\overline{3} \frac{\pi}{2}$ to 36 .

Antimonial Powder 32.

Linseed, Meal, and Honey, enough to form a Ball for one Dose.

Having at some length given Mr Gibson's and Mr Osmer's accounts concerning the symptoms and treatment of the Epidemics that occurred in their times, as well as those that occurred of late to $\mathrm{Mr}$ White, I shall now proceed to give an account of the Epidemics that have occurred in my own practice.

The Epidemical Disease in the horse, of which we are going to treat, as I have already stated, generally assumes much the appearance 


\section{1}

of a common cold or catarrhal affection, which generally prevails more or less in the spring of the year, and for the most part requires the same mode of treatment for its cure : there is generally, however, more cold shivering in the epidemic catarrh, and the febrile symptoms sooner commences, and generally run to a much greater height.

This complaint particularly affects the mucus membrane of the nose, throat, windpipe, and bronchia of the lungs, and is often attended with fever.

But sometimes there are a greater variety of symptoms, according to the nature of the constitution, which occasions some little variation in the mode of treatment.

With respect to the cause of this disease, it appears to arise from a contaminated state of the air, or rather from deleterious particles contained therein, at the same time the animal having a predisposition in the system to receive an impression from that source.

A long continuance of dry sultry weather seems to bring the air to a state tending to the production of this disorder.

The change of a long dry season, whether hot or cold, to a rainy one, seems to bring the temperature of the air to a state having a tendency to the production of epidemics.

Or when there is a long continuance of rain and cold winds in the spring of the year, and the preceding winter has been very mild, this also seems very conducive to the production of epidemics.

Horses breathing the confined air in stables not well ventilated, seems to give the system a predisposition to the disease.

Young horses are more subject to the complaint than old ones, and horses in regular work seem to suffer less than any others.

The first disease of this kind that came under my observation, occurred in the summer of 1798, there being at this time a long continuance of very sultry weather, and in this neighbourhood the complaint was very prevalent, and although it raged with great violence, yet it was not very fatal; but I understand, in many parts, and particularly in the metropolis, its fatality was very great. 
SYMPTOMS.

This complaint generally commenced with a shivering, a quick pulse, hot mouth, respiration somewhat accelerated, a violent straining cough, a great depression of strength, a dejected countenance, a discharge from the eyes, an alteration in the coat, which did not look so sleek as in the healthy state, diminution of appetite, costiveness frequently took place, and the secretion of urine was considerably diminished, and when evacuated it was high coloured.

These symptoms were often quickly followed by a soreness in the throat, and in the course of three or four days a discharge at the nose generally came on.

Sometimes the bronchia of the lungs were more the seat of the disease : then the complaint came on with a great shivering, a quick pulse, and difficult breathing, attended with a short confined cough, mouth hot, a dejected countenance, a great depression of strength, and a hanging of the head.

But in far the greater number of horses that were seized with the complaint at that time, the internal part of the throat was more the seat of the disease.

It sometimes happened, that considerable inflammation and swelling came on about the eyes.

And sometimes, although not often, swellings came on about the glands of the throat.

The next epidemic that was very prevalent, occurred in this country, in January, 1815, and continued for several months. During this period, there was a long continuance of wet weather, with cold winds, which seemed conducive to the production of this disease. 
SYMPTOMS.

The symptoms were in many respects similar to the epidemic that occurred in the year 1798, and for the most part, required the same mode of treatment.

But in the greater number of cases which I attended, the seat of the disease was more in the bronchia of the lungs : whereas in the epidemic that occurred in 1798 , the complaint affected the throat more than the lungs; and the disease seemed to be more general than that which occurred in 1815, as I understand scarcely a stable between Edinburgh and London could be entered, wherein the disorder did not prevail more or less among the horses.

Besides the above-mentioned symptoms, I frequently found throughout the course of the disease, that the mucus membrane of the intestines became affected ; then there was a considerable quantity of mucus discharged with the excrements.

Sometimes the brain became affected; then there was some degree of delirium.

The discharge at the nose was not near so copious as in the epidemic that occurred in 1798 : indeed, many horses that were attacked never had any discharge. In such cases, the febrile symptoms were often very great.

As this disease affects various parts of the body, it may not be amiss to treat of the different parts that become affected separately.

Therefore we shall begin with the affection of the internal part of the throat. 
ON THE AFFECTION OF THE MUCUS MEMBRANE OF THE THROAT.

This disease, as I have already stated, generally commenced 'with a shivering, a quick pulse, and respiration somewhat accelerated, attended with a violent straining cough.

Therefore, on being called in to this complaint, I generally found it necessary to bleed; but the quantity evacuated must depend upon the state of the pulse, and the degree of febrile symptoms attending the body. The age, size, and condition of the animal / must. likewise be taken into consideration.

If I found a quick pulse, with some degree of strength, mouth hot, and respiration a little accelerated, with other febrile symptoms, at the same time the horse being in a plethoric state, and of the cart" kind, about four quarts of blood were drawn from the jugular vein.

And if in the course of twelve hours, the pulse was still strong and frequent, at the same time, if the blood after standing until it coagulated, should exhibit a thick coat of size of a buff colour and tough consistence, the bleeding was repeated, but in a more moderate degree.

It is seldom necessary to repeat the bleeding more than once, when free evacuations are used at the commencement of the disease.

And from the experience I have had, I am fully convinced that venesection, if judiciously practised, is more to be depended upon than any thing else in the treatment of this complaint.

Two drachms of antimonial powder were given in a little bran mash, morning and evening, to act as a diapharetic, and if the horse would not eat it, it was given as a drench, mixed in one pint of a strong infusion of linseed.

If the intestines are found to be costive, an emollient clyster should be administered once or twice a day, and the following formula may be given :- 


\section{Emollient Clyster.}

\section{Olive Oil.}

2 Quarts Water Gruel.

If there should be much difficulty in swallowing, in consequence of the mucus membrane of the throat being inflamed, it becomes necessary to use means to counteract the internal inflammation.

Therefore, to relieve which, an external inflammation must be excited, by means of a blister, and it may be applied a little below the ears, across the throat, and about three inches down by the windpipe. The following formula may be applied after clipping the hair bare :-

\section{lilister for the Throat.}

$\zeta \frac{2}{2}$ Cantharides powdered.

36 Hog's Lard.

32 Oil Turpentine.

During the time the blister is operating, it will be necessary to tie the horse's head to the rack, so as to prevent him rubbing the blister off.

If the blister does not operate well, let it be repeated the next day.

But if the inflammation of the internal part of the throat is not very great, and the difficulty in swallowing not much, the following liniment may be applied to the external part of the throat once a day for a few days, and the head kept warm with a hood and wool underneath it.

It is probable by these means we shall determine the blood to the exterior part of the throat, and relieve the interior inflamed parts.

The body should be kept cloathed according to the season of the 2 P 
year: if the disease should happen in very cold weather, more cloathing will be necessary.

The head and chest seem to be more the seat of this complaint, therefore particular attention should be paid to the cloathing of those parts, and the stable should be well ventilated.

\title{
Liniment for the Throat.
}

\author{
$亏 6$ Hog's Lard. \\ $\xi \frac{x}{2}$ Oil Turpentine. \\ 32 Oil Rosemary. \\ $3 \frac{x}{2}$ Euphorbium powdered.
}

Means should be used in order to bring on a discharge at the nose as soon as possible, therefore the nostrils should be well fumigated once or twice a day over the vapour of a hot bran mash.

It is probable by this step we shall greatly facilitate the discharge at the nose, by relaxing the vessels, winich generally gives considerable relief.

When a discharge at the nose comes on, and it should be very copious, it often excoriates the parts; therefore the matter should be washed off the end of the nose once or twice a day with a sponge and a a little linseed infusion.

But by no means use injections or any irritating mixture, as such treatment often brings on ulcerations in the pituitary membrane, which become very troublesome.

Gibson mentions in the Epidemic that occurred in the year 1732, that in most of the horses which did amiss at that time, it was owing to their being unskilfully treated by syringing their noses with sharp stimulating things, which, by irritating those parts so much, brought on a continued running of purulent matter in some, that could not be stopped afterwards, with swellings under the jaw, which ended in waste and rottenness. 


\section{7}

It should be considered that the membrane lining the nose, called the pituitary membrane, is naturally very sensible, from its being supplied greatly with nerves, and when it becomes inflamed it is extremely irritable.

Therefore, in such cases, it is very improper to use any thing which tends to stimulate those parts, as such means only aggravate the disease.

But by inhaling the vapour of a hot bran mash, we sooth the action of the vessels of the inflamed membrane, and bring on a relaxation in those parts, whereby the animal is greatly relieved.

And keeping the body warm, as I have already observed, particularly about the head and chest, at the same time avoiding as much as possible, exposure to cold, until the running at the nose and the irritability of the mucus membrane have greatly subsided, is of the greatest importance, as it frequently happens, that from inattention to this circumstance, the disease degenerates into an inflammation of the substance of the lungs.

Then the case becomes extremely dangerous, and requires the most prompt means to be used, otherwise it is very probable it will terminate fatally.

It likewise not unfrequently happens, that this complaint, when originally assuming a catarrhal appearance, is converted into a pneumonic affection, from the want of venesection in due time, and at the same time drenching the animal with heating medicines, such as cordials, \&c. under the false idea of comforting the system, as many farriers term it.

Now, as this disease generally commences with a quickness of pulse, attended with fever, according to the severity of the attack, it must appear obvious, that the administration of such medicines as tend to excite an increased action of the heart and arteries must be highly injurious, by increasing the inflammatory diathesis in the system. The disease then often fixes upon some organ essential to life, for instance, the substarce of the lungs, brain, intestines, \&c. \&c. 
Whereas by opening a vein, and making such an evacuation at the commencement of the complaint, as the strength of the pulse, and other circumstances of the animal will admit of, and at the same time administering such medicines as will tend to restore the different secretions and excretions of the body, which in this disorder seem to be considerably retarded, we very frequently check the progress of the disease, and the horse often recovers in a few days.

When the inflammation of the mucus membrane takes place, there is generally an increased secretion of the mucus glands of the part affected, which greatly relieves the system; but the neutral salts continued in this secretion sometimes stimulate the parts affected and keep up the inflammation.

Therefore, in such cases, we should always endeavour as much as possible to prevent the mucus membrane from being stimulated by the neutral salts contained in this secretion.

And for this purpose mucilaginous medicines should be used, especially when there is a great soreness of the throat, and a frequent violent cough.

Strong infusions of linseed; or solutions of gum arabic, are very well calculated to relieve the inflamed parts, and a hornful or two may be given three or four times a day, observing not to keep the horse's head too high, as it may excite coughing; and let him have the same in a more diluted state for his common drink.

Or the following ball may be delivered between the grinders, so as. to dissolve gradually in the mouth two or three times a day, in order to keep the mucus membrane of the throat constantly covered with a mucilaginous matter.

This I have found to be of great service, as by this means we sheath the acrimony of the neutral salts contained in the fluid secreted in the part affected, and thereby diminish the irritability. 


\section{Mucilaginous Ball.}

$31 \frac{1}{2}$ Linseed Powder

$\zeta \frac{\pi}{2}$ Refined Liquorice, dissolved in a little Water

3. 2 Olive Oil

Mucilage of Gum Arabic sufficient to make a ball.

The diet in this disease should consist principally of warm bran mashes and linseed infusions, until the soreness of the throat and the difficulty in swallowing are removed.

If the horse will not drink the linseed infusion, let his mashes be made of it, and try him to drink water gruel : if he refuse this, let him have warm water.

When the season of the year will admit of it, cut grass is an excellent diet; and as this disorder sometimes prevails considerably in the spring of the year, it may generally be easily procured, and a little of it may be given frequently during the day.

This mode of treatment was continued until the soreness and difficulty in swallowing were removed, and if the febrile symptoms still continued, the following Fever Ball was administered morning and evening; and the diaphoretic drench I have previously ordered was given in the middle of the day.

\section{Fever Ball.}

$\zeta 1$ Nitre powdered.

$3 \frac{\pi}{2}$ Linseed powder.

32 Camphor dissolved in Olive Oil.

Treacle to make it the consistence of a Ball. 
The balls and drenches were continued until the secretion of urine was moderately increased; then the balls were omitted until the increased secretion had somewhat subsided, but the drench was continued.

It sometimes happened in this complaint, that as the internal part of the throat recovered, the bronchia of the lungs became much affected, as if a sort of metastasis had taken place; the breathing then became rather laborious, with an increase of febrile symptoms.

When glandular swellings appeared about the throat, or a tumour made its appearance in any part of the body, which seldom occurred, suppuration was promoted by the use of fomentations and poultices; and when the parts were in a state for an operation, the matter was evacuated and the wound dressed with digestive ointment.

Venesection, when such tumours come on, appears to be injurious, as also do purges.

In fact, the stronger sort of purgatives are always hurtful in this complaint ; whereas laxatives, diuretics, and diaphoretics, are generally useful.

When purgatives are administered in this disease, they stimulate the stomach and intestines so much, that a great determination of blood to the interior parts takes place ; and if at the same time there is a disposition to inflammation in the bronchia of the lungs, it tends to increase that disposition, and aggravates the disorder.

It frequently happens likewise, that the mucus membrane of the intestines is in a very irritable state, therefore if a purgative be given under such circumstances, it is a great chance but it brings on an inflammation in those parts, which will very probably terminate in mortification.

Therefore, from what has been observed, it must appear obvious, that when costiveness prevails in this complaint, the primæ viæ should be emptied by means of laxatives, either administered as drenches or clysters; and in some cases where the bowels are obstinately costive, they may both be given until the intestinal canal is gently opened; but upon no account use purgatives, for the reason I have assigned. 
In the treatment of this disease, it is of great importance to use such medicines as will increase the secretion of urine, and which, at the same time, tend to determine the blood to the surface of the body, so as to prevent any great accumulation in the interior parts.

The above Fever Balls and Drench will be found to answer this purpose; and their action will be greatly promoted by proper clothing and a well ventilated stable.

Having seen so many horses crowded together in hot ill ventilated stables, it induces ine to think that a repetition of the advice to have the stables well ventilated, particularly in the summer season, cannot be too much pressed; as it cannot be doubted, that the animal breathing the same air so repeatedly, must render it unfit for respiration; at the same time his being surrounded by noxious vapours arising from his fæces and urine, must aggravate his disorder very materially.

ON THE AFFECTION OF THE MUCUS MEMBRANE OF THE BRONCHIA OF THE LUNGS.

When the bronchia of the lungs were more the seat of the disease, the complaint generally came on with great shivering, a quick and hard pulse, and difficult breathing, attended with a short confined cough, mouth hot, a diminution of appetite, a hanging of the head, and a great depression of strength.

In such cases if the pulse was quick and hard, and the system attended with other inflammatory symptoms, I generally found it necessary to bleed more freely than in cases where the throat seemed more the seat of the disease.

Therefore, from three to five quarts of blood were drawn, according to the strength of the pulse, age, size, and condition of the horse.

And in the course of twelve hours, if the pulse were still quick, with some degree of strength, and the other inflammatory symptoms had not greatly abated, and at the same time if the blood that had been drawn 
exhibited a thick coat of size of a buff colour and tough consistence, the bleeding was repeated, but in a more moderate degree.

When the bronchia of the lungs are more the seat of the disease, the danger is then considerably greater, and the system is generally attended with more highly inflammatory symptoms; and if in this state the complaint is allowed to make much progress, or is unskilfully treated, pneumonic inflammation is brought on, which often terminates fatally.

In slight affections of the bronchia, bleeding and keeping the bowels temperate by means of emollient clysters, and administering the fever balls morning and evening, so as to increase the secretion moderately from the kidnies, generally answer the purpose of curing the disorder.

But if the inflammation has made such a progress as to extend to the more minute ramifications of the bronchia, an inflammation of the substance of the lungs is established.

-When the disease advances thus far, it is frequently owing to some neglect, or working the horse, when labouring under the complaint. The repeated exposure to cold brings on a pneumonic affection, which, as I have before stated, is not only extremely dangerous, but very difficult of cure, and requires the most prompt means to be pursued, in order to relieve the inflammatory affection of the lungs: though the attack of this disease may be so severe as to quickly bring on an inflammation in that viscus.

But whilst the complaint assumes a catarrhal affection it generally gives way to bleeding, and the administration of a few doses of fever medicines.

Sometimes the attack is so slight, that bleeding, and some attention to diet, is sufficient to cure the disease.

When the substance of the lungs becomes inflamed, the pulse still gets more quick and hard, with an increase of inflammatory symptoms : there is great difficulty in breathing, the mouth is extremely hot, and the extremities are cold: the horse seems to express great anxiety, he pants 
and shews great soreness in his chest, and particularly upon being the least moved; and his nostrils are much expanded: the depression of strength is very great, and the horse seldom lies down.

When these symptoms are found to occur, if at the same time the bowels should be costive, it will be necessary not only to bleed copiously, according to the state of the pulse, but it will likewise be necessary to moderately open the intestinal canal; and to answer this purpose, the following laxative drench and emollient clyster may be administered.

\section{Laxative Drench.}

\section{Castor Oil}

32 Barbadoes Aloes

1 Gill Water Gruel

Dissolve the Aloes in a little water, then mix the whole.

\section{Emollient Clyster.}

\section{6 Olive Oil}

2 Quarts Water Gruel

In such cases it is a matter of considerable importance to use means to counteract the progress of the internal inflammation, and for this purpose rowels should be inserted in the lower part of the chest, and a blister should be applied to the sides.

The following formula may be used :-

Blister for the Sides.

$\zeta 8$ Hog's Lard

$31 \frac{2}{2}$ Cantharides

31 Oil Turpentine 


\section{4}

By these means we determine the blood to the external part of the chest, and unload the internal inflamed vessels, and thereby take off their distention, which often puts the inflammation on the diminishing side; and if this important point be once obtained, the inflammation very frequently gradually subsides altogether.

The rowels may be dressed with common digestive ointment, mixed with oil of turpentine, in the quantity of about $\xi 2$ of the oil to $\xi 8$ of the ointment. Tents of tow dipped in this ointment must be inserted into the wounds every day, so as to fill them full, but easy.

I consider this a much better plan than the common mode of inserting a piece of leather wrapped with tow into the wound, and letting it remain ten days or a fortnight, or even longer, in the part. As by renewing the tents every day, we not only keep the wound more healthy, but I think it brings on a much greater discharge. Besides, the stimulus of the dressing every day tends to keep up a degree of external irritation in the part, which contributes to the relief of the internal inflamed parts.

If in the course of twenty-four hours, the blister does not operate well, and the difficulty of breathing is still the same, a second blister must be applied. But previous to its- application, let the parts be well rubbed with the fingers, so as to bring them into a state more susceptible of being acted upon.

If the rowels do not bring on some swelling in the course of twenty-four hours, they must be dressed once or twice with a little blistering ointment, added to the above ointment.

It is a matter of the greatest importance in this disease to excite an external inflammation opposite the part affected, whether it be the throat; lungs, intestines or brain, as has been already observed, and by that means counteract the progress of the internal inflammation, which counter-action greatly contributes to the recovery of the animal.

If the extremities should become cold, let them be rubbed with the following embrocation, and wrapped up with flannel :- 


\section{5}

\section{Embrocation.}

\section{Hog's Lard \\ $\zeta 1$ Oil Turpentine \\ $\zeta 1$ Mustard powder}

After the laxative drench has done operating, the fever balls may be administered morning and evening; and in the middle of the day the diaphoretic drench may be given.

The balls and drench must be continued until the secretion from the kidnies is moderately increased, and the inflammatory symptoms are greatly abated.

If it be found that the horse evacuates his urine very much after administering the balls a few days, let them be discontinued a day or two, or until the increased secretion has somewhat subsided; then let only one dose be given during the day; but the drench may be continued during the omission of the balls.

From what has been observed in the foregoing pages, it appears obvious that great attention is required at the commencement of this disease in removing the fever and catarrhal symptoms. And that rest, as long as the nature of the case requires, and avoiding exposure to wet or cold, is absolutely necessary.

When the mucus membrane of the throat anc. the bronchia of the lungs become once inflamed, even after the inflammation subsides, the parts seem for some time, still very susceptible of being injured by exposure to cold.

And it appears, also, that the external vessels of the body and those of the mucus membranes are nearly connected; for when the exhalent vessels are very much contracted by any sudden exposure to cold, while the body is in a profuse perspiration, that sudden contraction frequently causes a greater flow of blood upon the mucus membranes, which 


\section{6}

brings on an inflammation. Hence arise a cough and soreness of the throat and chest.

And unless that perspirable matter, which could not be evacuated on the surface of the body, be carried off by some other emunctories, or the process of perspiration be again restored, the disease may prove fatal, by fixing upon some important organ: hence the necessity of administering diaphoretics, diuretics, \&c. \&c.

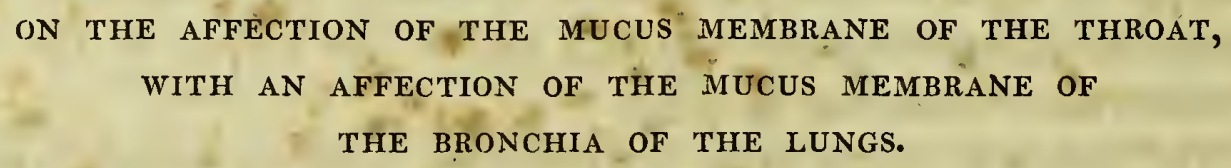

When the disease affects the mucus membrane of the throat, and that of the bronchia of the lungs, at the same time, there is not only a difficulty in swallowing, but there is likewise difficulty in breathing.

In such cases the pulse is generally much hurried, with high inflammatory symptoms; and those symptoms are often soon followed with a copious discharge at the nose, which generally relieves the system.

When the body is thus affected, free bleeding, at the commencement of the disease, according to the strength and frequency of the pulse, and repeating it in the course of eight or ten hours, if the pulse be still strong and frequent, and the animal does not seem to be relieved, are of the greatest importance, particularly if the blood that was drawn, exhibited when coagulated, much size at the top, of a buff colour, and tough consistence.

And keeping the bowels temperate, in the manner before pointed out, is another essential point.

At the same time, rowels should be inserted in the lower part of the chest; and a blister should be applied to the throat, and the whole extent of the trachea or windpipe. 


\section{7}

If the insertion of the rowels does not bring on some external swelling in the course of twenty-four hours, and if, at the same time, the breathing should be very difficult, they must be dressed with a little blistering ointment.

A blister should also be applied to the sides, and repeated in twenty-four hours, in the manner I have pointed out, provided the first blister does not excite much inflammation.

And if it be found on the application of a second blister, that it does not operate, although considerable friction had been used previous to applying it, and the difficulty in breathing is getting worse, it greatly indicates that a violent inflammation is going on in the lungs, and that the case is extremely dangerous.

In such cases I have known setons passed in the sides, smeared with blistering ointment, to bring on considerable external inflammation and swelling, when the application of a second blister has had little or no effect.

By which means the animal was soon relieved; and in the course of twenty-four hours the difficulty in breathing was greatly diminished, and he gradually recovered,

When swellings come on about the extremities, and at the same time the laborious breathing is greatly diminished, these are favourable symptoms. But if with those swellings, the horse should still have a great difficulty in breathing, and a staring unhealthy appearance of the coat, although the appetite and spirits should be considerably better, a dropsy in the chest must be dreaded.

Strong infusions of linseed, or the mucilaginous balls, which I have previously ordered to be delivered between the grinders, should be administered frequently, until the difficulty in swallowing is removed; and 32 of the diaphoretic powder, that is, the antimonial powder, may be mixed with a little bran mash and given him to eat, morning and evening. 
If the horse will not eat it, let it be mixed with a pint of strong linseed infusion, and given as a drench.

The diet in these cases, as I have already observed, should consist principally of warm bran mashes, linseed infusion, or water gruel; and the linseed infusion should be frequently offered to the horse, and made as mucilaginous as he can drink it.

By these means it is very probable the soreness of the throat, and difficulty in swallowing, will soon be removed.

Then fever balls and diaphoretic drenches must be administered as before directed, and continued until there is an increased secretion from the kidnies, and the inflammatory symptoms are greatly abated.

If during the time the horse is affected with a soreness of the throat and a difficulty in swallowing, the antimonial powder is mixed with linseed iníusion, and given as a drench morning and evening, the head must not be kept very high, otherwise it is probable it will excite the cough; therefore great care must be taken in not keeping his head too high.

On such occasions I always prefer it given in the mash, when they will eat it, or in linseed infusion or water gruel, when they will drink it.

If camphor or nitre be administered when the internal part of the throat is thus affected, they stimulate the mucus membrane and increase the inflammation.

Therefore, whatever medicine is given in such cases, it ought not to stimulate those parts; but, on the contrary, should be combined with some mucilaginous matter, so as to act as a substitute for the natural mucus that is brought off the parts in consequence of the inflammation.

But when the difficulty in swallowing is removed, I know of no medicine that tends to diminish the febrile symptoms more than camphor combined with nitre, and given as a ball morning and evening; and the diaphoretic drench in the middle of the day.

By such means we determine the blood to the external parts of the 
body; at the same time the kidnies are excited to action, and the combined effect of these medicines greatly contributes to the cure of the disease.

It may be thought strange that I have not combined the antimonial powder with the camphor and nitre in the fever ball, particularly as many writers on the veterinary art have prescribed a more strong preparation of antimony, combined in the same manner, to wit :-the tartarized antimony.

In regard to which, in the early part of my practice, I was a great advocate for the administration of tartarized antimony, combined with camphor and nitre, in febrile cases, in the quantity of 32 tartarized antimony, 32 camphor, and $\zeta 1$ nitre, for a dose, and given morning and evening.

But having reason to think that the stomach sustained some injury by such a combination, I considered that a more mild preparation of antimony, and given in linseed infusion, or any other mucilaginous matter, would have a better effect.

Therefore, I substituted the antimonial powder for the tartarized antimony, and gave it in linseed infusion as a drench, some lours after the camphor and nitre had been given as a ball.

And since I adopted this plan, in febrile cases, and particularly in the epidemic catarrh, the treatment has been attended with the greatest success.

When we consider that the epidemic catarrh is a disease that particularly affects the mucus membranes of the body, it becomes a matter of great importance to combine the febrifuge medicines with a mucilaginous matter.

And, as I have often had occasion to observe, the horse should frequently be tried to drink strong infusions of linseed.

A discharge at the nose frequently comes on, in the course of a few days, and great benefit is generally derived from it. 
Therefore, means should be used to promote such a discharge, and to answer this purpose, as I have already stated, the nostrils should be well fumigated, once or twice a day, over the vapour of a hot bran mash.

But when such a discharge comes on, and the system does not seem relieved by it, and at the same time, the pulse is hard and frequent, in such cases, venesection is likewise here of the greatest importance.

It has been the opinion of many practitioners, that bleeding, when there is a discharge at the nose, is hurtful; and, indeed, in the early part of my practice, I was of the same opinion, but experience has since taught me the contrary.

And, Mr White, of Exeter, has likewise practised venesection, under the same circumstances, with the most salutary effects, when the system did not seem to be relieved by a discharge at the nose.

ON THE AFFECTION OF THE MUCUS MEMBRANE OF THE INTESTINES.

It sometimes happens, in the course of this disease, that the mucus membrane of the intestines becomes affected. There is then often a considerable quantity of thickened mucus, which has a membraneous appearance, evacuated with the fæces, which are inclined to be hard.

When it is found that the bowels are thus affected, an emollient clyster should be given once or twice a day; and venesection, according to the state of the pulse, and other circumstances of the animal, should be used.

The diaphoretic drench may be administered morning and evening. If a purging should come on, attended with fever and griping pains, the case must be treated as a case of inflammation in the bowels: and bleeding here, according to the strength of the pulse and condition of the horse, is of great utility; and the embrocation should be applied to the inferior part of the abdomen with considerable friction; and if the extremities get cold, let them be well rubbed with the same, and wrapped up with flannels; and a good large rug or sheet should be applied round the abdomen, and tied or laced at the back. 


\section{1}

The horse should be allowed to drink plentifully of linseed infusion.

But if a diarrhoa should come on, unattended with any griping pains, and at the same time, there be little or no alteration in the pulse, let the following mild laxative ball be administered :-

\section{Laxative Bail.}

31 Barbadoes Aloes

34 Rhubarb powdered

\section{Soap}

Treacle, sufficient to make it to the consistency of a ball.

And if the purging do not subside in three days, let the following Astringent Ball be given morning and evening until it subsides :-

\section{Astringent Ball.}

34 Prepared Chalk

$3 \frac{1}{2}$ Opium powdered

31 Antimonial powder

34 Linseed powder

Mucilage of Gum Arabic, sufficient to make it to the consistence of a ball.

In such cases proper cloathing, according to the season of the year, and a well ventilated stable, will greatly contribute to the recovery of the horse.

In this complaint, it appears that the connexion between the exhalent vessels, that is, the vessels that throw out the sweat, and those of the mucus membranes, should always be held in view. Therefore, after increasing the secretion a little from the glands of the intestines, such 
steps should be taken as will tend to remove the flow of blood from the interior parts.

Particular attention should be paid to the diet, as it should consist principally of warm bran mashes, strong linseed infusions, and water gruel.

Cut grass in this case is not so proper, until the irritability of the mucus membrane is greatly diminished, as it seems too raw and flatulent, under such circumstances, and tends to bring on griping pains.

When a diarrhoea comes on in this disease, it must be considered as an effort of nature to get rid of something that is injurious to the system, and ought to be encouraged, provided, as I have already stated, the pulse be not considerably hurried, and the system affected with considerable fever, attended with griping pains.

And the above laxative ball may be considered as one of the most simple and most effectual that we can use ; and as the mucus membrane of the intestines at this time is in irritable state, the more simple the remedy the better.

After its laxative effect is over, it has a mild astringent one, which strengthens the tone of the stomach and intestines.

\section{ON THE AFFECTION OF THE HEAD.}

In some cases of this complaint, although not often, the brain becomes affected. When this is the case, the horse at first has a very stupid appearance, with a great distention of the blood vessels of the tumia conjunctiva of the eye, that is, of the membrane that covers the eye. The horse takes very little notice of objects about him; but this stupor is afterwards succeeded by a delirium: the animal then becomes very restless.

When the brain becomes affected, free bleeding, and keeping the bowels open, are of great utility. 
And either the jugular vein or temporal artery should be opened; and as free an evacuation made as the strength of the pulse, and condition of the animal, will admit of.

And if in the course of eight hours the pulse should still be strong and frequent, the bleeding should be repeated.

A rowel should be inserted under the jaw.

And a blister should be applied to the head.

By these means we shall probably determine the blood to the external part of the head, and thereby take off the distention of the vessels of the brain, which keeps up the delirium.

In this state of the animal, it becomes necessary to have him slung, otherwise he will run a great risk of injuring himself very much, by knocking his head and other parts of his body against the stall.

Besides, the horse being in a fixed situation, the medicines may be administered with much more ease and certainty.

The diet in this case should be of the antiphlogistic kind, and strictly adhered to, until the affection of the head subsides.

\section{ON THE AFFECTION OF THE EYES.}

It sometimes happens in this disease, that a considerable inflammation and swelling come on about the eyes.

In such cases, if the pulse be quick and strong, with other inflammatory symptoms, it will not only be necessary to bleed constitutionally; but locally likewise.

Therefore, after taking about five pints of blood from the jugular vein, the eye or angular veins may be opened, and about a pint drawn from each.

The eyes should be well fomented with warm milk and water, and afterwards bathed three or four times a day with the following lotion :- 
Lotion for the Eyes.

$31 \frac{\div}{2}$ Goulard's Extract

3 3 Liquid Laudanum

1 Pint water

The intestines should be kept open, and the fever balls administered in the manner I have pointed out.

If it be found, in the course of twenty-four hours, that the inflammation and swelling do not give way, but still appear to be increasing, and if, at the same time, the pulse should be pretty strong and frequent, let the bleeding be repeated both from the jugular and angular veins.

A rowel should be inserted under the jaw.

The diet in these cases should also be of the antiphlogistic kind, until the system is free from fever, and the inflammation of the eyes is entirely subsided.

When the febrile symptoms have subsided, if there be great debility remaining, which generally is the case, particularly when the attack of this disease has been violent, the powers of the body should be strengthened with tonics combined with cordials, and the following ball may be given every morning fasting :-

\section{Tonic Ball.}

34 Peruvian Bark, powdered

32 Gentian, ditto

32 Carraway Seeds, ditto

31 Ginger, ditto

Treacle, sufficient to make it to the consistence of a ball. 
At the same time a nutritious diet should be used, such as boiled barley, a malt mash, or a few dry oats mixed with bran, may be given three or four times a day.

But great attention should be paid in not giving too much of any of them at a time; for if you load the stomach, which is weak, you not only produce great uneasiness in that organ, but you cause great pressure upon the diaphragm, the part that divides the cavity of the chest from that of the belly; then the diaphragm presses upon the lungs, consequently the lungs cannot inhale the same quantity of air as before, and respiration again becomes difficult.

Therefore, it must appear clear that the quantity of food given at a time, should be small, and affording great nutriment, and often repeated.

By these means the organs of digestion will be better able to perform their functions; more chyle will be conveyed into the system, and the powers of the body much sooner restored.

The horse may now be led out into the open air, when the weather will permit, for twenty minutes or half an hour in the day at first, and increasing gradually, which will be found to contribute greatly to his recovery.

If the disease should occur in the grass season, he may be turned out a little in the day time; but great care should be taken to avoid exposing the animal to wet or damp weather and cold winds.

Having endeavoured to give a description of the cause, progress, and treatment of this disease, I shall now endeavour to point out its different terminations.

The terminations common to this complaint may be said to be five.

1st. $\mathrm{B}_{\mathrm{y}}$ what is termed resolution, that is, where the inflammation of the mucus membranes and febrile symptoms begin to subside, and continue so until the system is totally relieved. 
2ndly. By an effusion of coagulable lympth within the trachea or windpipe.

3rdly. By an effusion of coagulable lymph in the bronchia or air cells of the lungs.

4thly. By a kind of chronic cough, without any effusion of coagulable lymph, either in the trachea or its branches.

5thly. By tubercles forming on the lungs.

But when the disease has been neglected, or the horse has been frequently exposed to wet or cold weather, when labouring under an attack of this complaint; or has been unskillfully treated, by administering strong cordials and medicines of a heating nature,

The disorder is then often converted from a catarrhal to a pneumonic affection, which becomes extremely dangerous.

And this pneumonic inflammation likewise has various terminations.

In the first place, it may, like a catarrhal affection, terminate by resolution.

2ndly. By suppuration in the lungs.

3rdly. By gangrene and mortification in the lungs.

4thly. By an affection of the extremities, sometimes affecting the legs and sometimes the feet.

But the most common termination of pneumonic inflammation when it proves fatal, is an effusion of blood into the cellular texture of the lungs, whereby the circulation of the blood through that organ is interrupted, which produces suffocation; at the same time, we frequently find an adhesion of the lungs to the sides of the chest, in consequence of an effusion of coagulable lymph; there is likewise often a considerable effusion of the serous or watery part of the blood into the cavity of the chest, with a portion of coagulable lympth found floating in it, which constitutes the disease called hydrothorax, or dropsy in the chest.

This appearance, as well as the other terminations, when the disease was fatal, I have frequently observed upon dissection. 


\section{7}

Now, the most common, and most desirable termination of the epidemic catarrh, is by resolution ; and the most likely means to procure it, is, as I have frequently had occasion to observe, by free bleeding at the commencement of the disease.

A copious discharge at the nose likewise tends greatly to promote resolution, and should always be encouraged by fumigating the nose with the vapour of a hot bran mash, and keeping the body warm, particularly the head and chest.

When the disorder terminates with an effusion of coagulable lymph in the internal part of the trachea, or windpipe, there is a peculiar kind of whistling noise observed in respiration, when the animal is forced to any exertion, from the air not being admitted into the lungs with that freedom which takes place in the healthy state; hence that peculiar sound comes on, and the horse generally goes under the denomination of a Roarer.

When the complaint terminates by an effusion of coagulable lymph in the bronchia or air cells of the lungs, respiration becomes difficult, and the animal is termed Thick-winded.

And, if in this state he should be forced to much exertion, particularly upon a full stomach, it is a great chance but some of the air cells rupture; and when this is the case, the horse then becomes what is commonly termed Broken-winded.

When the disease terminates with a kind of chronic cough, without any effusion of coagulable lymph, either in the trachea or its branches, it appears to be owing to the rima glottis becoming very irritable, from some diseased action in the vessel that secretes the mucus which defends that part from the action of the air; the mucus not being of a good consistence, the air stimulates the membrane, and excites coughing; or it may arise from the fluid secreted in the part being of a stimulating nature. 


\section{8}

When tubercles form upon the lungs, the horse may exist some time, probably without much inconvenience being felt, until these little tumours either increase in size, so as to disturb respiration, or by some sudden exposure to cold, when the body is in a state of perspiration, the blood is thrown much upon the lungs, which causes some degree of inflammation in that viscus; then it sometimes happens that phthisis pulmonalis, or pulmonary consumption, is the consequence, which generally terminates in death.

These are the effects of the terminations common to this disease, whilst it assumes a catarrhal appearance.

But when it has degenerated into an inflammation of the substance of the lungs, the effects of the termination of the complaint then are as follow :-

1st. By resolution; as the inflammation in the substance of the lungs, and the febrile symptoms may gradually subside, until the system is free from complaint.

2ndly. When suppuration takes place in the lungs, pulmonary consumption is the consequence, which generally terminates fatally.

3rdly. When gangrene and mortification take place in the lungs, death very quickly approaches.

4thly. When there is an effusion of the serous or watery part of the blood into the cavity of the chest, constituting hydrothorax, or dropsy in that part, the horse appears at first to be considerably relieved ; the pulse is not so quick, and other inflammatory symptoms are somewhat abated; he has better spirits, his appetite is somewhat restored; but still there is difficulty in respiration; the legs swell; a rough unhealthy appearance may be observed in the coat; he seldom lies down, and if he do, he suddenly rises again; the integuments are strongly attached to the body, or what is commonly called Hide-bound.

'The animal continues in this state a few days, or until the watery 
part of the blood accumulates in the chest, so as considerably to impede the action of the lungs.

Then the breathing becomes extremely difficult, the pulse is hurried, the swellings suddenly leave the extremities, and the complaint returns with great violence, which soon puts a period to the existence of the horse.

When the legs become affected in this disease so as to produce lameness, there is often an effusion of coagulable lymph, which becomes inspissated about the flexor tendons, between the knee and the fetlock joint of the fore legs, and between the hock and fetlock joint of the hinder legs, which interferes with the action of those parts.

And the deposit in these parts is sometimes not larger than a good sized hazel nut, but it is astonishing the degree of lameness that is brought on from that cause.

And this lameness frequently alternately takes place, first in a fore leg, and then in a hinder leg; at other times the hinder leg will become first affected, and then a fore leg.

Sometimes there is an enlargement nearly the extent of the flexor tendon.

When the lameness first commences, if there should be much inflammation attending the part, the following lotion may be applied two or three times a day, and a flannel bandage, moistened with the same, may be applied gently round the part :-

\title{
Lotion.
}

\author{
31 Goulard's Extract \\ 3 Vinegar \\ Pure Water, one Quart
}


This may be continued a few days, or until the inflammation has a good deal subsided; and if the horse then is not much better of his lameness, a blister should be applied over the enlargement, which generally promotes the absorption of the deposit in the part, and brings the animal sound.

But sometimes, as I have before observed, the enlargement is very small, and attended with little inflammation, but considerable lameness; in such cases a blister may be applied in the first instance.

When the blister has done operating, the horse should be put into a loose stable for a week or two, then he may be turned to grass, provided the season of the year will admit of it.

When the feet become affected at the going-off of this complaint, it is generally the fore feet that suffer, and a considerable inflammation of the sensible laminæ of the coffin bone sometimes takes place, which laminæ, together with the insensible laminæ of the hoof, forming about 500 in number, establish the connection between the hoof and the coffin bone; and it is this connection that supports the weight of the horse.

Indeed, at other times, when a horse has had a violent attack of a common catarrhal inflammation of the lungs, so as to excite considerable fever, when the disease was neither epidemic nor contagious, I have known the disorder terminate with an affection of the feet.

In such cases, if the internal inflammation of the foot be not quickly diminished, it sometimes happens that the laminæ become so far diseased, that they are not capable of supporting the weight of the body as before, consequently the coffin bone descends; the horny sole also partakes of the same descent, and becomes convex instead of being concave.

There is then a considerable change in the shape of the hoof, as it loses its natural oblique direction, and approaches towards the horizontal line. 


\section{1}

But if proper means are used at the commencement of the lameness, it is probable a cure may be performed.

Whereas, if the inflammation has made some progress in the internal part of the foot, if the animal should recover the inflammatory state of the parts, it is very probable an incurable lameness will be the consequence, and the horse is seldom fit for any other purpose than that of ploughing or such like work in agriculture.

Therefore, it must appear obvious when this disease terminates with an affection in the feet, that it becomes a matter of the greatest importance to use means as quickly as possible to diminish the inflammatory state of the internal part of the foot, so as to prevent the descent of the coffin bone.

And local bleeding, from as near the part affected as you can, will be found of great service, and should be repeated in the course of twelve hours, if the pain and inflammation continue severe.

The shoes should be taken of; and if the hoofs have grown long, and the horny soles appear very strong, with thick scales upon them, let the superfluous parts be removed with a drawing knife, and the hoof reduced to its proper length.

If the sensible sole is bruised, which frequently is the case, the insensible sole must be pretty well thinned; and if suppuration has taken place between the sensible and insensible soles, which sometimes happens, every part of the insensible sole that is detached from the sensible sole must be removed.

When the horny or insensible sole is too strong, it causes great uneasiness, as it must be understood that the fleshy or sensible sole lies between two hard bodies, to wit, the coffin bone and the insensible sole; and when the sensible laminæ become inflamed, the sensible sole partakes of the inflammation; and if at this time the insensible sole is very thick and hard, it causes too great a compression upon the sensible sole, and tends much to keep up the internal inflammation of the foot.

Therefore, by removing those superfluous parts of the insensible 
sole, and reducing the hoof to its proper length, we greatly relieve the sensible sole.

After the hoofs and soles have been properly pared, they should be well fomented with warm water, and a poultice applied twice a day; and the following formula may be used :-

\section{Poultice.}

Linseed, Meal and Bran, equal parts.

Hot Water, sufficient to make a Poultice.

Hog's Lard, sufficient to keep it moist.

By these means we shall greatly soften the hoof and sole, which, from the complaint, naturally become hard and dry.

In affections of this kind, the horse should be put into an open stable, and allowed plenty of litter, in order to make his tread as soft as possible.

But the lameness is sometimes so great, that he lies more than he stands, as his feet cannot bear the weight of his body, consequently he finds great relief by lying, as then the weight of the body is removed from the parts affected.

If there should not be much swelling about the coronets, a blister should be applied round them, and it is very probable will be found to be of great service.

But if the pain is so severe as to cause such a degree of kmeness, that the horse cannot stand tied to the rack during the operation of the blister, let the following embrocation be well rubbed in round the coronets once a day, for two or three days together, or according to the degree of external inflammation excited by it.

If it is found by repeating it only once, that a considerable inflammation is brought on about the coronets, let the use of it be suspended until the swelling subsides. 
But if the inflammation that is brought on by a second application be trifling, let it be applied a third or fourth time; and to prevent the horse gnawing the part, put a muzzle on him for four or five hours after each application, until the stimulus of it is over.

\section{Embrocation for Coronets.}

\section{$\zeta 2$ Oil Turpentine \\ $\zeta 1$ Oil Rosemary \\ 31 Hog's Lard \\ 32 Euphorbium, powdered}

There is nothing tends to diminish the internal inflammation of the foot more than local bleeding, and blistering the coronet.

It is necessary in these cases, to attend to the constitutional state of the animal, as well as the local treatment; for although the original fever that attended the horse may have entirely subsided, yet a symptomatic fever may be brought on, from the pain in the feet.

Therefore, if the system is not much reduced by what the animal has suffered during the progress of the original fever, but at the same time the pain in the feet should bring on a symptomatic fever, the horse should be bled according to the strength and frequency of the pulse, and some fever medicines administered.

It sometimes happens, as I have already observed, that suppuration takes place between the sensible and insensible sole; and in order to ascertain whether matter is formed or not, a small aperture should be made through the horny or insensible sole, in one or two places, a little distance from the point of the frog, with a drawing knife.

If suppuration have taken place, it will soon be observed by the matter making its appearance; and if the part only bleed, you may be satisfied that the suppurative process has not begun.

When it is found that suppuration has taken place between the $2 \mathrm{Y}$ 
horny and fleshy soles, all that part of the horny sole which is detached from the fleshy sole, should be removed with a drawing knife.

And the wound should be well bathed with warm compound tincture of myrrh, and pledgets of tow, dipped in the following ointment made warm, and applied to the parts; the wound should be dressed every day, and a plate should be put upon the shoe so as to secure the dressings, and at the same time protect the sole from pressure until it becomes sufficiently hardened to bear it. The shoe should be set on with as few nails as possible, and they should be small.

\title{
Ointment for the Sole.
}

\author{
to 1 Common Tar \\ 38 Hog's Lard \\ 亏 2 Oil of Turpentine \\ Dissolve the Tar and Hog's Lard, then stir in the Oil of \\ Turpentine
}

If fungus excrescences arise, they must be kept down by caustic applications ; and they may be touched once in two or three days before the ointment is applied, with a little butter of antimony.

After the sole has become sufficiently strong to bear pressure, let the horse be shod with an open shoe, but the shoe must be sufficiently roomy, and set on with very small nails; and great care should be taken that the hoof, together with the junction of the bars, is the only part that receives pressure from the shoe.

He may then be turned to grass, provided the season of the year will admit of it.

I shall just make a few more observations concerning the symptoms when there is a descent of the coffin bone.

When the coffin bone descends, a considerable depression may be observed at the anterior part of the coronet; and the hoof, as I have 
already observed, instead of being in an oblique direction, approaches towards the horizontal line; the horny sole, instead of being concave, becomes convex; and when you come to move the horse, he is afraid of bearing any weight on his fore feet; he treads much upon his heels, and extends his feet as far forwards as he can; he therefore supports the greater part of the weight of the body with his hinder extremities, by bringing them as much under him as he can, and when moved, still continues his hinder feet as much as possible in the same situation.

When the hinder feet are affected, which very rarely happens, the reverse takes place; as the body is thrown forwards, and the fore feet are placed as far back as he can, in order to relieve the hinder feet of the weight.

Before I conclude this subject it may be necessary to observe, that the horse is liable to another complaint in the feet, which has symptoms similar to that we have been describing, but which originates from a very different cause, and is generally attended with considerably more violent pain and inflammation.

This disease originates from a horse being ridden to excess, upon stony or very hard roads; and afterwards taken into a pond or river in a state of profuse perspiration.

Or riding a horse very hard in deep snow for some time, has been known to produce this complaint, and it generally goes under the denomination of a Founder in the Feet.

When the feet are thus affected, we generally find an uneasiness may be observed in them a few hours after the horse has been put into the stable, as he does not stand so firmly as he had done, and is frequently moving his feet, and inclines much to lie down, as it takes the weight of the body from the parts affected, consequently he finds relief by it.

As the complaint advances, which is generally very rapid, his hoofs feel very hot, and he becomes very restless, a violent pain and inflammation take place in the sensible laminæ of the foot, which frequently 
terminate in suppuration, causing a total separation of the hoof, horny sole, and coffin bone, and it not unfrequently happens that all the four feet are affected in this manner at once.

The pulse becomes very quick, and a violent symptomatic fever comes on, which generally puts a period to the existence of the animal in the course of three or four days.

But sometimes the affection is not so great, and suppuration does not take place ; there is generally, however, a descent of the coffin bone, with great alteration from the natural structure of the foot; and if the horse do recover the inflammatory state of the parts, an incurable lameness is the consequence.

Now when the epidemic catarrh had, from frequent exposure to cold, or otherwise from being unskillfully treated, which brought on an inflammation of the substance of the lungs, terminated with an affection of the feet, I never knew an instance of suppuration taking place to such a degree as to cause a separation of the hoof, horny sole, and coffin bone.

And there is this difference likewise to be observed in those affections ; that in the one case, it is a consequence of fever, and in the other, it is an original complaint, brought on by hard riding, and the battering of the feet on hard roads for a considerable length of time, and exposing the animal to cold, which brings on a symptomatic fever.

And that in the one, the pain and inflammation in the feet generally come on in the course of a few hours; and in the other, it is sometimes ten days or a fortnight, and even longer, before any uneasiness is observed in those parts.

It may be necessary to remark, that this termination of the disease was by no means a common one, but instances now and then occurred.

And when we consider the connection between the coffin bone and the hoof, and that from this connection the whole weight of the horse is supported, we need not wonder, in febrile cases, where the circulation of the blood is frequently so irregular, at inflammation taking place within 
the hoof; and that this inflammation, causing an alteration in the organization of those parts, from their texture becoming so much weakened as to be no longer capable of supporting the weight they do in the healthy state, consequently the coffin bone descends, causing, as I have before stated, a great alteration in the structure of the foot.

We likewise find that this laminated connection between the hoof and the coffin bone, sometimes gives way, by a horse standing long upon one leg to ease another, and the following case is an instance of it:-

A CASE OF A DESCENT OF THE COFFIN BONE, FROM STANDING MUCH UPON ONE HINDER I.EG TO EASE THE OTHER HINDER LEG, WHICH HAD RECEIVED

A PUNCTURE OF THE FLEXOR TENDON OF THE FOOT.

This was the case of a mare, the property of Major St Paul, of Ewart Park.

On being called in to this case, I found the mare excessively lame of one of her hinder legs, and in violent pain; and on examining the limb, I observed a puncture in the pastern, which had penetrated the flexor tendon of the foot.

This accident happened near Newcastle, and the Major sent her to my Repository, where every attention was paid, in order to relieve the inflammatory state of the injured parts; and she so far recovered that the puncture was healed, and the mare was beginning to bear considerable weight on that limb.

But about a fortnight after the accident, from standing so much on the other hinder leg to ease the one that received the injury, an inflammation took place in the sensible laminæ of the foot, which weakened the laminated connection so much, that the weight of the body caused a great descent of the coffin bone and horny sole; matter likewise formed between the horny and fleshy soles, and the animal became very lame of 
this foot. The case then being considered incurable, Major St Paul ordered her to be shot.

I afterwards dissected the legs and feet, and now have them amongst my anatomical collection.

I have given an account of this case merely to shew that an inflanmation of the sensible laminæ of the foot may be brought on by various causes, which ultimately have the same effect in occasioning a descent of the coffin bone.

Which circumstances do not hitherto appear to have been particularly noticed by authors who have written on the veterinary art.

From what has been advanced, it appears, when a horse becomes very lame of one leg, either a fore or a hind leg, and for some days does not incline to lie down, he must of course bring great stress upon the leg and sensible laminæ of the foot on the opposite side. It therefore becomes necessary to have him slung; it is probable he will then occasionally bear his weight upon the slings, and relieve the laminated connection within the foot, and by this mode it is likely the descent of the coffin bone may be prevented.

It has been the opinion of many Farriers, that the weight of the horse was supported by the horny sole, frog, and bar; but our worthy and ingenious professor of the Veterinary College, Edward Coleman, Esq. some time ago put the matter out of doubt concerning the laminated connexion within the hoof supporting the weight of the horse.

In order to ascertain whether the weight of the animal was supported by this structure or not, he made the following experiment, an account of which may be found in the 2 nd vol. page 80 , of his very valuable work On the Structure, Economy and Diseases of the Foot of the Horse.

\section{EXPERIMENT.}

The soles, bars, and frogs had been taken away from both the fore feet of a horse. I saw the animal a few minutes after the operation, and 
he was trotted several yards without any alteration in the situation of the foot or coffin bone. To increase the weight of the animal on the laminæ of the fore feet, the off and near fore feet were alternately taken from the ground for several minutes, and the coffin bones were afterwards found in the same situation as before. It also happened, that on placing the hand on the loins of this horse, he kicked with great violence, and repeated his stroke several times. Now, during the period his lind legs were in the air, all the weight of the animal was sustained by the lamina of the two fore feet; and yet this extraordinary weight made not the smallest change in the situation of the foot bones.

Therefore, from what has been advanced by Mr Coleman, it is clear that the weight of the horse must be supported by the laminated connection within the hoof; for if it had been the horny sole, frog, and bar that supported the weight, their removal -would have caused a want of that support, and the coffin bone must have inevitably slipped through the hoof; but it was found different, as the coffin bone retained its natural situation.

It may be necessary to observe, that the laminæ which establish the connection between the hoof and the coffin bone, are possessed of a considerable degree of elasticity, they therefore naturally admit of being elongated to a certain degree, when the weight of the body comes upon those parts at every step the horse takes; the horny and fleshy sole also have some degree of elasticity, and in proportion as the laminæe are elongated, in proportion does the coffin bone press upon the sensible and insensible soles, which causes them to have a moderate descent likewise; but as soon as the foot is removed from the ground, the coffin bone and the sensible and insensible soles ascend, so that the descent and ascent of those parts, to a certain degree, is natural to all horses; and this structure is wonderfully formed to give a spring to the animal, and prevent concussion or fracture.

But when the sensible lamina take on a morbid action, in the manner before observed, the texture of the parts becomes so much weakened 
that they are no longer able to support the weight of the animal as before, consequently the coffin bone, and the sensible and insensible soles sink very much from their former situation, generally causing permanent lameness, with great alteration in the structure of the foot; the hoof, instead of being in an oblique direction, approaches the horizontal line, and the sole becomes convex instead of being concave.

Since I wrote the foregoing pages, I have been favoured with a letter from Mr Coleman, signifying that the division of the pastern nerves, as a remedy for chronic lameness in the feet of horses, has been practised at the Veterinary College with success.

And since I have received his account of the operation, I have performed it in such cases with success; and it is astonishing to see the alteration in the going of the animal immediately after the operation, even when he has been lame for two or three years.

Now how far a division of those nerves may be of utility at the commencement of an acute inflammation in the sensible laminæ, when it comes on as a termination of a complaint, I cannot pretend to say, not having as yet tried the experiment; nor do I know of any other person that has done it; but $I$ think it is worth while to try it, where there appears much risk of the structure of the foot becoming altered in the manner I have described.

Having given a description of the different terminations of the Epidemical Catarrh, whilst it assumes a catarrhal appearance, as well as given a description of the different terminations, when it has degenerated into a pneumonic affection or inflammation of the lungs, with the modes of treatment, I shall now proceed to make some observations relative to what Messrs Gibson, Osmer, and White, have advanced concerning the treatment of the epidemics that occurred to them. 
With respect to $\mathrm{Mr}$ Gibson and Mr Osmer, there is little doubt but they were both men of respectability, and of considerable practice in the veterinary line; and in their treatises on the diseases of horses, many judicious and useful observations may be found. Mr White has certainly spent much of his time for the improvement of the Veterinary Art, and the public is indebted to him for some valuable publications.

Although there are some variations in the description of the Epidemics given by Gibson and Osmer, still by paying particular attention to their accounts, and comparing them with those that occurred lately, it appears to be the same kind of disease, though in different stages.

It may be observed again, by attending to the modes of treatment stated by Gibson and Osmer, that there is in some respects a similarity between their treatment and that adopted by Mr. White and myself; though there are some circumstances I cannot but remark upon in Osmer's treatment of this disease.

One is the too powerful medicines which he orders, to increase the secretion of urine. I believe that if the dose which he orders, be administered and repeated in the manner he has directed, it will not only tend to bring on extreme debility, but by stimulating the internal coat of the stomach, will tend very much to impair the digestive powers, and if often repeated, will very probably bring on an inflammation in that important organ.

But the administration of such medicines in a more moderate degree is generally found to be of essential service.

There is another circumstance I think it necessary to notice in $\mathrm{Mr}$ Osmer's treatment of this complaint.

He say's, that in cases where there is a discharge at the nose, bleed- 
ing does harm, because that discharge is an effort of nature, and is a kind of crisis to get rid of the complaint.

I agree with him, that the system is generally relieved by such a discharge, and it always ought to be encouraged; but at the same time I am confident, from practice, that when such a discharge comes on, and the system does not seem to be relieved by it, bleeding is of considerable utility, when the pulse is strong and frequent, and the body attended with other inflammatory symptoms, as I have in many instances seen it give immediate relief, and the horses gradually recovered.

Mr White likewise illustrates his work with an account of two cases, which he treated successfully by bleeding freely when there was a copious discharge at the nose, and has in many instances been convinced of the propriety of the treatment.

In cases where bleeding would be hurtful in this disease, the skilful practitioner will generally be able to discriminate. In the first place by the slowness and feebleness of the pulse, and a want of inflammatory symptoms, the degree of debility the animal seems to move with, and the reduced state of his condition. And, as I have previously observed, when any large and critical abscesses are forming, particularly about the glands of the throat, bleeding seems to do harm.

It may not be amiss here to make further remarks on venesection.

There is an erroneous idea prevails among many Farriers concerning the appearance of blood, after it is drawn from a vein, in inflammatory cases, and allowed to stand to coagulate, that is, to thicken : they consider the buffy or sizy part of the blood to be grease or humours; and when the blood exhibits this appearance, it is their opinion, that a repetition of the operation is necessary, in order to draw more of this grease or humour out of the system.

Now, this buffy part of the blood is called the coagulable lymph, and is neither grease nor humours, as they term it; it is more of a gluey nature, and in fact, it is the most essential part of the blood, as it is by this buffy part that all wounds are healed by the first intention. What 
is meant by healing by the first intention, is simply bringing the lips of a recent wound in contact, by means of sticking plaister or bandage : by this mode the divided surfaces are quickly glued together as it were, and a bond of union soon takes place, and new vessels are said to be formed in two or three days out of this coagulable lymph, and the part heals without any other application.

But to have a correct idea of the blood's appearance in inflammatory cases, it seems necessary to attend to the following circumstances.

When blood is drawn from a vein, it appears to be one uniform fluid; but upon letting it stand a short time, it is found to be different, as it separates into three parts, which are called the red particles, coagulable lymph, and serum; and the red particles are the heaviest.

Now, in inflammatory cases, where the heart and arteries are acting quickly and strongly, with some degree of vibration, the blood that is drawn from a vein under such circumstances is longer in coagulating; therefore, the red particles being of more specific gravity than either the coagulable lymph or serum, settle to the bottom of the vessel, and leave a greater proportion of tough coagulable lymph, which has a sizy appearance, and is of a buff colour, at the top.

Whereas, when blood is drawn from a vein where the system is unattended with any inflammatory symptoms, it quickly coagulates, and the red particles not having time to settle to the bottom of the vessel, they are diffused throughout the whole mass, and the blood, when coagulated, exhibits little or no size.

The size of the orifice will also make some difference in the appearance of blood, as, when it is drawn in a very small stream, it will sooner coagulate, and the red particles then also become more diffused, so as to cause the blood not to exhibit so much size or buff at the top, particularly if the vessel it is received in be a spacious one; but such blood, in inflammatory cases, is generally of a tough consistence.

So that the buffy or sizy appearance of the blood, together with its toughness, will depend principally upon the inflammatory state of the 
system, which appearance forms a very good criterion how we are to proceed, that is, it strongly indicates the necessity of repeating the bleeding, provided the pulse is still strong and frequent, with other inflammatory symptoms, not for the purpose, as many farriers suppose, of extracting the grease or humours from the system, but to diminish the increased action of the heart and arteries, and thereby take off their distention, so as to put the inflammation on the diminishing side, which, if once obtained, it generally gradually subsides altogether.

Now when blood is drawn from a horse in a debilitated state, instead of having much size at top, there is little or none; and the red particles are more diffused and loosely connected, and there is generally a considerable quantity of serum. In such cases bleeding must do harm.

Therefore, from what has been observed, it will be found that the appearance of the blood in a diseased state of the body, must be of considerable importance in pointing out the necessity of repeating the operation of bleeding, or desisting from it.

In Mr Gibson's treatment of the Epidemic he attended in the year 1732, he speaks much of bleeding being of great utility; but he observes, that after having bled the horse, he administered aromatic powders, combined with balsam, sulphur, and other medicines, in the form of balls.

Now, I cannot see the propriety of Mr Gibson's administering those medicines, and particularly in the form of balls, and delivered in the gullet, after having freely bled the horses, as he observes they were very feverish, with their throats raw and sore, and attended with great difficulty in swallowing.

The administration of such medicines, I consider, in the first place, given in the form of balls, and delivered in the. gullet, must greatly tend to keep up the irritability and soreness of the internal part of the throat; and in the next place, by their heating nature, they tend to counteract the good effect of a free bleeding, by exciting an increased action of the heart and arteries. 


\section{5}

But it is probable the bleeding put the inflammatory state of the system so much on the diminishing side, that it subsided altogether, independent of the action of those aromatic powders, \&c. ; and that his success in the treatment of this disease has greatly depended upon venesection being freely used, and some attention to diet.

In regard to the contagious nature of epidemics, Mr Gibson is clearly of opinion, that the epidemic he attended in the year 1732, was contagious.

Mr White observes, that in the late epidemic, though several horses were attacked in the same stable, and sometimes even a whole team, either nearly, or at the same time, or in succession, he does not think it was contagious, as many horses escaped that stood in the same stable with such as were diseased.

In the late epidemic, I found the same circumstances to occur, as I have known the disease attack nearly about twenty horses in one stable in the course of a few days; but there were horses in the same stable which did not take the complaint.

But still a horse not taking the disease when standing in the same stable with others affected with the complaint, is no proof of the disease not being contagious.

This may arise from a want of a predisposition in the system to be acted upon by the contagious matter.

It appears, however, that much may be said concerning it being contagious, as well as to contradict it.

Therefore, upon the whole, in such cases, I think it advisable to use some precaution in keeping the diseased separate from the healthy horses, as it may prevent great destruction.

I am greatly induced to think, from the experience I have had, that epidemical complaints among horses occur more frequently, but in a much less formidable degree than is generally supposed; and such diseases seem to be greatly influenced by a long continuance of wet weather, s.ttended with frequent cold winds. 


\section{6}

I should wish to impress upon the mind, that when the disease commences with a violent shivering, a quick and hard pulse, and difficult breathing, the case must be considered dangerous; and the danger must always be considered in proportion to the quickness of the pulse, and the difficulty in breathing.

In such cases, the horse seldom lies down, and if he do, he generally rises again very soon, as the weight of his body contracts the chest, and the lungs have not the power of inhaling that quantity of air which they do when the animal is upon his legs, consequently he finds great uneasiness at every inspiration, which causes him suddenly to rise again.

It frequently happens that horses thus affected will stand until the very last, when they drop down, and expire immediately.

When the breathing is very difficult, the roller or girth ought not to be buckled too tight, otherwise the chest will be contracted, and the lungs will not have so much power of expanding themselves.

The depression of strength on the attack of this complaint is sometimes so great, that in attempting to walk a horse a few yards from the stable, the proprietor is frequently glad to get him in again, for fear he should fall.

Therefore, it is evident, in such cases, the animal should be kept at rest, as much as possible, until the inflammatory state of the body has greatly subsided.

It must also be considered, when the bronchia of the lungs are in a state of inflammation, that the breathing, even in a state of inaction, is considerably accelerated; therefore, if you attempt to move an animal labouring under such a complaint, you hurry respiration much more, which certainly tends to increase the inflammation in that viscus.

In this disease, as I have already stated, the body should be kept warmly cloathed, and particularly about the head and chest, as by this we determine the blood to the external parts, which greatly assists the action of the medicines given internally.

It is likewise of the greatest importance to have the stable well ven- 


\section{7}

tilated, so as a sufficient quantity of pure air may be admitted for the purpose of respiration; as it must consist with reason, that if a horse be kept in a very warm stable, and frequently breathing the same air, that it must become very noxious and unfit for that purpose. And it frequently happens, that those people who are such great advocates for very warm stables, are equally as fond of loading the horse with body clothes. Therefore, what with the warmth of the stable, and the impure air the animal breathes, at the same time the additional heat the system is brought into by the clothes, it increases the action of the heart and arteries so much, that the febrile symptoms are greatly augmented; and if some means be not used to check the progress of the fever, the horse is frequently very quickly cut off.

The temperature of the stable should be in a medium way, and the pure air that is admitted should be conveyed in such a manner as not to come immediately upon the horse.

I have sometimes been called in to cases of this disease, where the stables have been so close, that, that alone has increased the pulse and respiration to a great degree, and after ordering an admission of more air into the stable, in the course of a short time the pulse became not near so frequent, and respiration was much more calm.

As the admission of pure air into stables is a matter of considerable importance to horses, either in a healthy state or in a state of sickness, it may not be amiss to mention at some length, the judicious observations on this subject made by Mr James Clark, of Edinburgh, in his Treatise on the Prevention of Diseases incident to Horses, page 20; and the following is his account:-

Young horses, says he, generally are accustomed to live and breath in a pure open air, till they come of age and are fit for labour; it is then found convenient to house them. This produces a considerable change in their bodies, and makes them liable to be greatly affected by the temperature of the air which surrounds them. 
That the generality of stables are kept too close and hot, requires no demonstration, as every one who goes into them, even when the weather is pretty cool, must bave discovered it from his own feelings; and in the summer season, the heat within them is increased to a very great degree. What renders it still worse, it frequently happens, that from the situation and structure of many stables, no opening can be made to allow a sufficient quantity of fresh air to render the animals in any degree easy.

The door is the only entrance for air, and that can only happen occasionally when it is open. It is true, the intercourse that must unavoidably take place through the day, in going out and in, renders such stables tolerably sweet aired; yet, in the morning, when the door has been shut up for some hours through the night, and especially in summer, the heat is so intolerable, and the air is so foul, that a man can hardly breathe in it; whilst, at the same time, the sharpness of the salts arising from the horses' urine, \&c. attacks his nose and eyes, and occasions a copious discharge of tears.

Many of the hovels at present used as stables, do not even deserve the name, and it is surprizing, that considering the value and usefulness of horses, so little attention is paid to their health in this respect. For, surely, there can be nothing more hurtful than keeping a number of them, perhaps thirty or forty, shut up in a close warm stable, where they must constantly breathe a hot foul air, which,' at the same time, is strongly impregnated with the putrid steams of their own dung, wind, and urine, besides the exhalations that arise from their bodies, which, in this case, are kept in constant strong perspiration by the great heat of the air which surrounds them; and to add to all this, they are perhaps wrapt tight up in body clothes. How can it be expected that a horse, who has passed the night in this situation, should be active and vigorous to perform his day's work? Will he not rather be faint, languid, and dull, his whole system as it were being unhinged, and in a relaxed state? Let any man, who is an advocate for this treatment of 
horses, try the experiment on himself : let him sleep in a heated close room covered up with clothes, sweat it out for the night, and try the condition he will be in the next day for any employment whatever.

Although the description I have given of the situation of horses in large close stables through the night may appear exaggerated to those who have not had an opportunity of knowing it from their own observation, it is however a true one, and the same observation will hold with respect to those stables that are of smaller dimensions, even although they should contain fewer horses, if at the same time the stable is made so close as to exclude the admission of fresh air. It is well known to be a common practice to shut up every crevice that would admit the least quantity of air. The very threshold of the door is choaked up with dung, and even the key hole is filled with straw:

Every man knows from his own experience, that when a number of people are met together in a close room, the air within it becomes moist and hot, which renders breathing difficult; and if continued for a length of time, this uneasy sensation would be increased. In churches and crowded assemblies lighted with candles, the effect of a heated foul air is evident to the sight, from the lights burning dim and very faintly; and although the loftiness of the roofs in those places contributes to render it less perceptible to those who are on the lower or ground floor, as the heater foul air always ascends, yet in the higher parts of galleries the oppression it occasions in breathing is great, the perspiration becomes profuse, and thirst becomes intolerable.

The lowness of the generality of stable roofs renders them unwholesome from this circumstance alone; the horses' heads being too near the stable roof, they are under the necessity of breathing a heated foul air almost constantly during the time they are in the stable, especially through the night, when the doors \&c. are shut up; it is still worse in the warm months of summer.

A heated foul air is noxious to animal life in general. How then can it be expected that horses should thrive in it? At the same time can 
there be any thing more inconsistent than keeping horses warm to an excess in the house, by the use of body clothes, in a constant state of strong perspiration, and stripping them naked the moment they are to go abroad, in all weathers. The constitution of a horse, strong as it is, cannot withstand this treatment. It must and indeed does give way, and too often falls a sacrifice. The sudden and frequent transitions which horses undergo, almost every day, from being surrounded with and breathing a cold air, to that of a hot foul air, and vice versa from a hot to a cold one, were there no other causes, are sufficient of themselves to produce a number of the most violent diseases.

It is to be observed, that great heat and profuse perspiration dissipate the watery parts of the blood, and render it too thick for circulation, and from that cause alone many diseases proceed.

The constantly inspiring of a hot foul air does not expand the lungs sufficiently so as to promote the circulation of the blood through them; hence it accumulates and proves another source of diseases in that organ. It likewise renders them liable to fevers, faintings, languor, frequent sickness, and loss of appetite. It exposes them to all those external complaints which arise from obstructed perspiration, as rheumatism, tumours in the glands, scabs, lumps, scales on the skin, staring of the hair, \&c. But the danger is still greater when the perspirable matter is thrown upon some of the internal viscera, as the lungs, intestines, brain, pleura, \&c. From the first of these proceed coughs, peripneumony or inflammation of the lungs, consumptions, \&c. From an affection of the intestines proceed obstructions in the bowels, and diarrhœea, or scouring, as it it is called, in horses. When it settles on the brain, it produces vertigo or staggers, apoplexy, epilepsy, \&c.; and when on the pleura, it is attended with the most acute pain or stiches, sympioms which nearly resemble those of the gripes or cholic. 'These complaints, if not speedily relieved, generally prove fatal to horses.

Together with the heated foul air which generally prevails in such stcivies as are kept too hot and close, there is always a dampness or 
moisture. This is occasioned by their being made too close, and kept so, insomuch that no fresh air can be admitted into them, but what passes in at the stable door, and that only, as I have already observed, when it is occasionally open. Hence the moisture from the horses' breath, and which may be increased from a low or damp situation, gathers, or is collected in large drops on the roof, walls, and glass windows, and runs down in small streams; at the same time, the stable is filled with a hot, damp, and moist air, which is not only extremely pernicious to the horses' health, but destructive to their furniture of every kind. Foul air, whether from putrid steams, or exhalations of any kind, is noxious to all animals, and productive of various diseases which prove fatal. It would be needless to enter here into an enquiry concerning the properties of air, as every one, from his own experience, must have observed at some time or other, the great difference arising from his breathing in a foul, or in a fresh air. It will be sufficient to observe, that air is the chief instrument of health, and principle of life, without which no animal can subsist. It is likewise necessary to observe, that there is a peculiar matter thrown from the lungs of every animal, together with the air, which renders it unfit for respiration or breatling.

Besides, particular situations and seasons often alter the qualities of the air, and render it more or less unfavourable to animal life. Nature accordingly makes use of all possible ways to preserve the air in a wholesome state, for it is thinned and purified by leat, and kept in continual motion by the winds.

Although the air is by such means often preserved in a wholesome state, yet, as has been before observed, particular situations and seasons often alter its qualities, so as to render it more or less hurtful. Its dryness produces one set of diseases, its moisture another, its heat or its cold others, and so on. It is well known that no animal can exist long in the same individual quantity of air. Thus it is computed that a gallon of air is spoiled of its elasticity by the steams of a man's breath in one minute, consequently a hogshead of air would not supply a hunran 
creature one hour, nor indeed can he live in it one-third of the time. Hence, therefore, we may learn that without a continual.supply of fresh air, the lungs cannot perform their office. This will appear still more necessary, when it is considered that the lungs are supposed to be the chief instrument of sanguification, and mixing the blood and chyle, by their expansion and dilatation, \&c.

Dr Hails, to whom the world is much indebted for his curious and useful experiments on air, tells us, that he could not live half a minute without uneasiness in seventy-four cubical inches of air, and not one minute in the same quantity without danger of suffocation. The effluvia from animal bodies are likewise very hurtful to the air. Three thousand men living within the compass of one acre of ground, would make an atmosphere of their own steams seventy feet high, which would soon become pestilential, if it were not dispersed by the winds. The air of prisons for this reason produces mortal fevers, \&c.

Moist air relaxes all animal fibres. Such diseases, therefore, as proceed from laxity of fibres, must be the common diseases both of moist seasons and moist situations. Dry air, by producing opposite effects, produces opposite diseases.

Cold air, by bracing the fibres, and giving them a stimulus, produces that strength and activity of which we are so sensible in frosty weather. Hot air likewise relaxes the fibres, so as to occasion that faintness and debility, so often experienced in hot weather.

Those stables which contain a great many horses, are attended with other disadvantages beside those I have already mentioned, especially to tired or fatigued horses, from the great intercourse which must unavoidably happen in the people going out and in, especially in public stables. Hence those horses that are shy to lie down, or are easily disturbed, will not rest themselves in that horizontal posture, which is of great consequence for keeping their legs fine and clean, as it forwards the circulation of the blood, \&c. in the vessels, and prevents swelling and gourdiness of the legs and heels, which are generally the fore-runners of ulcers, scabs, 
grease, \&c. Rest to horses that are tired and fatigued becomes absolutely necessary : in order to recruit and refresh nature, we know how agreeable and necessary it is to ourselves; horses are susceptible of the same sensations, therefore every opportunity of resting and stretching their legs should be given them.

Large crowded stables contribute greatly to communicate contagious or infectious diseases; a great number of horses breathing in one place, contaminate the air ; and if it has not a free current it soon becomes unwholesome, and like the air of jails, it contracts a malignant quality, which produces fevers in those horses which stand in them; and on changing them to other stables they likewise communicate the infection to others.

Hence it has been remarked in those epidemical diseases amongst horses, which appeared, in Britain, that it raged with most violence in those stables where a great number of horses were confined together in one large stable, whilst its effects in small well aired stables were more mild and less destructive.

To enumerate all the disadvantages which arise to horses from their being kept too warm, and breathing a hot foul moist air in close stables, would take up too much of the reader's time, or perhaps weary his patience. As the impropriety of this treatment to horses must be obvious to every one who allows himself to reflect only upon the subject, and to apply these reflections to what he has experienced from his own feelings in the like situations, I shall therefore only add further, that it renders horses exceedingly delicate; it enervates the whole system, and of course renders them unfit for the laborious exercise required of them.

On the other hand, too cold stables are liliewise hurtful to horses, more especially after labour or exercise, or when they are kept standing fixed to one place, or when the cold air is directed upon them in a current or stream from any door or window.

A current of cold air is more noxious to animals that stand in it but for a short time, than heat. The natural quality of the former is one of 
the principal causes of the distempers it produces, for its coldness checks perspiration by contracting the skin and closing and shutting up the pores.

It is a common saying among stable people, that horses feed best when kept in darkness ; but this is by no means the case : they feed equally well in light, are fond of it, and shew evident symptoms of pleasure when they are brought from a dark stable into the light, by their frisking, \&c. Such stables are generally unwholesome, for as they have no windows, fresh air is excluded as well as light.

Very dark stables are hurtful to the eyes; horses are naturally timorous, more especially when they see but imperfectly around them; hence they are the more constantly upon their guard. By this means the pupils of the eyes are too much dilated or opened in search of the least ray of light, in ordèr to discover objects near them. This constant dilatation of the pupils greatly weakens their contractile power, so that when the horse is brought out to the open day, the rays of light fall so suddenly and so strongly upon the eyes, as to cause a kind of quivering or convulsive motion in them, and in the eye-lids, the immediate effort of the poor animal to keep out those rays of light which give him so much pain, and that at other times is so very agreeable to him. But this is not the only bad effect that arises to horses from their standing in dark stables. It affects their seeing objects distinctly when abroad, and causes them to startle and be alarmed at every thing they meet with, which makes them exceedingly troublesome to their riders. The poor animals are blamed, when in fact it is in a great measure owing to the dismal situation in which they are too constantly kept. Light to horses is as cheering, agreeable, and natural as it is to the human species, therefore they ought not to be denied that common privilege.

Farmers, from a view of making dung, lay great quantities of straw under their horses, where they sometimes let it remain for weeks together. The dung, urine, together with the heat of the stable, soon reduce it to a state of putrefaction, from which issue steams of a most 
noxious quality, which the horses constantly breathe in; and in wet weather, when they are more confined in the stable, this hot foul air may occasion fevers of the most malignant kind ; and perhaps this may be the cause of those epidemical fevers which break out in many seasons.

In my observations upon the shoeing of horses, and the diseases of their feet, I have frequently hinted at the bad effects of keeping their hoofs and legs too hot, by means of too great a quantity of litter at all times, night and day, and perhaps large quantities of heated dung; the great heat of the stable, together with the accumulated heat arising from too great a quantity of litter about the legs, occasion a more than ordinary derivation of blood to the legs, \&c. which causes a dilatation or fulness of the blood vessels, and of course, a swelling or gourdiness of the legs : hence proceed a stiffness and numbness, greasy heels, \&c. If the horse lies down for relief, the great heat of the litter soon forces him to get up again; and after repeatedly lying down, and being forced to get up immediately, from the above cause, he attempts it no further, but stands upright, or perhaps a little stradling, often shifting the weight of his body from one leg to another.

This erect position, in which he is obliged to stand, increases the swelling of his legs, \&c. Recourse is then had to all the remedies commonly prescribed for swelled heels, under the notion of carrying off humours, rowels, purging, diuretics, \&c. \&c. I have been tlie more particular in the above description, as many cases have occurred, arising from the above cause, when no disease did at first actually exist, and which might have easily been prevented by removing the quantity of litter, as soon as the horse's legs began to swell, keeping them cool, and washing them frequently with cold water.

The Earl of Pembroke, in his Military Equitation, has a very judicious remark on this head. After working, says he, and at night of course, as also in lameness and sickness, it is good for horses to stand on litter : it also promotes staling, \&c. At other times it is a bad custom; 
the constant use of it heats and makes the feet tender, and causes swelled legs. Moreover, it renders the animal delicate; swelled legs may frequently be reduced to their proper natural size by taking away the litter only, which, in some stables, where ignorant grooms and farriers govern, would be a great saving of physic and bleeding, besides straw. I have seen, by repeated experiments, legs swell and unswell, by leaving litter, or taking it away, like mercury in a weather glass.

The Arabians, who are remarkably careful in the management of their horses, and have them in the greatest perfection, litter them with their own dung dried in the sun, and afterwards beat down to a powder, and spread thinly upon the floor, about four or five inches thick; and after being soiled, it is dried a second time in the sun, which clears it entirely of its offensive odour ; and in order to keep their legs cool, wash them carefully with cold water, morning and evening. This practice has not only the desired effect on the legs, but it keeps their hoofs cool and moist in that dry and warm climate.

The same author likewise tells us, that the Arabians keep their horses as much as possible in the open air. Every day, says he, from morning to night, all the Arabian horses stand saddled at the tent doors; and as the Arabians live in tents, these tents serve them likewise for stables.

This method of managing horses approaches, as near as it is possible, to the natural or wild state, and cannot fail of being attended with salutary effects to the constitution of this useful animal ; and although this practice cannot be adopted or recommended in our cold and changeable climate, yet the inference is very obvious, and cannot fail of shewing the propriety and usefulness of keeping our horses in well aired ventilated stables.

The above author likewise observes, that very warm climates, it would appear, are destructive to horses; and when they are transported from a mild climate to a very warm one, the species degenerates. This observation, together with the arguments produced in support of it, and 


\section{7}

which appears to be founded in fact, shews how pernicious and unnatural too lot stables are to the constitution of horses. Stables, with double heads, as they are called, that is, when the horses stand with their tails opposite to one another, are very improper, unless there is a considerable open space behind them, as horses are apt to kick and fight, by which they lame and wound one another: instances of which occur almost every day. A precaution of this kind is the more necessary, as many, if not most horses, when not feeding, stand as far back as the stalk of their collar will admit. This practice I have observed to prevail mostly in those stables that were kept too hot, probably owing to a foul hot air prevailing near the rack and manger, or from putrid steams arising from old musty litter below the manger, or from that under the horse's fore feet : for it is to be observed, that horses and geldings, when they stale, throw their urine considerably forward; and if the wet litter is allowed to remain under them, which, indeed, is too frequently the case, the saline steams arising from it are so sharp and disagreeable to the organs of smelling, that horses stand as far back as they can, in order to avoid the smell, and to breathe a freer and fresher air.

From what has been said, it is obvious, that the prevailing custom of keeping horses too warm in their stables, and where at the same time a hot foul air must of course prevail, cannot fail of being attended with bad consequences to their health, \&c. and shews the necessity of accommodating them properly with well aired stables, free from all damp or foul air, and so contrived as to be kept at all seasons of a proper temperature, avoiding the extremes of heat and cold.

It is well known that in hot houses, where exotic and other delicate plants are kept, a thermometer is used to ascertain the heat of the air within the house, which becomes absolutely necessary, as any excess of heat or cold would injure the plants.

This practice should be adopted in stables, that when the heat within them is increased to a certain degree, the ventilators should then be 
opened; and when too cold, they may be shut or nearly so, as may be found necessary.

All stables should be built in a dry situation and in a free air. They ought to be at a distance from all boggy or marshy grounds, and free from all noise or disturbance. The cieling or roof should be high and lofty, as the heated foul air always ascends. The dung should never be allowed to rot within the stable, as is done in some places, nor even at the stable door; but every thing about horses should be kept sweet and clean. The stables should be frequently well aired, by keeping the doors and windows open when the horses are out through the day. Experience teaches us how agreeable and even necessary it is to admit fresh air into our own apartments-it is equally necessary and useful to horses. No stables should contain more than six or eight horses at most, for the reasons already mentioned. The stalls should be large and roomy, six feet wide, in order that a horse may stretch his legs out when he lies down, with freedom; and as horses are sociable creatures, and always thrive best in company with one another, no stable should be made of one stall only, unless it be so situated that the horse standing in it may be within the hearing of other horses. The stable windows should be large, in order to admit a good deal of light, and made so as to let down from the top occasionally. The damp or moisture that settles on the glass windows should be frequently wiped off, and they should be kept clean and dry. The litter under the horses should always be put up through the day below the manger, especially when a horse goes abroad, in order to let the pavement dry and cool; and when the litter is spread down, it ought never to be too thick, for the reasons already mentioned. A horse should never be allowed to stand on litter through the day, unless he is unwell or fatigued, when it is presumed he will lie down to rest himself.

Having already hinted that too much clothing to horses whilst they stand in the stable, contributed greatly to render them tender and delicate, besides exposing them to all the diseases arising from too great 
heat about their bodies, and likewise to those arising from an obstructed perspiration from cold when they go abroad, it will be proper, here, to observe, that in some cases, clothing becomes highly necessary. What I condemn, is the too constant and improper use of it, even to excess in warm weather, and in warm stables. When a horse is in health and stands idle, very little clothing is necessary; a single sheet or rug will be sufficient, unless the stable he stands in is very cold; but when a horse has been overheated from violent labour or exercise, more clothing will be necessary, as circumstances may require, till he becomes moderately cool.

On this head 1 cannot help taking notice of that pernicious custom of girding horses' bodies so very tight above their clothing, by means of very broad girths or rollers, with a considerable number of straps and buckles, with the view of taking up their bellies, as the phrase is. If such bandages are necessary, of which I have some doubt, why are they used to those horses that are light-bellied? Post and road horses, when they are fed for some time with clean dry food, have as light bellies as the finest hunters or racers, and yet no such thing as broad rollers are applied to them.

Broad girths, when drawn too tight round the body, impede the free action of the lungs, and by their compressing the liver and other viscera, the circulation of the blood, \&c. in them, is considerably affected. I have seen many horses, when labouring under a feverish disorder, girded so tight with rollers, that it occasioned a more than ordinary difficulty of breathing, attended with great anxiety and restlessuess; and on ungirding the rollers, the animal seemed greatly relieved.

Having made some observations concerning Messrs Gibson, Osmer, and White's treatment of the Epidemics they attended; at the same time, given Mr J. Clark's observations concerning the utility of a well ventilated stable, \&c. \&c. I shall now proceed to give the history of a few cases of the epidemical complaints that came under my care, in the years 1798 and 1815 . 


\section{CASE I.-June 23rd, 1798.}

A saddle horse, four years old, was seized with a shivering; and this symptom was soon succeeded by a quick pulse, about 80 beats in the minute; hot mouth; respiration accelerated but not laborious; he had a violent straining cough; a dull countenance, with a discharge from his eyes ; a diminution of appetite ; a great depression of strength ; the bowels were inclined to be costive; and there was a diminution of the secretion of urine, which, when evacuated, was high-coloured.

These symptoms were soon followed by a soreness of the throat, and a difficulty in swallowing.

Having examined the case, three quarts of blood were drawn from the jugular vein.

The mucilaginous balls were administered in the morning, and repeated in the evening. They were delivered between the grinders, so as to dissolve gradually in the mouth, in order to keep the mucus membrane of the throat constantly covered with a mucilaginous matter.

Two drachms of antimonial powder were mixed in a little bran mash, made with linseed infusion, and offered him in the morning, and repeated in the evening, to act as a diaphoretic, which he partly eat, and when he did not eat it, the same quantity of antimonial powder was mixed in about a pint of strong linseed infusion, and given as a drench.

An emollient clyster was likewise administered in the morning, and repeated in the evening.

A blister was applied to the throat.

His nostrils were well fumigated with the vapour of a hot bran mash. infusion.

His diet was principally cut grass, warm bran mashes, and linseed

The head and chest were kept warm, and the stable was well ventilated. 


\section{1}

On the 24th, the pulse about seventy beats in the minute; mouth not quite so hot; respiration not so much accelerated; the difficulty in swallowing not so great.

The bleeding was repeated, and about five pints were drawn.

The mucilaginous balls were continued, as also the emollient clysters.

The diaphoretic powder was also repeated, as likewise the fumigation to the nose.

The blister was also repeated.

On the 25th, the pulse about sixty-five beats in the minute; respiration less hurried; cough not so troublesome; the difficulty in swallowing still less.

A copious discharge came on at the nose.

The bowels were pretty open, and the appetite better.

The mucilaginous balls were repeated, as also the diaphoretic powder and fumigation.

On the 26th, the pulse about fifty-eight beats in the minute; respiration considerably easier; the difficulty in swallowing greatly removed, and the cough much subsided; bowels pretty open; appetite much better.

The mucilaginous balls were repeated, as also the diaphoretic powder; he discharges freely at the nose.

On the 27 th, the pulse about fifty beats in the minute; respiration calm; mouth cool; the difficulty in swallowing nearly removed; he is discharging freely at the nose.

The mucilaginous balls and diaphoretic powder repeated.

On the 28th, the pulse about forty-six beats in the minute; the breathing is pretty regular; he coughs very little.

The diaphoretic powder repeated morning and evening, and continued until the 31 st, when the febrile symptoms and difficulty in swallowing were totally removed.

But some debility remaining, tonics, combined with cordials, were $3 \mathrm{~F}$ 
administered, which, together with a nutritious diet, soon restored the powers of the system.

\section{CASE II.-July 1 st.}

A coach horse, six years old, was attacked with a shivering, and soon after a quick pulse, about seventy beats in the minute; mouth hot; respiration accelerated, but not laborious; he had a violent cough and a soreness of his throat; his eyes were dull, attended with a discharge ; his appetite was diminished; his strength was much depressed; his bowels were inclined to be costive; and there was a diminution of the secretion of urine.

Having examined the case, about four quarts of blood were drawn from the jugular vein.

The mucilaginous balls were administered between the grinders in the morning, and repeated in the evening.

The diaphoretic powder was also given in the morning, and repeated in the evening, in the manner I have pointed out.

An emollient clyster was administered.

A blister was applied to his throat.

His diet consisted principally of warm bran mashes and linseed infusion.

The head and chest were kept warm, and the stable was well ventilated.

On the 2nd, the pulse about sixty beats in the minute; respiration not so much accelerated; mouth more cool; appetite rather better; the difficulty in swallowing not quite so great, and he does not cough so much. The diaphoretic powder repeated, as also the mucilaginous balls, and likewise the fumigation to the nose.

The blister operating well.

On the $3 r$, the pulse about fifty-five beats in the minute; respira- 
tion pretty easy; appetite still better; the difficulty in swallowing much diminished.

The diaphoretic powder repeated, as also the mucilaginous balls and fumigation.

On the 4 th, the pulse about fifty beats in the minute; the breathing calm, the difficulty in swallowing nearly removed, and the cough greatly subsided ; the appetite considerably better.

The diaphoretic powder, mucilaginous balls, and fumigation repeated.

A copious discharge came on at the nose.

On the 5th, symptoms still favourable.

He discharges freely at the nose.

The diaphoretic powder and mucilaginous balls repeated, and continued until the 10th, when the horse was cured of the complaint.

Some debility remaining, tonics, combined with cordials, were administered, which soon restored the strength of the system. The horse was afterwards turned to grass, and got into an excellent condition.

\section{C.ASE III.-July 15 th.}

A draught horse, five years old, was seized with a shivering, which was soon succeeded by a quick pulse, about seventy beats in the minute, hot mouth, and difficult respiration, attended with a short confined cough ; there was great depression of strength, a dejected countenance, with a discharge from the eyes, a diminution of appetite; the bowels were costive, and the secretion of urine diminished; he likewise had some soreness of his throat, and difficulty in swallowing.

Having examined the case, about four quarts of blood were drawn from the jugular vein.

The diaphoretic powder was administered in the morning, and repeated in the evening, as also the mucilaginous balls. 
And, an emollient clyster was given in the morning, and repeated in the evening.

A blister was applied to the throat, and the whole extent of the trachia or windpipe.

The nostrils were well fumigated over the vapour of a hot bran mash.

Two rowels were inserted in the inferior part of the chest.

The diet was cut grass, warm bran mashes, and linseed infusion.

On the 16th, the pulse being still hurried, with some degree of strength, the bleeding was repeated, and about three quarts were drawn from the jugular vein.

The difficulty in swallowing was greatly removed, but the difficulty in breathing was getting worse.

Therefore, a blister was applied to the sides, and the rowels were dressed with a little blistering ointment, mixed with digestive ointment.

The diaphoretic powder was repeated as on the preceding day, as also the mucilaginous balls.

The bowels still inclining to be costive, the emollient clysters were continued.

Fumigation to the nostrils repeated.

On the 17th, the pulse about sixty beats in the minute.

The blisters caused some swelling in the sides, and the difficulty in breathing is not quite so great; the difficulty in swallowing is quite removed, and he coughs more freely.

A copious discharge came on at the nose.

The fever balls were administered in the morning, and repeated in the evening, and the diaphoretic drench was given in the middle of the day.

The emollient clysters were repeated, as also the fumigation to the nose.

On the 18th, the pulse about fifty beats in the minute, respiration not near so difficult, the blisters operating well, as the sides were well swelled; likewise the rowels. 
He discharges freely at the nose.

Appetite better.

The fever balls were repeated, as also the diaphoretic drench, and emollient clyster.

On the 19th, the pulse about forty-five beats in the minute, and very little difficulty in respiration.

The fever balls increasing the secretion of urine, they were omitted; but the diaphoretic drench was repeated, and continued until the 24th, when the horse was cured of the complaint.

There was some debility remaining, and to strengthen the system, tonics, combined with cordials, were administered, which, together with a nutritive diet, soon restored the powers of the body.

\section{CASE I.-January 15th, 1815.}

A saddle horse, five years old, was attacked with some difficulty in breathing, attended with a short confined cough; a quick pulse, about sixty beats in the minute; mouth hot; a diminution of appetite; strength much depressed; a dejected countenance; the bowels were inclined to be costive, and the secretion of urine somewhat diminished, and when evacuated was high-coloured.

Having examined the case, about seven pints of blood were drawn from the jugular vein.

The fever balls were administered in the morning, and repeated in the evening, and the diaphoretic drench was given in the middle of the day.

An emollient clyster was administered.

His nostrils were well fumigated over the vapour of a hot warm mash.

His body was well clothed, and particularly about his head and chest. 


\section{6}

Diet principally warm bran mashes and linseed infusion.

On the 16 th, the pulse about fifty beats in the minute; respiration more calm; mouth more cool.

The bowels pretty open.

The fever balls and drench continued.

Nostrils fumigated.

On the 17 th, the pulse about forty-eight beats in the minute; the breathing more regular; he coughs more frequently and more freely.

Fever balls and drench continued; nostrils fumigated; appetite better.

On the 18th, the pulse about forty-five beats in the minute; respiration pretty calm.

A copious discharge came on at the nose.

The balls increasing the secretion of urine, they were omitted; but the drench was repeated, and continued until the $22 \mathrm{~d}$, when the cough and febrile. symptoms were removed. Some debility remaining, to strengthen the system, tonics, combined with cordials, were administered, which, together with a generous diet, soon restored the strength of the body.

\section{CASE II.-January 21st.}

A draught mare, six years old, was attacked with a shivering; which was soon succeeded by a quick pulse, about seventy beats in the minute; hot moutl and difficulty in breathing, attended with a short confined cough; a dull countenance; a diminution of appetite ; a great depression of strength; her bowels were inclined to be costive, and the secretion of urine diminished, and when evacuated was high-coloured.

'The case being examined, about four quarts of blood were drawn from the jugular vein.

The fever balls were administered in the morning, and repeated in 
the evening, and the diaphoretic drench was given in the middle of the day.

Two rowels were inserted in the inferior part of the chest.

An emollient clyster was administered, and her nostrils were well fumigated with the vapour of a hot bran mash.

The body was well clothed, particularly aboit the head and chest.

Her diet was principally warm bran mashes and linseed infusion.

On the 22nd, the pulse still about seventy beats in the minute, with some degree of strength, mouth hot, and respiration difficult; the bleeding was repeated, and 4 quarts were drawn.

A blister was applied to the sides.

'The rowels were also dressed with a little blistering ointment mixed with digestive ointment.

The fever balls and drench repeated.

'The bowels having a tendency to be costive, the emollient clyster was repeated, and the nostrils were fumigated.

On the $23 \mathrm{rd}$, the pulse about sixty-five beats in the minute, respiration still difficult.

1 he blister to the sides did not excite much inflammation, therefore it was repeated, but previous to its application, considerable friction was used.

The fever balls increasing the secretion of urine, their use was suspended, but the drench was continued.

Nostrils fumigated.

On the 24 th, the pulse about sixty beats in the minute; mouth more cool ; respiration not so difficult.

The blister operating freely, and the sides are well swelled, as also the inferior part of the chest where the rowels were inserted; bowels pretty open.

Nostrils fumigated.

She coughs more frequently and more freely.

On the 25th, the pulse about fifty beats in the minute, mouth pret- 
ty cool, respiration considerably easier, appetite better, and her countenance more lively.

The diaphoretic drench continued.

On the 26th, the pulse about forty-five beats in the minute, respiration quite calm.

The cough is greatly subsided.

Appetite much better.

The diaphoretic drench repeated, and continued until the 28th: when the febrile symptoms were entirely removed, and the cough had nearly subsided.

Some debility remaining, a nutritious diet was used, which soon restored the powers of the system.

\section{CASE III.-January 22nd.}

A waggon horse, ten years old, was attacked with a shivering; and soon after a quick pulse, about eighty beats in the minute; hot mouth, and laborious breathing, attended with a short confined cough ; a diminution of appetite; a dull countenance; his bowels were inclined to be costive, and the secretion of urine was diminished, and when evacuated was high-coloured.

But I should observe, that previous to my being called in to this case, the horse had had a slight attack of the complaint; and little attention being paid to it, at the same time working the animal, and exposing him much to cold and wet weather, no doubt were the causes of the disease making such an extensive progress.

Having examined the case, about nine pints of blood were drawn from the jugular vein,

The fever balls were administered in the manner $I$ have pointed out, as also the diaphoretic drench.

Two rowels were inserted in the lower part of the chest.

An emollient clyster was given in the morning, and repeated in the 
erening, his nostrils were well fumigated over the vapour of a hot bran mash.

His diet was principally warm bran mashes and linseed infusion.

His body was warmly clothel, particularly about the head and chest.

On the 23rd, the pulse still frequent, with some degree of strength, his mouth hot, and respiration difficult; the bleeding was repeated, and about seven pints were drawn.

A blister was applied to his sides.

The ferer balls and drench repeated; an emollient clyster was given, as his bowels were still inclined to be costive; nostrils fumigated; rowels dressed with blister.

On the 24th, the pulse frequent but not strong, respiration very difficult. The blister was repeated to the sides, but previous to its application, considerable friction was used. The fever balls and drench continued.

On the 25th, the pulse and respiration much about the same as on the preceding day. The blisters operated very little.

Two setons were passed in each side, smeared with blistering ointment; and the blister was repeated to the sides.

His extremities becoming cold, they were rubbed with the embrocation, and wrapped up with flannels. The fever balls increasing the secretion of urine, their use was suspended, but the drench was continued.

On the 26th, the pulse not so frequent, and respiration not so difficult. The setons and blister excited a considerable external inflammation, which lessened the internal one ; the horse appeared more lively, and his appetite became in some measure restored.

The diaphoretic drench was repeated. The bowels inclining to be costive, an emollient clyster was administered.

On the 27th, the pulse and respiration still less hurried, mouth 
much more cool, he coughs more frequently and more freely. The setons are discharging freely, and there is considerable swelling in the sides. The diaphoretic drench repeated.

On the 28th, the pulse about sixty beats in the minute, respiration more calm, appetite a good deal better. The increased secretion of urine having subsided, one fever ball was administered during the day, and the drench as before, and were continued until the 31 st, when the cough and febrile symptoms were removed.

There being some debility remaining, a nutritious diet was used, which soon restored the powers of the system.

\section{CASE IV.-January 26th.}

A draught horse, six years old, was attacked with a shivering; a quick pulse, about sixty beats in the minute; mouth hot; respiration accelerated but not laborious; he had a bad cough; a great depression of strength; a diminution of appetite; the bowels were inclined to be costive, and the secretion of the urine was somewhat diminished.

These symptoms were soon followed by a soreness in the throat, and a difficulty in swallowing.

After inspecting the case, about four quarts of blood were drawn from the jugular vein.

The mucilaginous balls were administered in the manner I have pointed out, as also the diaphoretic powder.

An emollient clyster was given.

A blister was applied to the throat; and the nostrils were well fumigated with the vapour of a hot bran mash.

The diet was principally warm bran mashes and linseed infusion.

The body was warmly clothed, and particularly about the head and chest.

On the 27 th, the pulse about fifty-three beats in the minute; respi- 
ration not near so much accelerated; mouth more cool ; bowels pretty open; he does not cough so much.

The blister operated vell, and the difficulty in swallowing is not so great.

The mucilaginous balls and diaploretic powder repeated, as also the fumigation to the nose.

On the 28th; the pulse about forty-eight beats in the minute; respiration more regular; the difficulty in swallowing a great deal better; the appetite in some measure restored.

The mucilaginous balls and diaphoretic powder repeated, as also the fumigation.

On the 29th, the pulse about forty-five beats in the minute; respiration much easier; the difficulty in swallowing nearly removed.

The mucilaginous balls and diaphoretic powder repeated, as also the fumigation.

A copious discharge came on at the nose; appetite considerably better.

On the 30th, the pulse about the natural standard, that is, about forty beats in the minute; respiration calm and regular; the nostrils discharge freely.

The mucilaginous balls and diaphoretic powder repeated, and continued until the ist of February, when the febrile symptoms, cough, and difficulty in swallowing, were entirely removed.

There being some debility remaining, tonics combined with cordials, were administered, which, together with a nutritious diet, soon restored the powers of the body.

From what has been advanced in the foregoing pages, it may be observed, that the symptoms of the epidemic that occurred in the year 1798, were, in many respects, similar to those which occurred in the year 1815; at the same time, there is in many respects, a similarity in the mode of treatment. But besides those symptoms I have mention- 
ed, there were various others, according to the nature and peculiarity of constitution, and the susceptibility of the different parts of the body to be acted upon by the general cause that produced the disease.

Therefore, in such complaints, as the symptoms vary much, it becomes necessary for the practitioner to use some discrimination in such cases, from those that appear sporadically, or are not epidemic: for where it proves complicated, the method of cure must vary; and more or less of the inflammatory diathesis prevailing, may lead to mistakes with respect to the genuine nature of the disease. The weather, constitution, and intercurrent diseases, all unite to vary the appearance of the epidemic. To all of these, the cautious and prudent practitioner ought strictly to attend.

THE END.

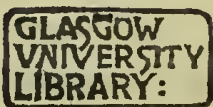

Edw. Walker, Printer, Newcastle. 





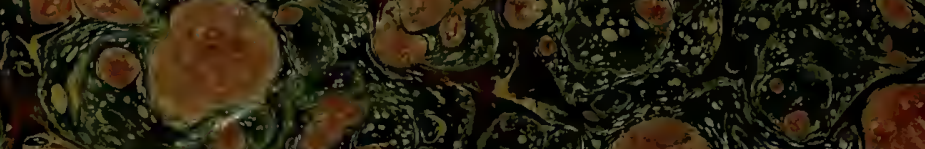

$\rightarrow \infty$

(3).

हैं क्षित की

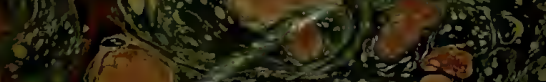

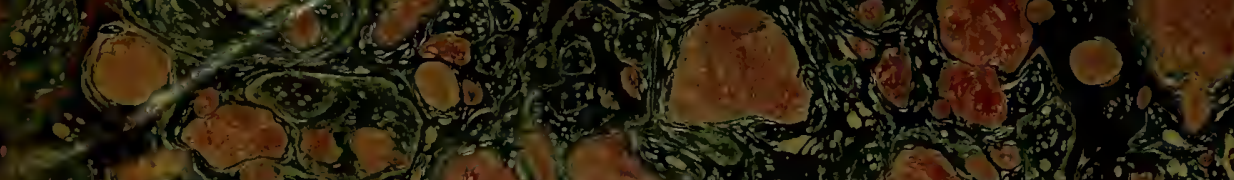

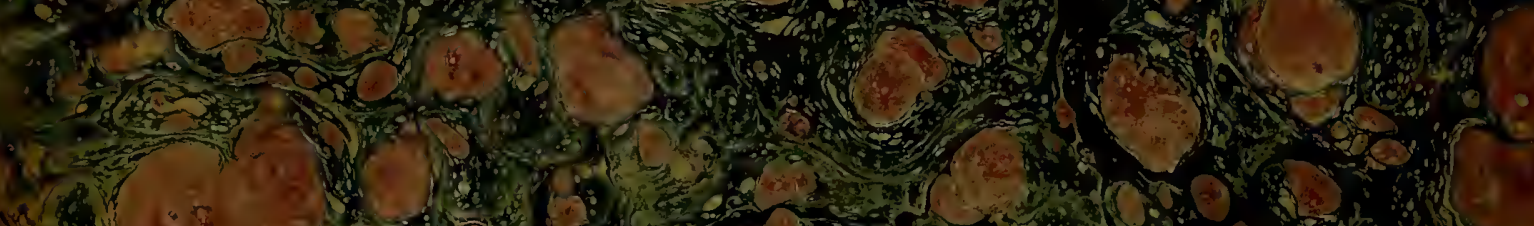

M.

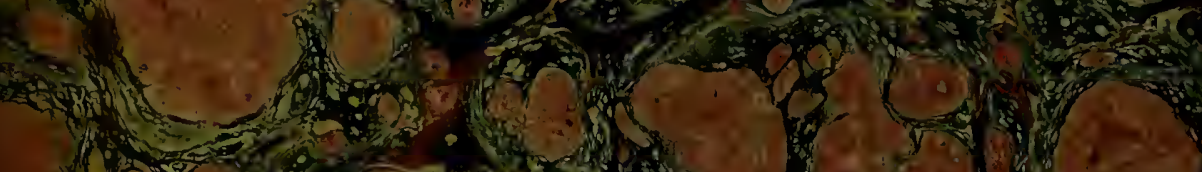

y

M(1)
P.
b) $-\infty$
(fise $\rightarrow)^{4} \cdot \mathrm{C}^{3}$

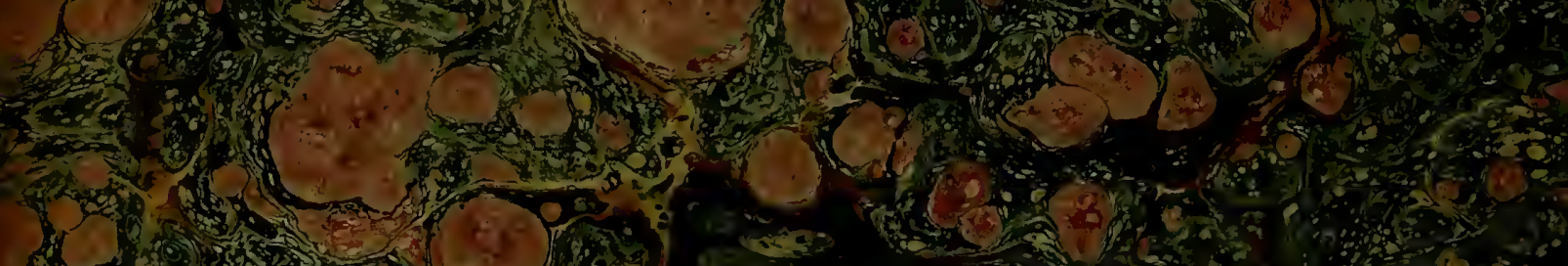

d.

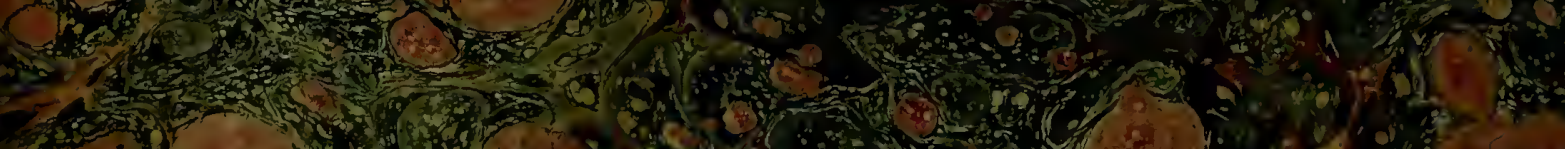

(2)

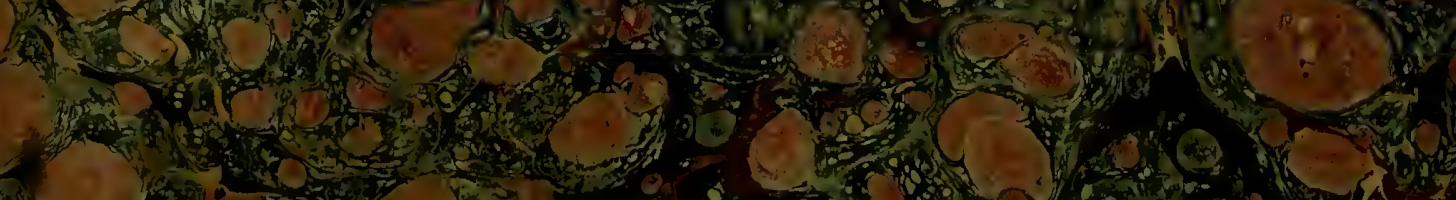

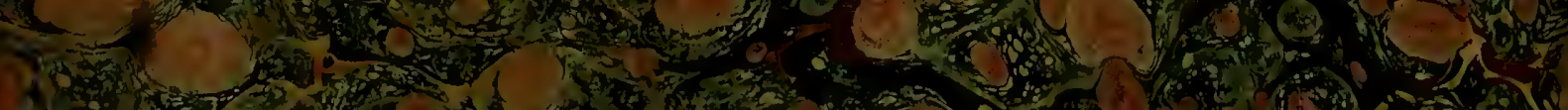

3450)

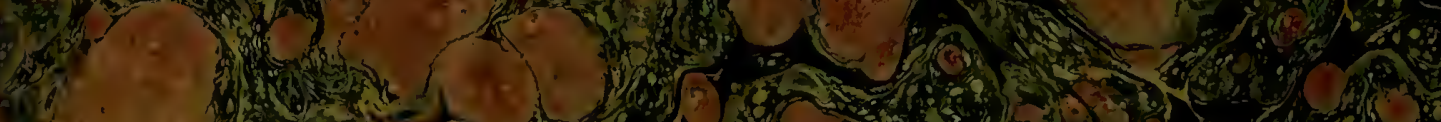

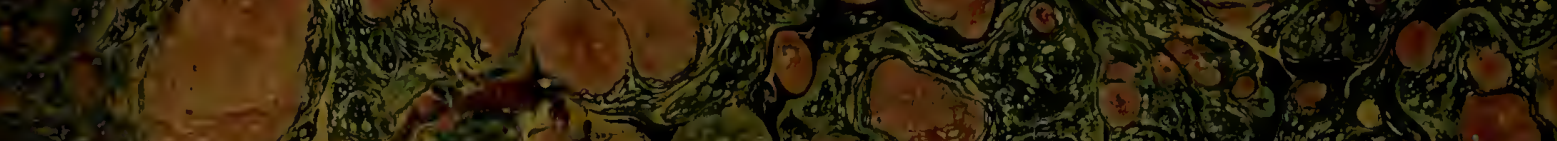

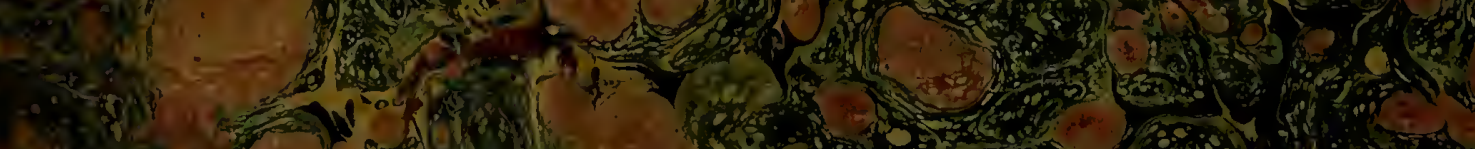

Aly

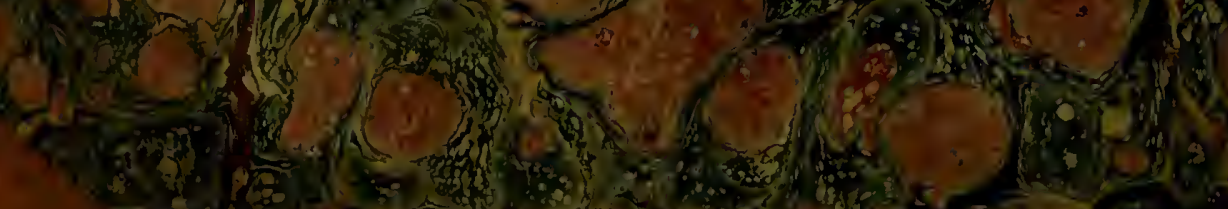

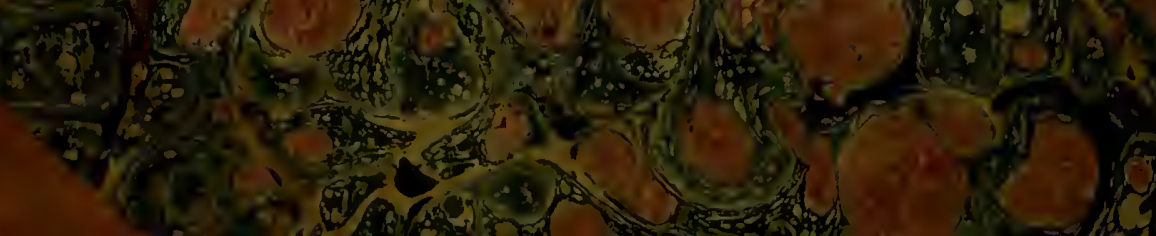

